\title{
Relational Contracts in Competitive Labour Markets
}

\author{
SIMON BOARD and MORITZ MEYER-TER-VEHN \\ Department of Economics, UCLA
}

First version received February 2010; final version accepted August 2014 (Eds.)

\begin{abstract}
We analyze a large, anonymous labour market in which firms motivate their workers via relational contracts. The market is frictionless and features on-the-job search, in that all acceptable vacancies are immediately filled and the employed compete with the unemployed for vacancies. While firms and workers are $e x$ ante identical, the unique equilibrium exhibits a continuous distribution of contracts in which high wage firms have higher retention rates, more motivated workers and higher productivity. The model thus generates dispersion in wages, productivity and human resource strategies, and gives rise to endogenous job ladders. An exogenous increase in on-the-job search increases the quantity of jobs but decreases their quality; with sufficient on-the-job search there is full employment, and wage dispersion rather than unemployment motivates workers.
\end{abstract}

Key words: On-the-job search, Relational contracts, Matching, Efficiency wages, Wage dispersion, Productivity dispersion

JEL Codes: C73, J31, L14

\section{INTRODUCTION}

There is an extensive empirical literature studying the joint distribution of residual productivity and wages, i.e. the components of firms' productivities and workers' wages that cannot be explained by observable characteristics. This literature has documented significant dispersion and a strong correlation between productivity and wages 1 This article shows how such dispersion arises endogenously among ex-ante identical firms and workers in a model of relational contracting with on-the-job search.

Our theory is based on the idea that workers at high-wage firms have higher retention rates, are better motivated, and thus more productive. As a case-in-point, the retailer Costco pays $40 \%$ more than its rival Sam's Club and also offers health care and pension contributions; in return, Costco has lower turnover and theft by employees, and a higher level of customer service 2 More broadly, our mechanism is consistent with the findings that high-wage firms

1. On the productivity side, Foster et al. 2008 find that the standard deviation of productivity is 20 log-points within homogeneous 7-digit industries, implying a $90^{\text {th }}$ percentile firm is $67 \%$ more productive than a $10^{\text {th }}$ percentile firm under log-normality. On the wage side, Card et al. 2013) show that the standard deviation of firm-effects in the matched wage regression is also $20 \mathrm{log}$-points. Looking at the correlation between wages and productivity, Abowd and Kramard 2005 ) find that a $1 \%$ increase in the wage firm-effect is associated with a $0.35 \%$ increase in productivity.

2. See "How Costco Became the Anti-Wal-Mart", New York Times, 17th July 2005. 
have higher retention rates Abowd et al. 2006, fewer disciplinary actions Raff and Summers. 1987; Cappelli and Chauvin. 1991), and higher reported commitment and effort Levine. 1993).

We build on a continuous effort version of the efficiency wage models of Shapiro and Stiglitz 1984) and MacLeod and Malcomson (1998) in which firms motivate their workers through the promise of future wages inherent in long-term relationships. These articles assume that firms only recruit from the pool of unemployed, inducing an equilibrium in which all firms offer the same job; this has given rise to the view that "If all firms were identical, one would not expect to see different firms paying different wages even if efficiency wages were important." Krueger and Summers 1988, p. 261). We contribute to this literature by introducing a versatile formulation of on-the-job search and showing that it generates productivity and wage dispersion. Empirically, on-the-job search is a first-order phenomenon: job-to-job transitions outnumber job-to-unemployment transitions two-to-one Nagypal, 2008). Moreover, Hornstein et al. (2011) argue that any plausibly parameterized model of wage dispersion must include on-the-job search in order to rationalize the relatively short durations of unemployment. The underlying idea-that on-the-job search reduces the opportunity cost of taking up low-wage jobs-is the driving force behind productivity and wage dispersion in our model.

There are other models of wage dispersion, such as Burdett and Mortensen 1998), Delacroix and Shi 2006), and Galenianos and Kirchen 2009), that are based on search frictions rather than a contracting problem 3 In comparison, our model generates dispersion in productivity as well as in wages. This dispersion helps explain the heterogeneity of employment systems documented by Osterman 1994), whereby some firms adopt a flexible organizational structure with broad job definitions, autonomous teams, and worker participation-all of which require highly motivated workers-whereas other firms adopt more rigid job structures and focus on cost cutting. Since the value of a job is endogenous, our model also has different comparative statics. Labour market policies such as minimum wages can further motivate workers, and raise productivity and welfare. And as search frictions decline, e.g. because of job websites, search models become competitive, whereas unemployment and contract dispersion persist in our model.

In the model, a continuum of identical workers and firms play an infinitely repeated game. At the beginning of each period, workers compete for vacancies that arise because of exogenous turnover. Next, each firm pays its worker a wage $w$ and the worker chooses his effort $\eta$. At the end of the period, either party can terminate the relationship; separation may also occur exogenously. We assume that each firm chooses a relational contract, that is a sequence of wage and effort levels $\left\langle w_{t}, \eta_{t}\right\rangle$, to maximize its profit subject to its worker's incentive compatibility constraint. To interpret this constraint we can decompose the worker's wage into a fixed cost that compensates him for the job offers he forgoes by being employed, and a marginal cost that compensates him for the disutility of effort and additionally includes an incentive premium. This marginal cost increases in the turnover rate since a wage increase incentivizes effort today only to the degree that the worker is still employed to collect the raise tomorrow. Equating the marginal benefit and marginal cost of effort, there may be multiple optimal solutions to the firm's problem: an increase in the wage lowers the firm's turnover and the marginal cost of effort, enabling it to increase its effort requirement and offset the wage rise. Indeed, in equilibrium, firms are indifferent between a continuum of contracts.

3. There is another set of models that generate wage dispersion in which workers or firms are ex ante heterogeneous. These include Bulow and Summers 1986, Montgomery 1991, Albrecht and Vroman 1992, Walsh 1999, Acemoglu 2001), Moscarini 2005) and Peters 2010). For example, Postel-Vinay and Robin 2002b) investigate how exogenous productivity differences map into the distribution of wages. 
At the start of each period, some jobs are vacant because of exogenous turnover. These vacancies may be filled by employed or unemployed workers; if an employed worker accepts a job offer, this frees up his current employer to immediately offer the vacancy to other workers 4 Our matching market is frictionless, in that all acceptable jobs are filled, and anonymous, in that job offers depend on a worker's history only via their employment status. This formulation nests many interesting matching technologies with different degrees of on-the-job search: under ShapiroStiglitz matching, job offers first go to the unemployed; under Symmetric matching, employed and unemployed workers receive the same job offers; under Intern matching, job offers first go to the employed, whereas the unemployed are only offered left-over entry-level jobs. Each firm's contracting problem depends on the entire contract distribution, so it might seem that one has to solve for the equilibrium contract distribution with a functional fixed-point theorem. Our formulation of the matching technology simplifies this problem: a firm's retention rate, and therefore its optimal contract, depends on competing jobs only via its ordinal rank in the job distribution. This allows us to solve for the optimal contract of each quantile in the distribution of firms and thereby characterize individual equilibrium jobs explicitly in terms of wages and productivity 5

We show that there exists a unique industry equilibrium. With on-the-job search, the equilibrium distribution of contracts must be continuous, possibly with an atom at the bottom. Intuitively, a firm that raises its wage above an atom in the job distribution no longer loses its workers to these competitors; therefore, its retention rate jumps up and its marginal cost of effort jump down, as shown in Figure 1 1 a). Since the marginal benefit of effort is continuous, this implies that either an upward or a downward deviation is profitable. In equilibrium, contracts must therefore be distributed continuously so that the marginal cost and benefit coincide at all contracts, as in Figure 1 b).

The model is highly tractable and allows us to study the impact of on-the-job search on the equilibrium job distribution. Under Shapiro-Stiglitz matching, $n<1$ firms offer identical contracts. There is no contract dispersion because the lack of on-the-job search means the marginal cost of effort is constant. Unemployment arises because the opportunity cost of taking a job implies a positive fixed cost of offering a job. The introduction of on-the-job search lowers this opportunity cost and allows additional firms to enter at the bottom of the market; it also raises turnover, so that these firms cut their required effort and wages. That is, as the level of on-the-job search increases, the quantity of jobs improves but the quality declines. For example, under Symmetric matching there is no opportunity cost of taking a job. In equilibrium, there is a continuous distribution of contracts and we obtain full employment as the fixed operating cost vanishes; workers are then motivated by fear of losing their jobs and having to rebuild their careers, rather than by the risk of long-term unemployment. Under Intern matching, the opportunity cost of taking a job is negative and low-wage firms act as gatekeepers for better paid jobs. In equilibrium, there is full employment with an atom of firms offering low-wage "internships" which leverage the prospects of climbing the job ladder to motivate their workers.

This discussion highlights how the economic forces behind the job dispersion in our model differ from those in the search literature. Specifically, our results are driven by the

4. Akerlof et al. 1988 study vacancy chains in a similar matching model with match-specific utility and a fixed number of firms and workers. Their observation, that quit rates are higher and vacancy chains are longer when unemployment is low, also obtains in our model.

5. In contrast, typical papers of competitive contracting do not feature on-the-job search, implying that each firm cares about the other firms via a single state variable, namely the value of unemployment. Examples include MacLeod and Malcomson 1998) and Rocheteau 2001) with moral hazard; Krueger and Uhlig 2006) and Rudanko 2009) with insurance and limited commitment, and Moen and Rosén 2006, 2011) with adverse selection. The directed search papers of Shi 2009) and Menzio and Shi 2011) are even more tractable because firms' problems are separable, or "block recursive." 
(a)

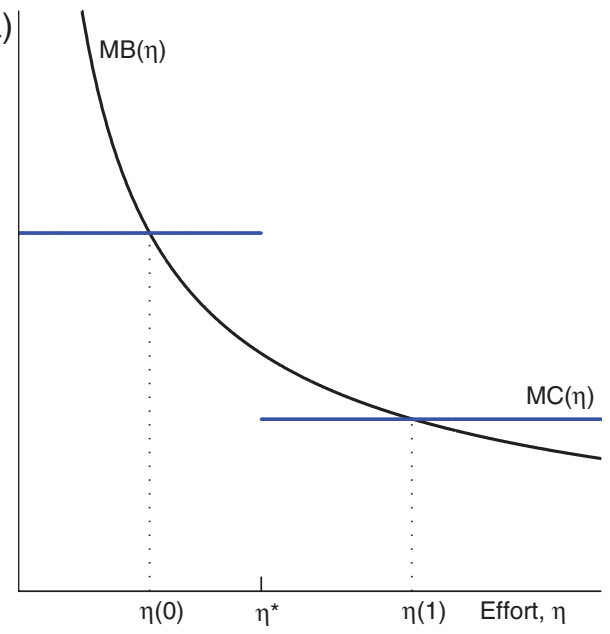

(b)

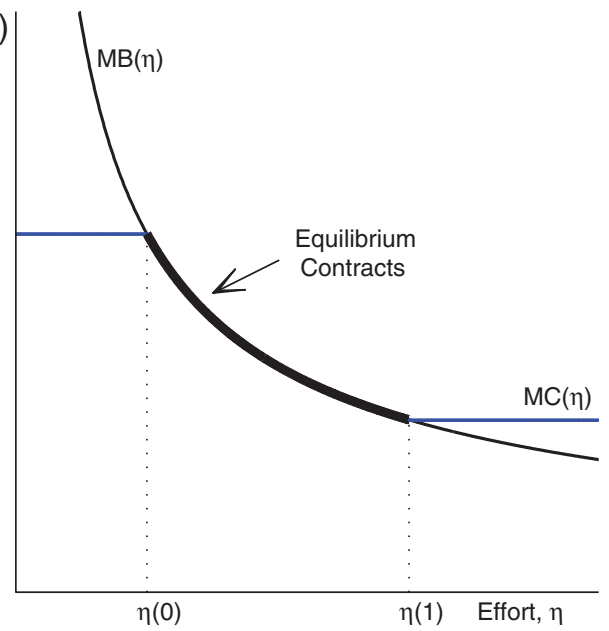

FIGURE 1

Marginal cost and benefit of effort

Panel (a) supposes all other firms offer the contract $\left\langle w^{*}, \eta^{*}\right\rangle$. Since $\mathrm{MB}<\mathrm{MC}$ just below $\eta^{*}$ and $\mathrm{MB}>\mathrm{MC}$ just above $\eta^{*}$, there are profitable downward and upward deviations. Panel (b) shows the equilibrium, in which all contracts equate the marginal cost and benefit of effort. This figures assumes $\phi(\eta)=\eta^{1 / 3}, \alpha=\delta=3 / 4, c=0.2$ and Symmetric

matching

intensive margin of increasing a single worker's effort, whereas search models focus on the extensive margin of attracting more workers. For example, in Burdett and Mortensen, on-thejob search allows a firm to poach workers from its competitors by raising its wage slightly. This motive is absent in our model because acceptable vacancies fill immediately. Rather, on-the-job search matters because it allows the firm's employee to search for better jobs; so on-the-job search acts as a non-pecuniary job benefit to its worker, and enables the firm to cut wages. Thus, in contrast to Burdett and Mortensen, our firm would never want to ban its employee from searching and does not care to match outside offers ( $c f$. Postel-Vinay and Robin. 2002a).

Our analysis rests on the assumption that firms offer stationary contracts. To justify this assumption, we follow Shapiro and Stiglitz 1984) and MacLeod and Malcomson 1998) by assuming firms can terminate a contract at will and then show that stationary contracts are optimal. Ideally, the firm would like to back-load wages to reuse the worker's incentives, but such contracts are not self-enforcing since the firm would deviate by firing expensive old workers and replacing them with cheap new workers 6 While stationary contracts are optimal, there are non-stationary contracts that are also optimal. Indeed, each firm could replicate the equilibrium job trajectory of our equilibrium under some, arbitrary matching technology. This could lead to full employment even without on-the-job search. However, such back-loaded contracts are bilaterally inefficient, in that a firm could raise its worker's utility without affecting its profits.

6. If firms could commit to long-run contracts, they could pay the worker in period $t+1$ for his work in period $t$ eliminating the moral hazard problem and inducing first-best. The debate over firms' ability to back-load has a long history (e.g. Carmichael, 1990 versus Lang and Kahn, 1990). Our reading is that there are limits to back-loading in many circumstances; for the sake of tractability, we adopt the extreme assumption that firms have no commitment power. 
Moreover, such equilibria are inconsistent with the observed prevalence of job-to-job transitions and weak evidence of returns to tenure 7 and they do not help us explain the dispersion of wages, productivity, and employment systems across firms.

We use the model to analyze the impact of labour market regulations on the level of unemployment, and the distribution of wages and productivity in the economy. Such considerations are important for welfare: When laid off, U.S. workers experience median earnings losses of $25 \%$ in the following year and, as they reclimb the job ladder, $10 \%$ a decade later Davis and von Wachter, 2011). In our model, a minimum wage destroys some low-wage, lowproductivity jobs, and simultaneously induces other low-wage firms to raise their wages and productivity. Intuitively, a minimum wage makes it more costly to employ a worker but also raises his rents and allows his employer to make the job more demanding. The latter effect, which is absent in traditional search models, implies that minimum wages may increase total surplus. Unemployment benefits are a worse policy. They destroy low-wage, low-productivity jobs but without improving the quality of the remaining jobs. Moreover, even the unemployed do not gain from the policy: the temporary gain from the benefits is offset by the long-run loss of opportunity. In contrast, welfare is improved if the government subsidizes the entry of firms, adding jobs and raising productivity and wages.

Finally, we extend the model to heterogeneous firms and workers. Firm heterogeneity allows us to purify the mixed equilibrium in the baseline model. In equilibrium, on-the-job search amplifies exogenous productivity differences, illustrating how firms choose employment systems to complement their corporate strategy. For example, Costco provides more incentives than Sam's Club because its customers put a higher value on quality of service. When workers are heterogeneous, firms offer overlapping wage scales, catering to different types of workers. Highwage firms refuse to hire low-type workers because effort is too costly; low-wage firms refuse to hire high-type workers because their outside options are too high, making them "overqualified." In the middle, firms are indifferent between hiring high-type workers with low retention rates and low-type workers with high retention rates.

The article is organized as follows. Section 3 considers the problem of a single firm contracting with a sequence of workers; the interactions with other firms are captured through exogenous outside options of the workers. We show that there exist firm-optimal self-enforcing contracts that are stationary, and characterize the solution of each firm's contracting problem. Section 4 describes our formulation of job market transitions. Section 5 integrates the single-firm analysis with the matching process and solves for industry equilibrium as a fixed point of firm-optimal contracts. Section 6 considers policy analysis, and extends the model to heterogeneous workers and firms.

\section{MODEL}

Basics. Time is discrete and infinite, $\tau \in\{1,2, \ldots\}$, and there is a continuum of identical workers and firms. The measure of workers is exogenous and normalized to 1 , whereas the measure of firms $n$ is determined endogenously through entry; we will show that $n \leq 1$ in equilibrium. The timing of each period is summarized in Figure 2 Every firm would like to hire one worker each period.

7. Using matched firm-worker data, the returns are negligible in France and Denmark, and $1.5 \%$ per year in Portugal Abowd et al. 2006, Buhai et al. 2014). The returns in the U.S. may be much higher; a matter of some controversy Buchinsky et al. 2010). 


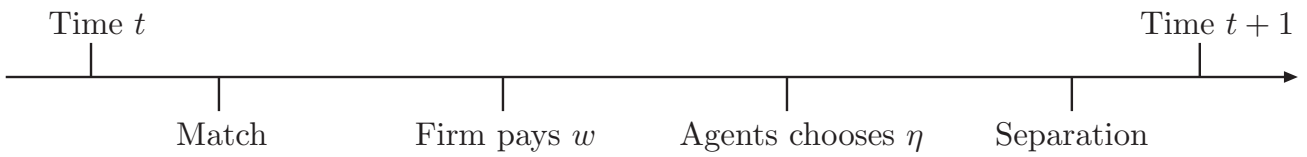

FIGURE 2

Timeline of one period

At the start of the period, workers are matched to vacancies; this may involve a worker separating form his current employer. Then, the firm pays its worker and the worker exerts effort. Separation may also occur at the end of the period

Job market matching. At the start of each period some firms have vacancies and make job offers. These offers may go to employed or unemployed workers. If an employed worker accepts the offer, this frees up his current employer to immediately make an offer to another worker. We solve for the employment transitions based on two axioms. First, matching is frictionless in that all vacancies, including those that arise in the matching process, are filled subject to the workers' participation constraint. Second, matching is anonymous in that a worker's probability of receiving a job offer does not depend on his past behaviour; however, it can depend on whether or not he is currently employed. We elaborate on the matching process in Section 4

Jobs. After a worker has been matched to a firm, each period consists of three stages. First, the firm pays its worker wage $w \in \mathbb{R} \otimes$ Second, the worker chooses observable but non-contractible effort $\eta \in[0, \infty)$ and produces output $\phi(\eta)$. Third, either party can terminate the relationship; separation may also occur exogenously with probability $1-\alpha$. Note that separation may additionally occur at the start of the subsequent period in the matching phase if the worker receives a better job offer. Since we wish to model a large, anonymous labour market, we assume the firm and worker perfectly observe actions in their own relationship but not in other relationships, in particular not in the past relationships of their current partner. Firms do not observe outside job offers of their workers.

Payoffs. The firm's profit and worker's utility are given by

$$
\pi:=\phi(\eta)-w-c \quad \text { and } \quad u:=w-\eta,
$$

where $c$ is the firm's operating cost (or the rental value of the entry cost); the firm incurs this cost even if it does not hire a worker. We assume that the production function $\phi$ is continuously differentiable and strictly concave with $\phi(0)=0, \phi^{\prime}(0)=\infty, \lim _{\eta \rightarrow \infty} \phi^{\prime}(\eta)=0$. Firms and workers discount the future at a common rate of $\delta \in(0,1)$ per period. To avoid a trivial solution, we also assume a single firm can make positive profits,

$$
\max _{\eta}\left[\phi(\eta)-\frac{\eta}{\alpha \delta}-c\right]>0
$$

Remark. The classic model of Shapiro and Stiglitz 1984) is a special case of our model in which only unemployed workers receive job offers. Formally, there are other differences. First, effort is binary in Shapiro and Stiglitz; this is not restrictive in their model as firms offer the

8. We assume that workers can reject negative wages. In principle, workers may be willing to accept negative initial wages in return for high continuation values, e.g. under Intern matching. However, we will find that equilibrium wages are non-negative. 
same job in equilibrium, but it would be restrictive in our model where job dispersion arises endogenously. Second, time is continuous and monitoring is imperfect in Shapiro and Stiglitz; we find it conceptually easier to work in discrete time with perfect monitoring and comment on the continuous-time limit of job market matching in footnote 23

\section{SINGLE FIRM'S PROBLEM}

This section focuses on the interaction between a single firm and its sequence of employees; the effect of other firms is captured by the outside options available to the firm's employees. After describing the firm's contracting problem, Section 3.1 shows that stationary contracts are weakly optimal in response to stationary conditions, and Section 3.2 characterizes the firm's optimal contract via a simple first-order condition.

First, consider a firm that entered period $\tau$ without a worker, or lost its worker in the matching stage of period $\tau$. Suppose the firm offers a job with continuation value $W_{1}$ for the worker. Given our assumption of frictionless matching, the probability the position is filled depends solely on $W_{1}$ and equals

$$
p\left(W_{1}\right)= \begin{cases}0 & \text { if } W_{1}<\underline{W} \\ 1 & \text { if } W_{1}>\underline{W}\end{cases}
$$

for some reservation value $\underline{W}$.

Next, consider a firm with a worker at the start of period $\tau$, and suppose they are in period $t$ of the current job. The worker may receive job offers during the matching stage. From the worker's perspective the continuation value of his best offer $\hat{W}_{t}$ is a random variable with distribution $F^{e}$; since the current employer does not observe $\hat{W}_{t}$, it does not counter the offer and the worker accepts the offer if $\hat{W}_{t}$ exceeds the continuation value of his current job, $W_{t}$. After the matching stage, the rest of period $t$ transpires as in Figure 2 first, the firm pays its worker wage $w$, then the worker exerts effort $\eta$, and finally the worker, firm or nature can terminate the relationship.

We assume that the contracts offered by other firms are such that the outside conditions $F^{e}, p$, and the continuation value of an unemployed worker at the beginning of a period, $V^{\varnothing}$, are stationary. We call strategies of the firm and its sequence of workers contract-specific if (1) the current wage $w_{t}$ only depends on past wages and effort levels in the current job, $\left(w_{1}, \eta_{1}, \cdots, w_{t-1}, \eta_{t-1}\right)$, (2) current effort $\eta_{t}$ additionally depends on $w_{t}$, and (3) separation decisions additionally depend on $\eta_{t}$. Contract-specific strategies are thus independent of calendar time $\tau$ and the identity of the worker. This restriction captures the idea that workers interpret a firm's contract offer as a firm policy that will also be offered to subsequent workers?

We define a self-enforcing contract as a subgame-perfect equilibrium in pure, contract-specific strategies with no voluntary separation on the equilibrium path 10 A self-enforcing contract remains self-enforcing if deviations from the equilibrium path are punished in the harshest possible way. For our game, this means that the worker shirks and quits if the firm deviates from equilibrium wage $w_{t}$; similarly, the firm fires a worker if he deviates from equilibrium effort $\eta_{t}$. This allows us to write a self-enforcing contract as a sequence of wages and effort levels $\left\langle w_{t}, \eta_{t}\right\rangle$.

9. This is akin to the assumption of symmetry beliefs in the contracting with externalities literature McAfee and Schwartz.1994).

10. Self-enforcing contracts are an equilibrium selection rather than a constraint on players' optimal strategies because contract-specific strategies are weakly optimal for the firm if workers' strategies are contract-specific, and vice-versa. 
The Bellman equations for employed workers' pre- and post-matching continuation values in period $t$ of contract $\left\langle w_{t}, \eta_{t}\right\rangle$ are given by

$$
V_{t}=\int \max \left\{W_{t}, \hat{W}\right\} d F^{e}(\hat{W}) \quad W_{t}=w_{t}-\eta_{t}+\delta\left(\alpha V_{t+1}+(1-\alpha) V^{\varnothing}\right) .
$$

Similarly, the firm's pre-matching continuation profit with a vacancy or in period $t$ of its contract equals

$$
\begin{aligned}
\Pi_{\varnothing} & =p\left(W_{1}\right) \Pi_{1}+\left(1-p\left(W_{1}\right)\right)\left(-c+\delta \Pi_{\varnothing}\right), \\
\Pi_{t} & =F^{e}\left(W_{t}\right)\left(\phi\left(\eta_{t}\right)-w_{t}-c+\delta\left(\alpha \Pi_{t+1}+(1-\alpha) \Pi_{\varnothing}\right)\right)+\left(1-F^{e}\left(W_{t}\right)\right) \Pi_{\varnothing} .
\end{aligned}
$$

A contract is self-enforcing if it satisfies the following incentive constraints:

$$
\begin{aligned}
w_{t}-\eta_{t}+\delta\left(\alpha V_{t}+(1-\alpha) V^{\varnothing}\right) & \geq w_{t}+\delta V^{\varnothing}, \\
\Pi_{t} & \geq \Pi_{\varnothing} .
\end{aligned}
$$

The worker's incentive constraint (W-IC) requires that the worker's cost of effort $\eta$ is outweighed by the prospect of keeping his job; the value of this prospect $V_{t}-V^{\varnothing}$ is discounted both by $\delta$ and the natural retention rate $\alpha$. (W-IC) implies that the worker does not want to quit the job at the end of the period since he would be better off shirking that period and being fired.

The firm's incentive constraint (F-IC) requires that the firm does not want to fire and replace its worker. (F-IC) implies that the firm does not want to deviate from the expected wage $w_{t}$ because doing so causes the worker to shirk and quit, so the firm might as well have fired the worker in the previous period. The firm's problem is thus to choose a self-enforcing contract to maximize profits $\Pi_{\varnothing}$ subject to (W-IC) and (F-IC).

Lemma 1. An optimal self-enforcing contract is accepted with probability one, $p\left(W_{1}\right)=1$. Thus, $\Pi_{\varnothing}=\Pi_{1}$.

Proof If $p\left(W_{1}\right)=0$, then profits are negative, equal to $\Pi_{\varnothing}=-c /(1-\delta)$ and the firm would rather exit the market. If $p\left(W_{1}\right) \in(0,1)$ and $\Pi_{\varnothing} \geq 0$, then $\Pi_{1}>\Pi_{\varnothing}$. If the firm raises wages by $\varepsilon$ it attracts a worker with probability 1 , and raises initial profits to $\Pi_{1}-\varepsilon /(1-\delta)$ which exceeds $\Pi_{\varnothing}$ for small $\varepsilon$.

\subsection{Stationary contracts}

We now argue that we can restrict attention to stationary contracts $\langle w, \eta\rangle$, i.e. contracts with $w_{t}=w$ and $\eta_{t}=\eta$ for all $t$.

Lemma 2. (Stationary contracts). Assume stationary outside conditions $F^{e}, p, V^{\varnothing}$, and fix a non-stationary, self-enforcing contract $\left\langle w_{t}, \eta_{t}\right\rangle$ with non-negative profits, $\Pi_{\varnothing} \geq 0$. There is a stationary self-enforcing contract $\left\langle w^{*}, \eta^{*}\right\rangle$ that yields either strictly higher profits, $\Pi_{\varnothing}^{*}>\Pi_{\varnothing}$, or weakly higher profits and strictly higher value for the worker, $\Pi_{\varnothing}^{*} \geq \Pi_{\varnothing}, W_{1}^{*}>W_{1}$.

Proof The proof is constructive; we give an overview of the construction here and provide details in Appendix A.1 For fixed $\left\langle w_{t}, \eta_{t}\right\rangle$ we define the stationary contract $\left\langle w^{*}, \eta^{*}\right\rangle$ by setting maximal effort $\eta^{*}=\max _{t} \eta_{t}$, and wages $w^{*}$ such that $W^{*}=W_{t^{\prime}}$, where $t^{\prime}=\arg \max _{t} W_{t}$. 
This contract satisfies (F-IC) because profits are constant, and (W-IC) because it requires no more effort than the maximal effort in the self-enforcing contract $\left\langle w_{t}, \eta_{t}\right\rangle$ and provides a weakly higher continuation value. To see why $\left\langle w^{*}, \eta^{*}\right\rangle$ is weakly more profitable than $\left\langle w_{t}, \eta_{t}\right\rangle$, note that profits of the stationary contract $\Pi_{\varnothing}^{*}$ are higher than continuation profits $\Pi_{t^{\prime}}$ because surplus is higher by choice of $\eta^{*}$, and the worker's continuation value is the same by choice of $w^{*}$. Continuation profits $\Pi_{t^{\prime}}$ in turn must exceed initial profits $\Pi_{\varnothing}$ by the firm's incentive constraint not to fire and replace its worker.

Ideally, the firm would like to back-load payments to incentivize effort in both early and late periods. Indeed, if the firm's outside option were exogenous, the optimal contract would be backloaded. However, when the outside option is endogenously determined by the possibility to hire a new worker on the same back-loaded terms, the firm would then wish to fire expensive old workers and replace them with cheap new workers. This idea is originally due to Shapiro and Stiglitz 1984) and formally shown by MacLeod and Malcomson 1998). Lemma 2 extends their result to a setting with on-the-job search.

Lemma 2 leaves open the possibility of non-stationary firm-optimal contracts. For example, given any stationary firm-optimal contract one can construct a non-stationary firm-optimal contract by reducing wage and effort in the first period in a way that leaves profits constant. In this article, we focus on stationary firm-optimal contracts because, by Lemma 2 , non-stationary contracts harm the worker without benefiting the firm 11 Additionally stationary contracts have the advantage of tractability, giving rise to a unique equilibrium 12

We have made a number of assumptions reflecting the large, anonymous nature of the labour market. First, we assume that firms and workers cannot observe each other's behaviour in past relationships. This is important: if worker 2 could observe firm $f$ 's behaviour with its previous worker 1 , then 2 could punish $f$ for unfairly firing 1 , thereby enabling $f$ to profitably back-load 1 's wages. Second, we assume that a worker's current employer cannot observe (and respond to) outside wage offers. This assumption is not critical: firms do not care to respond to outside offers because they can always obtain another worker with probability one 1314 Third, we consider equilibria in contract-specific strategies. If the firm and workers conditioned their behaviour on calendar time or the identity of a worker, they could cut the wage in the first period of the game for the first worker, without affecting incentives for subsequent workers. We abstract away from such strategies since they require the first worker to believe he is special, which is inconsistent with our idea of a large anonymous labour market in which job offers are a matter of firm policy.

In addition, we do not allow for bonus payments, which play an important role in MacLeod and Malcomson 1998) and Levin 2003). This assumption is not critical: we show in Appendix A.2 that for any self-enforcing contract with bonuses, there is a weakly more profitable self-enforcing contract without bonuses. Intuitively, the firm prefers to pay the worker for effort

11. Restrictions to bilaterally efficient contracts are common in the relational contracts literature, e.g. Ghosh and Rav 1996) and Levin 2002). We should point out that bilateral efficiency is also violated in most equilibrium contracts in our baseline model as workers strictly prefer high wage jobs; however, it is restored by any degree of firm heterogeneity, as shown in Section 6.2

12. If one allows for back-loaded contracts, the idea that on-the-job search leads to job ladders and high employment continues to hold. For example, any equilibrium under Symmetric matching must have full employment as the operating $\operatorname{cost} c$ vanishes. With Shapiro-Stiglitz matching, there is a set of equilibria, ranging from the classic equilibrium in stationary contracts, to equilibria in back-loaded contracts with full employment. This suggests that a version of our comparative static (Theorem 2 still holds in a set order.

13. Moreover, if firms are heterogeneous (see Section 6.2 then optimal stationary contracts are unique, and matching competing offers is strictly unprofitable.

14. This is in contrast to the frictional labour search literature where a firm would wish to make a counter-offer Burdett and Mortensen.1998; Postel-Vinay and Robin.2002a). 
$\eta_{t-1}$ at the latest possible moment before $\eta_{t}$. This makes it weakly profitable to shift bonus $b_{t-1}$ into next period's wage $w_{t}$.

Lemma 2 allows us to focus on stationary, firm-optimal, self-enforcing contracts $\langle w, \eta\rangle$, and simplify the expression for value functions. First, we rank contracts according to their attractiveness to workers, writing them as $\langle u, \eta\rangle$ in terms of utility $u=w-\eta$ rather than wage $w$. Next, we write the distribution of outside job offers $F^{e}(u)$, as well as the probability of filling a job $p(u)$ in terms of per-period utility $u$ rather than the continuation value $W$. Finally, we write the worker's pre- and post-matching continuation value, $V(u)$ and $W(u)$, as a function of per-period utility. Writing $[\underline{u}, \bar{u}]$ for the support of contracts in the economy, the support of $F^{e}(u)$ is contained in $\varnothing \cup[u, \bar{u}]$, where " $\varnothing$ " means that a worker receives no job offer. The value functions are then given by

$$
\begin{aligned}
V(u) & =\int \max \{W(u) ; W(\hat{u})\} d F^{e}(\hat{u}), \\
W(u) & =u+\delta\left(\alpha V(u)+(1-\alpha) V^{\varnothing}\right) \text { and } W(\varnothing)=\delta V^{\varnothing} .
\end{aligned}
$$

\subsection{First-order condition}

In a stationary contract the firm's incentive constraint is automatically satisfied, so the firm's problem reduces to choosing a stationary contract $\langle u, \eta\rangle$ to maximize flow profits $\phi(\eta)-\eta-u-c$ subject to the worker's incentive and participation constraints

$$
\begin{aligned}
-\eta+\delta\left(\alpha V(u)+(1-\alpha) V^{\varnothing}\right) & \geq \delta V^{\varnothing}, \\
p(u) & =1 .
\end{aligned}
$$

We rewrite (IC) as $u \geq u_{*}(\eta)$, where $u_{*}(\eta)$, the utility to incentivize effort $\eta$, is defined by

$$
\eta=\alpha \delta\left(V\left(u_{*}(\eta)\right)-V^{\varnothing}\right) .
$$

For this section, assume that (IC) binds and (IR) is slack; in Section 5 we verify that (IC) indeed binds in equilibrium and also address (IR). Substituting $u=u_{*}(\eta)$ into profits, the firm maximizes its reduced-form profits

$$
\pi_{*}(\eta)=\phi(\eta)-\eta-u_{*}(\eta)-c .
$$

As discussed in the introduction, we can decompose the firm's cost into fixed and marginal costs. The fixed costs $u_{*}(0)+c$ cover the firm's operating cost and the worker's opportunity cost of being employed. The marginal costs $\eta+u_{*}(\eta)-u_{*}(0)$ compensate and incentivize the worker's effort.

We now characterize the firm's first-order condition. The marginal cost of incentivizing effort is connected to the marginal continuation value of utility via equation (4). To calculate the latter,

15. These value functions assume that firms and workers follow the prescribed strategies, and that employed workers switch jobs whenever they receive a better offer.

16. Note that $u_{*}(\eta)$ is well defined by the intermediate value theorem if the value function $V(u)$ is unbounded below; for $V(u)$ is strictly increasing and continuous with $\lim _{u \rightarrow \infty} V(u)=\infty$. If the value function is bounded below (because workers in low-utility jobs leave with probability one) and the LHS of (IC) always exceeds the RHS, then we set $u_{*}(\eta)=-\infty$. 
we differentiate the Bellman equations (2) and (3). Assuming that the offer distribution $F^{e}$ is continuous at $u$ (as proved in Lemma 3 below) we obtain

$$
V^{\prime}(u)=\left(1+\alpha \delta V^{\prime}(u)\right) F^{e}(u)=\frac{F^{e}(u)}{1-\alpha \delta F^{e}(u)} .
$$

Intuitively, the perpetuity value of an extra util is calculated at the contract-specific discount rate, which incorporates discounting $\delta$ and the job's retention rate $\alpha F^{e}(u)$. Moreover, the extra util only benefits the worker if he stays with the firm at least this period, i.e. with probability $F^{e}(u)$. The marginal cost of effort to the firm is then given by

$$
\frac{d}{d \eta}\left(\eta+u_{*}(\eta)\right)=1+\frac{1}{\alpha \delta V^{\prime}\left(u_{*}(\eta)\right)}=\frac{1}{\alpha \delta F^{e}\left(u_{*}(\eta)\right)}
$$

Intuitively, today's effort is motivated by tomorrow's wages, so the marginal cost of effort decreases in the retention rate. That is, a worker who is likely to quit tomorrow is very expensive to motivate since he will not be around to collect any promised wage rise. Setting the marginal cost of effort equal to the marginal benefit, the first-order condition for contract $\left\langle u_{*}(\eta), \eta\right\rangle$ is thus

$$
\phi^{\prime}(\eta)=\frac{1}{\alpha \delta F^{e}\left(u_{*}(\eta)\right)} .
$$

As both marginal benefits and marginal costs decrease in effort, the solution to the firm's problem need not be unique. Indeed, we will see that there is typically a continuum of optimal contracts in equilibrium.

To complete the single-firm analysis, we now verify our continuity assumption:

Lemma 3. Assume that $\eta$ maximizes reduced-form profits (5). Then $F^{e}(u)$ is continuous at $u=u_{*}(\eta)$ and the first-order condition (8) holds.

Proof Assume to the contrary that $F^{e}$ has an atom at $u$. Then, equations 6 and 77 remain valid for the right derivative because $F^{e}$ is right-continuous. For the left derivative we need to replace $F^{e}(u)$ by $\lim _{\epsilon \rightarrow 0} F^{e}(u-\epsilon)$. The necessary left- and right-handed first-order conditions for the optimality of $\left\langle u_{*}(\eta), \eta\right\rangle$ are thus

$$
\lim _{\epsilon \rightarrow 0} \frac{1}{\alpha \delta F^{e}(u-\epsilon)} \leq \phi^{\prime}(\eta) \leq \frac{1}{\alpha \delta F^{e}(u)} .
$$

As the LHS exceeds the RHS, 90 implies that $F^{e}$ is indeed continuous at any optimal contract. $\|$

Intuitively, $F^{e}$ must be continuous at an optimal contract because a jump at $u_{*}(\eta)$ means that the marginal cost of effort jumps down at $\eta$. Thus, either increasing or decreasing $\eta$ and $u_{*}(\eta)$ marginally increases profits, as illustrated in Figure 1 a).

\section{JOB MARKET MATCHING}

In this section, we characterize job market transitions based on our axioms of frictionless and anonymous matching. A key role is played by the matching technology $\psi$, which describes the relative competitiveness of employed and unemployed workers in the matching market. 
This formulation is the major methodological contribution of this article and enables the ordinal solution approach in Section 5 .

At the start of each period some firms have vacancies and offer them to workers. The vacancy may go to employed or unemployed workers; if an employed worker accepts an offer, this frees up his current employer to immediately offer the vacancy to other workers.

First, we determine the firms' probability of filling a vacancy $p(u)$. When there is unemployment, $n<1$, the worker's reservation value equals the value of continued unemployment. Assuming that unemployed workers accept a job when indifferent, frictionless matching implies

$$
p(u)= \begin{cases}0 & \text { if } W(u)<\delta V^{\varnothing} \\ 1 & \text { if } W(u) \geq \delta V^{\varnothing}\end{cases}
$$

With full employment, $n \geq 1$, the reservation utility also captures employment opportunities at other firms. Let $F(u)$ be the distribution of utilities of firms' contracts and denote its support by $[\underline{u}, \bar{u}]$. If $n=1$, we have

$$
p(u)= \begin{cases}0 & \text { if } W(u)<\delta V^{\varnothing} \text { or } u<\underline{u}, \\ 1 & \text { if } W(u) \geq \delta V^{\varnothing} \text { and } u \geq \underline{u} .\end{cases}
$$

If there was an excess supply of jobs, $n>1$, then not all jobs would be filled for sure, implying $p(\underline{u})<1$. But then the job with utility $\underline{u}$ would not be firm-optimal by Lemma 1 It follows that $n \leq 1$ in equilibrium.

Next, we analyze the transitions of workers between unemployment and jobs. Since we are interested in large, anonymous labour markets, we assume that job offers do not depend on a worker's history with current or previous employers. We do, however, allow job offers to depend on whether or not the worker is currently employed. For example, unemployed workers may receive better offers because they have more time to search; on the contrary, employed workers may receive better offers because of superior job market connections. These arguments may even hold simultaneously for different segments of the job market; i.e. unemployed workers have better chances of finding entry-level jobs whereas employed workers have an easier time finding the top jobs.

Workers' transitions under anonymous matching can be described by two distribution functions: the distribution of the best offer to an unemployed worker $F^{\varnothing}(u)$, and that to an employed worker $F^{e}(u)$; both of these distributions have support in $\varnothing \cup[\underline{u}, \bar{u}]$. We assume that employed workers stay with their current employer when indifferent 17 then, $F^{e}(u)$ coincides with the retention rate at a job with utility $u$.

Absent voluntary terminations, there are $\alpha n$ filled jobs, $(1-\alpha) n$ vacancies, and $1-\alpha n$ unemployed workers going into the matching phase. Frictionless matching for jobs above $u$ implies

$$
\underbrace{(1-\alpha n)\left(1-F^{\varnothing}(u)\right)}_{\text {unemployed }}+\underbrace{\alpha n F(u)\left(1-F^{e}(u)\right)}_{\text {employed below } u}=\underbrace{(1-\alpha) n(1-F(u))}_{\text {vacancies above } u} .
$$

To build some intuition for equation 12 , note that the jobs offered to unemployed workers are subject to a negative selection (even conditional on receiving an offer). Formally, equation (12) implies that $1-F^{\varnothing}(u) \leq \theta(1-F(u))$, where $\theta:=(1-\alpha) n /(1-\alpha n)=1-F^{\varnothing}(\varnothing)$ is the labourmarket tightness. Intuitively, there is more competition for higher quality jobs since the unemployed are competing with more and more employed workers.

17. This assumption seems reasonable to us but is not important to our analysis. 
To determine the two distributions of job offers $F^{\varnothing}(u), F^{e}(u)$ from the market clearing condition (12) we need to specify the relative competitiveness of employed and unemployed workers in the labour market. We do so by supposing that all workers draw independent, exogenous matching priorities $z \in[0,1]$ and then get to pick vacancies in order of their priorities, with highest priorities getting first pick. We normalize the priorities for employed workers to be uniform on $[0,1]$, but allow for any distribution $\psi$ on $[0,1]$ for unemployed workers. The employed worker with quantile $z$ then ties with the unemployed worker with quantile $\psi(z)$, so $F^{\varnothing}(u)$ and $F^{e}(u)$ in equation (12) are connected by $F^{\varnothing}(u)=\psi\left(F^{e}(u)\right) 18$

Equation (12) implies that the retention rate of a contract, $F^{e}(u)$, depends on other contracts only via its rank in the distribution $F(u)$. We can thus express the job distribution and retention rates in terms of quantiles, $q=F(u)$, rather than utilities. This ordinal perspective is key for the explicit characterization of equilibrium contracts in Section 5 Specifically, given $n$ firms, we define the retention rate at a job with quantile $q, \beta_{n}(q)$, independently of the distribution $F$ via 19

$$
(1-\alpha n)\left(1-\psi\left(\beta_{n}(q)\right)\right)+\alpha n q\left(1-\beta_{n}(q)\right)=(1-\alpha) n(1-q) .
$$

On the range of $F$ we then have $F^{e}(u)=\beta_{n}(F(u))$.

The following lemma summarizes some useful properties of $\beta_{n}(q)$. We say a matching technology exhibits on-the-job search (OJS) if $\psi$ is continuous; we justify this terminology after Lemma 4 It is helpful to introduce an order on matching functions by saying that $\tilde{\psi}$ has (strictly) more OJS than $\psi$ if $\tilde{\psi}(z)>\psi(z)$ for all $z \in(0,1) 20$

Lemma 4. The retention rate has the following properties:

(a) $\beta_{n}(q)$ continuously increases in the job's quantile $q$ with $\beta_{n}(1)=1$.

(b) If there is OJS and $\beta_{n}(q)>0$, then $\beta_{n}$ strictly increases in $q$.

(c) $\beta_{n}(0)$ decreases in $n$, and in $\psi$. If $n<1$ and $\psi(z) \leq z$ then $\beta_{n}(0)>0$.

18. This assumes that

$$
(1-\alpha n)\left(1-\psi\left(F^{e}(u)\right)\right)+\alpha n F(u)\left(1-F^{e}(u)\right)=(1-\alpha) n(1-F(u))
$$

has a unique solution $F^{e}(u)$. This is the case if $\psi$ is continuous and $\psi(0)=0$ : For then the LHS of equation [13 strictly and continuously decreases in $F^{e}(u) \in[0,1]$ with boundary conditions $1-\alpha n(1-F(u)) \geq(1-\alpha) n(1-F(u))$ for $F^{e}(u)=0$ and $0 \leq(1-\alpha) n(1-F(u))$ for $F^{e}(u)=1$.

If $\psi$ is discontinuous, one employed worker ties with an atom of unemployed workers who need to be rationed to satisfy equation 12. In this case, we accordingly define $F^{\varnothing}, F^{e}$ as the unique right-continuous functions that satisfy equation 12 together with $F^{\varnothing}(u) \in\left[\lim _{\epsilon \rightarrow 0} \psi\left(F^{e}(u)-\epsilon\right), \psi\left(F^{e}(u)\right)\right]$. If $\psi(0)>0$ and the RHS of equation 13 exceeds the LHS for $F^{e}(u)=0$, all employed workers receive jobs above $u$ and the remaining jobs must be rationed among the unemployed. In this case, we accordingly set $F^{e}(u)=0$ and define $F^{\varnothing}(u)$ via equation 12.

19. As in note 18 equation 14 uniquely defines $\beta_{n}(q) \in[0,1]$ if $\psi$ is continuous with $\psi(0)=0$. Otherwise, we proceed as in note 18 If $\psi$ is discontinuous, we define $\beta_{n}(q)$ and $x$ as the unique solution of

$$
(1-\alpha n)(1-x)+\alpha n q\left(1-\beta_{n}(q)\right)=(1-\alpha) n(1-q)
$$

and $x \in\left[\lim _{\epsilon \rightarrow 0} \psi\left(\beta_{n}(q)-\epsilon\right), \psi\left(\beta_{n}(q)\right)\right]$. If $\psi(0)>0$ and the RHS of equation 14 exceeds the LHS for $\beta_{n}(q)=0$, we set $\beta_{n}(q)=0$.

20. This definition is unusual in two ways: First, it requires strict inequality $\tilde{\psi}(z)>\psi(z)$ for all $z \in(0,1)$ rather than only for some such $z$; this is just for convenience in Theorem 3 Second, as $\psi$ is the priority distribution of unemployed workers, the order is the opposite of first-order stochastic dominance. 
Proof (a) The RHS of equation (14) continuously and strictly decreases in $q$. Since $\psi$ increases, the LHS strictly decreases in $\beta_{n}(q)$. Thus, $\beta_{n}(q)$ must continuously increase in $q$. (b) If $\psi$ is continuous, the LHS of equation (14) is also continuous in $\beta_{n}(q)$ and $\beta_{n}(q)$ strictly increases in $q$. (c) For the lowest job, equation 14 simplifies to $\psi\left(\beta_{n}(0)\right)=(1-n) /(1-\alpha n)$, so $\beta_{n}(0)$ decreases in $n$ and $\psi$. If $n<1$ and $\psi(z) \leq z$ then $0<\psi\left(\beta_{n}(0)\right) \leq \beta_{n}(0)$.

If there is OJS then every non-trivial interval of jobs $\left[q, q^{\prime}\right]$ is offered to an employed worker with positive probability. Since these jobs are accepted by the worker in job $q$ but not by the worker in job $q^{\prime}$, job $q^{\prime}$ has a strictly higher retention rate than job $q$. Conversely, if $\psi$ is discontinuous then no employed worker receives offers in some interval $\left[q, q^{\prime}\right]$ and the retention rate is the same at all these jobs.

We illustrate the framework with three examples:

Shapiro-Stiglitz matching: All jobs are offered to unemployed workers, so $\psi^{\mathrm{S}}(z)=0$ for $z \in[0,1)$. The retention rate is then given by $\beta_{n}^{\mathrm{S}} \equiv 1$.

Symmetric matching: Employed and unemployed workers receive job offers from the same distribution, so $\psi^{\mathrm{Y}}(z)=z$. Equation (14) then implies that the retention rate is given by

$$
\beta_{n}^{\mathrm{Y}}(q)=\frac{1-n(1-q)}{1-\alpha n(1-q)} .
$$

The probability $d \beta_{n}^{\mathrm{Y}}(q)$ of receiving a job offer in $[q, q+d q]$ decreases in $q$. This is because the demand for such jobs from employed workers increases in $q$, whereas the supply of such jobs decreases in $q$ as fewer of them open up during the matching process.

Intern matching: All jobs are first offered to employed workers, so $\psi^{\mathrm{I}} \equiv 1$. In this case, employed workers leave the worst jobs, so

$$
\beta_{n}^{\mathrm{I}}(q)=\left\{\begin{array}{cl}
0 & \text { for } q \in[0,1-\alpha], \text { and } \\
\frac{q-(1-\alpha)}{\alpha q} & \text { for } q \in[1-\alpha, 1] .
\end{array}\right.
$$

In Section 5.3 we show that more than $1-\alpha$ firms offer identical jobs at the bottom of the job distribution, so any job has quantile $q=F(u)>1-\alpha$ and a strictly positive retention rate 21

Our framework differs from other matching models (e.g. Pissarides, 2000; Burdett and Mortensen 1998) in three respects. First, it describes matching outcomes axiomatically rather than specifying an underlying process where firms post offers and workers choose to accept or reject received offers 22 Second, it is frictionless in that every acceptable job is filled. This allows us to focus on the firm's problem of motivating a worker rather than its problem of attracting a worker. Third, our matching technology $\psi$ is flexible enough to specify the relative competitiveness of employed and unemployed workers at every type of job. A case in point is Intern matching where good jobs are exclusively offered to employed workers whereas unemployed workers only receive entry-level jobs.

Our ordinal approach to matching provides a tractable way to solve for equilibrium jobs. The approach has it limits; e.g. it does not allow for switching costs or endogenous search

21. Defining the class of matching functions $\psi^{\lambda}(z)=\max \{0,1+(z-1) / \lambda\}$, Shapiro-Stiglitz matching corresponds to $\lambda=0$, Symmetric matching corresponds to $\lambda=1$, and Intern matching corresponds to $\lambda=\infty$.

22. In a finite economy, these outcomes would arise from the firm-offering Gale-Shapley algorithm when firms are indifferent between workers and break ties according to $\psi$. 
intensity. With these extensions, one job's retention rate would depend on the entire cardinal utility distribution, rather than just on the ordinal rank of job 23

\section{EQUILIBRIUM}

In this section, we define and characterize industry equilibrium. First, we integrate the analysis of a single firm's problem in Section 3 with the job market analysis in Section 4 Section 5.1 considers the case in which unemployed workers receive better offers, $\psi(z) \leq z$; this restriction includes the canonical cases of Shapiro-Stiglitz and Symmetric matching, and simplifies the analysis since it turns out that the (IR) constraint is slack. Section 5.2 investigates how the equilibrium job distribution depends on the matching function $\psi$. Finally, Section 5.3 extends the analysis to general matching technologies, and addresses the complications associated with a binding (IR) constraint.

To finish the specification of the economy we define the value of an unemployed worker:

$$
V^{\varnothing}=\int W(\hat{u}) d F^{\varnothing}(\hat{u})
$$

where $W(u)$ is defined by equation (3). The worker's value function when employed, (2), and unemployed, 16, is thus determined by the distribution of offers, $F^{\varnothing}$ and $F^{e}$.

We can now define an equilibrium in our economy.

Definition: An industry equilibrium is a distribution of contracts $\langle u, \eta\rangle$ with mass $n \leq 1$ such that:

(a) Every contract $\langle u, \eta\rangle$ has zero profits, and is firm-optimal given outside conditions $F^{e}(u)$, $F^{\varnothing}(u), p(u)$.

(b) Job offers $F^{e}(u), F^{\varnothing}(u)$ are derived from the distribution of jobs $F(u)$, the number of firms $n$, and the matching technology $\psi$ via market-clearing (12).

(c) The probability that a firm fills its position $p(u)$ is derived from $F(u)$ and $V^{\varnothing}$ via equation (10) if $n<1$, or equation (11) if $n=1$.

Recall, that the firm's problem is to maximize its profits $\phi(\eta)-\eta-u-c$ subject to the worker's incentive and participation constraints,

$$
\begin{aligned}
& \alpha \delta\left(V(u)-V^{\varnothing}\right) \geq \eta \\
& W(u) \geq \delta V^{\varnothing}, \text { and, if } n=1, u \geq \underline{u} .
\end{aligned}
$$

We now show that (IC) binds. If the unemployed obtain better offers, then (IR) is slack (Section 5.1 but otherwise it may bind (Section 5.3.

Lemma 5. In any equilibrium job $\langle u, \eta\rangle$, the $(I C)$ constraint binds, so that $u=u_{*}(\eta)$.

Proof See Appendix A.3 \|

23. As discussed at the end of the Section 2 the model could also be formulated in continuous time rather than discrete time. In that version, $1-n$ unemployed workers and $n q$ underemployed workers compete for an infinitesimal measure $(1-\alpha) n(1-q) d t$ of vacancies at every instant. Thus, only workers with the highest priority $z$ receive any job offer and the density of these top priorities $\psi^{\prime}(1)$ becomes a sufficient statistic for $\psi$. Our examples of Intern, Symmetric and Shapiro-Stiglitz matching correspond to $\psi^{\prime}(1) \in\{0,1, \infty\}$. 
For an intuition, assume that there is unemployment and wages are positive. Then (IC) implies (IR) because a worker can choose to collect the wage and shirk, which is better than rejecting the job and remaining unemployed. By firm optimality the constraints cannot both be slack; therefore (IC) must bind.

The (IC) constraint neatly illustrates the externalities between firms. Any firm $f$ 's contracting problem depends on the job distribution in two ways. First, attractive job offers by other firms increase the outside option of $f$ 's employee, $V^{\varnothing}$, and tighten (IC). This negative externality is at the core of Shapiro-Stiglitz's equilibrium unemployment result. In our model, on-the-job search gives rise to a second, positive externality because other firms' job offers also increase the value of $f$ 's job, $V(u)$, and relax (IC) 24 The magnitude of this positive externality depends on the matching technology and the rank of firm $f$ 's contract in the contract distribution. We will see in Section 6.2 that under Intern matching the net externality can be positive. This discussion implies that a firm would never want to block its employees from searching; this would be tantamount to shutting off the positive externality provided by outside job offers.

\subsection{Equilibrium with $\psi(z) \leq z$}

We now characterize equilibrium when the unemployed receive better offers than the employed. This assumption simplifies our analysis because it implies that (IR) is slack.

Lemma 6. Assume $\psi(z) \leq z$ for all $z$. In equilibrium, any contract $\langle u, \eta\rangle$ has strictly positive utility and effort, there are $n<1$ firms and the (IR) constraint is slack.

Proof We first show that any contract has strictly positive utility and effort. Any equilibrium contract $\langle u, \eta\rangle$ has zero profits and, by Lemma $5 u=u_{*}(\eta)$. Our assumption $\psi(z) \leq z$ implies that the opportunity cost of taking a job, $u_{*}(0)$, is weakly positive, and the firm's fixed cost $u_{*}(0)+c$ is strictly positive. The zero profit condition implies that the job must therefore entail strictly positive effort in order to cover the fixed cost. Equation (7) implies $u_{*}(\eta)$ strictly increases in $\eta$, so incentive compatibility implies utility is strictly positive. This is illustrated in Figure 3

Next, we show that $n<1$ and (IR) is slack. Since $\eta>0$, (IC) implies that $V(u)>V^{\varnothing}$ in every equilibrium job. If $n=1$ then an unemployed worker receives some job offer for sure, and obtains better offers than the employed worker, so $V(\underline{u}) \leq V^{\varnothing}$, yielding a contradiction. With $n<1$, the binding (IC) constraint implies (IR) is equivalent to $w=u+\eta \geq 0$. This constraint is slack because we have already established that both $u$ and $\eta$ are strictly positive.

Lemma 6 shows that (IR) is slack. Intuitively, if unemployed workers receive better offers then wages must be positive to compensate workers for the cost of giving up the better offers, $u_{*}(0)$. As argued after Lemma5 (IC) then implies (IR). The result also shows that there must be unemployment in equilibrium. Intuitively, each job needs to have positive effort to cover the fixed cost $u_{*}(0)+c$. However, if $n=1$ and the unemployed receive better offers than the employed, then it is impossible to motivate the worker in the lowest job to take this effort.

Characterizing equilibrium contracts explicitly could seem difficult since any firm's contracting problem depends on the entire distribution of contracts. Rather than solving for equilibrium using a functional fixed-point theorem, we exploit the insight that a firm's retention rate, and thus its first-order condition depends on other jobs only via its rank in the job distribution.

24. This positive effect is familiar from the back-loading literature, where high future wages are promised exclusively to $f$ 's current employee. 
REVIEW OF ECONOMIC STUDIES

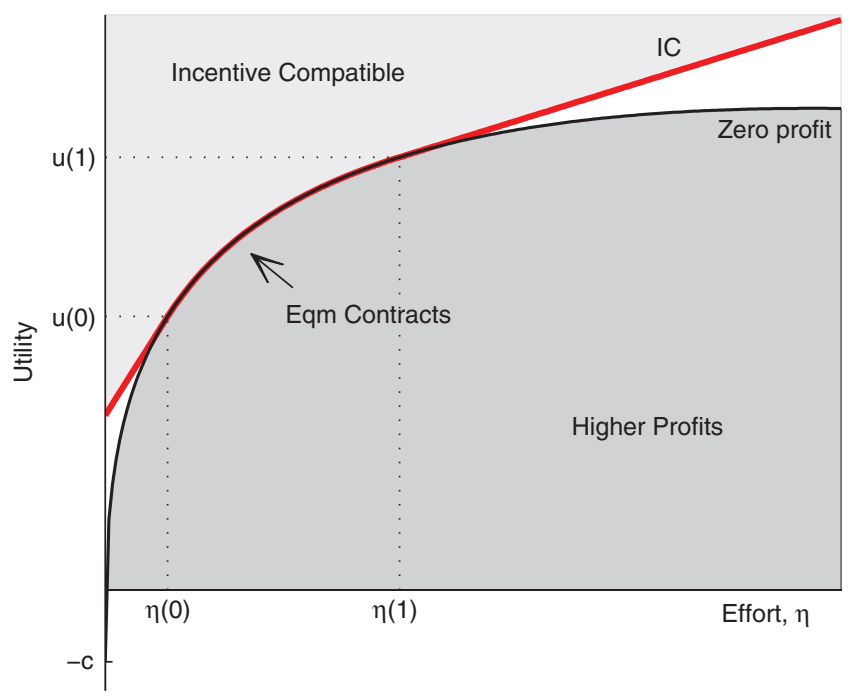

FIGURE 3

The set of equilibrium contracts

This figure shows the firm's zero profit curve $u=\phi(\eta)-\eta-c$ and the worker's (IC) constraint $u=u_{*}(\eta)$ in equilibrium.

Contracts under the zero profit line are more profitable for the firm; contracts above the (IC) constraint are incentive compatible. When solving for equilibrium, the firm's first-order condition says the zero profit curve must be tangent to the (IC) constraint; profits are determined so these curves coincide over the range of equilibrium contracts. This figures assumes $\phi(\eta)=\eta^{1 / 3}, \alpha=\delta=3 / 4, c=0.05$ and $\psi(z)=\max \{2 z-1,0\}$

Thus, we can first solve for the effort of a contract with quantile $q$ via the first-order condition, and then solve for wages via zero profits.

To express the model in terms of quantiles, we label the identical firms by $x \in[0,1]$, write their jobs as $\langle u(x), \eta(x)\rangle$, and assume without loss of generality that $u(x)$ weakly increases; we also write job distributions with $n$ firms as $\{u(x), \eta(x), n\}$. The quantile of a firm's job equals its label, $q=F(u(x))=x$, unless the distribution $F$ has an atom at $u(x)$. Using Lemmas 3 , 5 and 6 any equilibrium contract $\langle u, \eta\rangle$ satisfies the firm's first-order condition 8 . We now express this first-order condition as a function of the firm's quantile. If firms $[\underline{x}, \bar{x}] \ni x$ offer the same job, then the retention rate equals $\beta_{n}(\bar{x})$ at firm $x$ 's job and $\beta_{n}(\underline{x})$ just below. Then the left- and right-handed first-order conditions (9) become

$$
\frac{1}{\alpha \delta \beta_{n}(\underline{x})} \leq \phi^{\prime}(\eta(x)) \leq \frac{1}{\alpha \delta \beta_{n}(\bar{x})} .
$$

Since the retention rate $\beta_{n}(x)$ at job $x$ weakly increases in $x$, the first-order condition for firm $x$ is

$$
\phi^{\prime}(\eta(x))=\frac{1}{\alpha \delta \beta_{n}(x)},
$$

for all $x \in[0,1]$. We can then solve for the equilibrium job distribution $\{u(x), \eta(x), n\}$ in three steps:

1. Effort $\eta(x)$ of each firm $x$ is uniquely determined by the firm's first-order condition 17 up to the number of firms, $n$. Equation 177 requires the firm's isoprofit curve to be tangent to the worker's incentive constraint (see Figure 3). 
2. Utility $u(x)$ is determined up to $n$ by the zero profit condition

$$
u(x)=\phi(\eta(x))-\eta(x)-c .
$$

Jointly, equations (17) and 18 can be interpreted as a marginal incentive constraint: If contract $\langle u(1), \eta(1)\rangle$ is firm-optimal, and equations (17) and 18 hold for all contracts $\langle u(x), \eta(x)\rangle$, then all these contracts are firm-optimal.

3. The number of firms $n$ is uniquely determined by the worker's (IC) constraint for firm $x=1$ (or any other firm),

$$
\eta(1)=\alpha \delta\left(V(u(1))-V^{\varnothing}\right) .
$$

Intuitively, the equilibrium number of jobs $n$ is unique because an increase in the number of firms benefits unemployed workers more immediately than employed workers, and tightens the (IC) constraint of the highest firm 19.

To formalize this characterization it is useful to define a candidate equilibrium with $n$ firms as a set of contracts $\{u(x), \eta(x), n\}$ that satisfy the first-order condition 177 and zero profits 18, but ignoring step 3. If we define the incentive to shirk by $I:=\eta(1)-\alpha \delta\left(V(u(1))-V^{\varnothing}\right)$, then $\{u(x), \eta(x), n\}$ is an equilibrium if $I=0$. As Lemma 6 rules out negative equilibrium wages, we restrict the definition of candidate equilibria to $n$ such that the lowest job has non-negative wage. Lemma 4 implies that the retention rate in the lowest job $\beta_{n}(0)$, and thus its effort and wage, decrease in $n$. We thus restrict the domain to $n \in\left(0, n^{*}\right]$, where $n^{*}$ is where the lowest wage hits zero in a candidate equilibrium (we set $n^{*}=1$ if the lowest wage is non-negative for all $n$ ). Lemma 7 in Appendix A.5establishes that $I(n)$ strictly single-crosse 25 in $n \in\left(0, n^{*}\right]$ and strictly decreases in the amount of on-the-job search $\psi$.

Theorem 1 (Equilibrium characterization). Assume $\psi(z) \leq z$ for all $z$. Industry equilibrium exists and is unique. There is unemployment, $n<1$. Every job $\langle u(x), \eta(x)\rangle$ is determined by the first-order condition (17), the zero profit condition (18) and the binding (IC) constraint (19). The job distribution $F(u)$ has no gaps and, under OJS, no atoms.

Proof Characterization. We first argue that equations [17- 19] characterize equilibrium. By Lemmas 3 [ 5and 6 these equations are necessary for equilibrium. We now establish sufficiency. Figure 3 illustrates why all contracts $\langle u(x), \eta(x)\rangle$ are firm-optimal. Formally, all of these contracts generate zero profit, and contracts $\langle u, \eta(x)\rangle$ with $u<u(x)$ violate (IC). To see that no incentive compatible contract $\left\langle u, \eta_{-}\right\rangle$with $\eta_{-}<\eta(0)$ is more profitable, we extend the definition of $u_{*}(\eta)$ to all $\eta \in \mathbb{R}^{+}$using (4), so $\left\langle u_{*}\left(\eta_{-}\right), \eta_{-}\right\rangle$is the most profitable incentive compatible contract with effort $\eta_{-}$. As $\langle u(0), \eta(0)\rangle$ is the lowest contract offered by other firms, the marginal cost of effort on $\left[\eta_{-}, \eta(0)\right]$ equals $1 / \alpha \delta \beta(0)$ whereas the marginal benefit $\phi^{\prime}(\eta)$ is greater than $\phi^{\prime}(\eta(0))=1 / \alpha \delta \beta(0)$. With marginal benefits exceeding marginal costs, $\left\langle u_{*}\left(\eta_{-}\right), \eta_{-}\right\rangle$is less profitable than $\langle u(0), \eta(0)\rangle$. Similarly, if $\eta_{+}>\eta(1)$ then marginal costs of effort equal $1 / \alpha \delta=\phi^{\prime}(\eta(1))$ on $\left[\eta(1), \eta_{+}\right]$and exceed marginal benefits $\phi^{\prime}(\eta)$, so $\left\langle u_{*}\left(\eta_{+}\right), \eta_{+}\right\rangle$is less profitable than $\langle u(1), \eta(1)\rangle$.

Existence and Uniqueness. For fixed $n$, equations (17) and (18) pin down equilibrium contracts $\langle u(x), \eta(x)\rangle$. Lemma7 in Appendix A.5 establishes that shirking incentives $I$ strictly and continuously single-cross on $\left(0, n^{*}\right]$. When $n=n^{*}$, then (IC) is violated: If $n^{*}<1$, then the bottom job has zero wage; if $n^{*}=1$ then $n=1$. In either case the proof of Lemma 6 shows that (IC) is violated. We now show that (IC) is slack as $n \rightarrow 0$, so there exists a unique $n \in\left(0, n^{*}\right)$ where (IC) binds.

25. A function $f(x)$ single-crosses on $[\underline{x}, \bar{x}]$ if there exists $x^{*}$ such that $f(x) \leq 0$ for $x \in\left[\underline{x}, x^{*}\right)$ and $f(x) \geq 0$ for $x \in\left(x^{*}, \bar{x}\right]$. It strictly single-crosses if the inequalities are strict. It (strictly) single-crosses from above if the inequalities are reversed. 
As $n$ approaches 0 , unemployed workers never find a job and $V^{\varnothing}$ vanishes. Thus $V(u(1))$ approaches $u(1) /(1-\alpha \delta)$, and incentives approach

$$
\lim _{n \rightarrow 0} \alpha \delta\left(V(u(1))-V^{\varnothing}\right)-\eta(1)=\frac{\alpha \delta}{1-\alpha \delta} u(1)-\eta(1)=\frac{\alpha \delta}{1-\alpha \delta}\left(\phi(\eta(1))-\frac{1}{\alpha \delta} \eta(1)-c\right)
$$

using the zero profit condition. Since $\eta(1)$ maximizes $\phi(\eta)-\eta /(\alpha \delta)$, our nontriviality assumption (11) implies (IC) is slack as $n \rightarrow 0$.

Contract distribution. The inverse marginal productivity $\left(\phi^{\prime}\right)^{-1}$ strictly and continuously decreases. By Lemma 4 a), $\beta_{n}(x)$ continuously increases in $x$, so that effort $\eta(x)=\left(\phi^{\prime}\right)^{-1}\left(1 / \alpha \delta \beta_{n}(x)\right)$ and utility $u(x)=\phi(\eta(x))-\eta(x)-c$ continuously increase as well; in other words, the distribution $F(u)$ has no gaps. Moreover, as $\psi(z) \leq z$ and $n<1$ (by Lemma 6 , Lemma 4 (c) implies $\beta_{n}(0)>0$. Thus, under OJS, $\beta_{n}(x), \eta(x)$ and $u(x)$ increase strictly by Lemma 4(b); in other words, the distribution $F(u)$ has no atoms.

At the top of the job distribution, the retention rate is $\beta_{n}(1)=1$ so effort at the top job is given by $\eta(1)=\left(\phi^{\prime}\right)^{-1}(1 / \alpha \delta)$, independent of the matching technology $\psi$. At the bottom of the job distribution, effort is given by $\eta(0)=\left(\phi^{\prime}\right)^{-1}\left(1 / \alpha \delta \beta_{n}(0)\right)$ which is strictly positive since $n<1$ and $\beta_{n}(0)>0$. Between the extremes, effort $\eta(x)$ is continuous and, if the matching technology satisfies OJS, strictly increasing. In other words, the contract distribution $F$ has no gaps, and with OJS, no atoms. Intuitively, if an atom of firms $[\underline{x}, \bar{x}]$ offer the same job $\langle u, \eta\rangle$ then the marginal cost of effort falls at $\eta$ from $1 / \alpha \delta \beta_{n}(\underline{x})$ to $1 / \alpha \delta \beta_{n}(\bar{x})$. If no employed workers are offered jobs $x \in[\underline{x}, \bar{x}]$, then $\beta_{n}(\underline{x})=\beta_{n}(\bar{x})$ and this is consistent with equilibrium. However, if $\psi$ obeys OJS, then $\beta_{n}(\underline{x})<\beta_{n}(\bar{x})$, so the marginal cost of effort jumps down, and either an upward or downward deviation is profitable (see Figure1a)). Similarly, if there is a gap in the contract distribution, the marginal benefit of effort decreases over this gap but the marginal cost of effort does not, which again is incompatible with local optimality.

\subsection{Comparative statics in on-the-job search}

We now examine how on-the-job search affects the equilibrium job distribution. We start with a comparison of Shapiro-Stiglitz matching and Symmetric matching. Figure 4 illustrates these examples.

Figure 4 a), (b) show the Shapiro-Stiglitz equilibrium in which all firms offer the same contract. Fixing the number of firms and the job distribution, Figure 4 (c), (d) show how the introduction of on-the-job search enables a single firm to increase its profits by offering a contract with lower wage and effort. Intuitively, on-the-job search lowers the opportunity cost of taking a job and increases the worker's value for such low-wage contracts. Thus the deviating firm can offer lower wages while maintaining its worker's incentives, making the downward deviation strictly profitable. This profit opportunity induces entry by additional firms. Figure 4(e), (f) show the equilibrium with Symmetric matching.

Shapiro-Stiglitz matching. Suppose that only unemployed workers receive job offers, so the retention rate equals $\beta_{n}^{\mathrm{S}}(x) \equiv 1$. By Theorem 11 all firms offer contract $\left\langle u^{\mathrm{S}}, \eta^{\mathrm{S}}\right\rangle$ with $\eta^{\mathrm{S}}:=\left(\phi^{\prime}\right)^{-1}(1 / \alpha \delta)$ and $u^{\mathrm{S}}:=\phi\left(\eta^{\mathrm{S}}\right)-\eta^{\mathrm{S}}-c$.

Under Shapiro-Stiglitz matching, accepting a job means forgoing the opportunity of further job offers. Specifically, the worker's incentive premium $u_{*}(\eta)$ has a positive intercept of $u_{*}(0)=$ $(1-\delta) V^{\varnothing}$, which represents the opportunity cost of not searching for other jobs. The marginal 
(a) Marginal Costs and Benefits

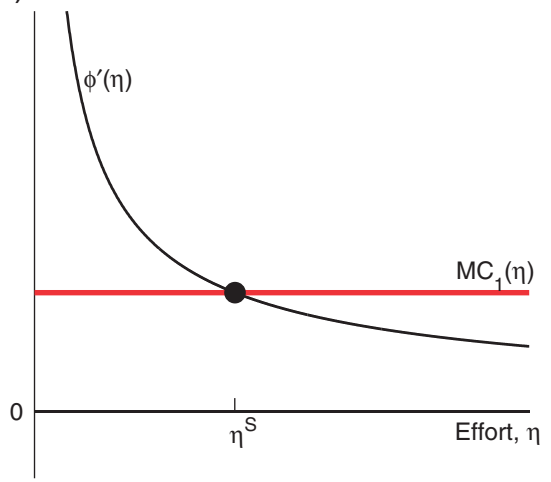

(c)

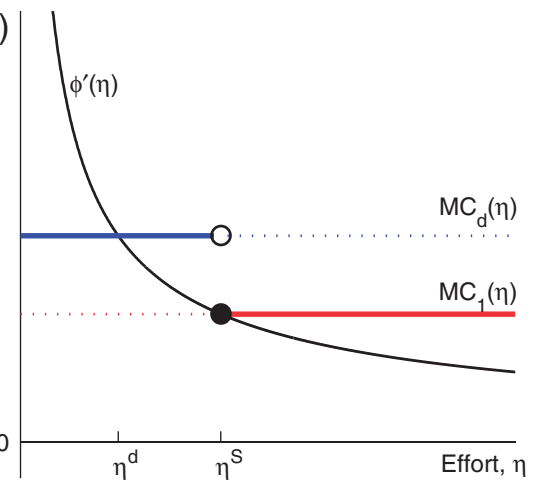

(e)

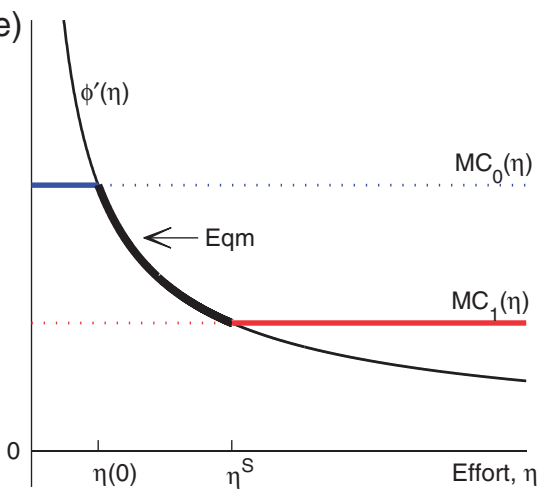

(b) Contract Space

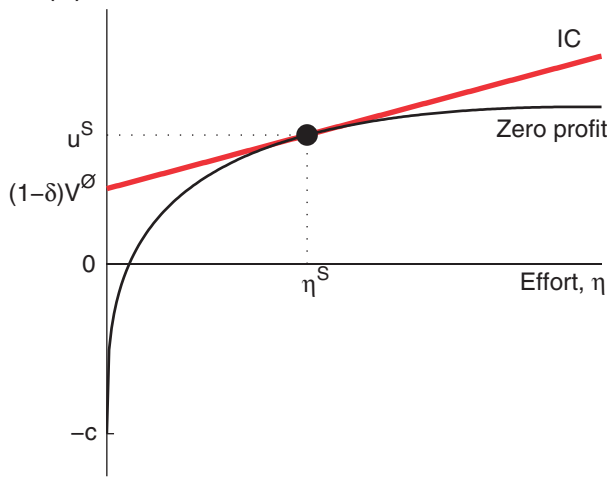

(d)

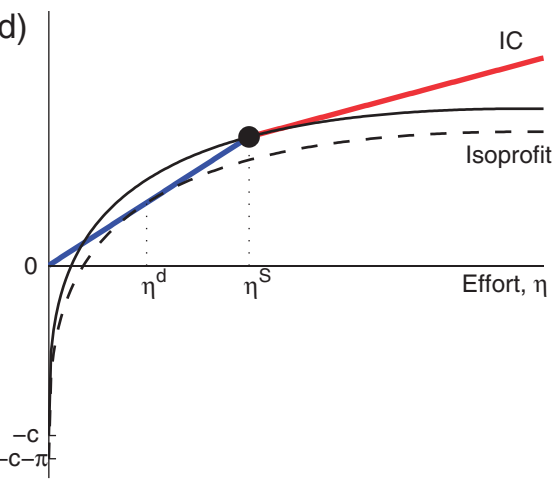

(f)

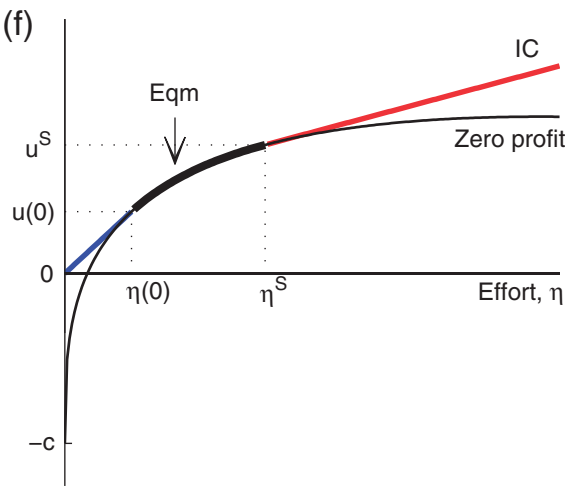

FIGURE 4

The impact of on-the-job search

Panel (a) illustrates the marginal cost and benefit of effort in the Shapiro-Stiglitz equilibrium. Panel (b) shows the firm's zero profit function and the worker's (IC) constraint in $\langle u, \eta\rangle$ space. Panels 4(c), (d) introduce Symmetric matching and suppose other firms continue to offer the Shapiro-Stiglitz contract. When the firm defects and offers a lower wage, it

faces a lower retention rate and higher marginal cost $\mathrm{MC}_{\mathrm{d}}(\eta)$, but does not need to compensate its worker for the opportunity cost of forgone searching. This yields a profitable deviation with effort $\eta^{\mathrm{d}}$. In equilibrium with Symmetric matching, the positive profits attract more entrants. Panels 4(e), (f) show the marginal costs for highest and lowest firms in this equilibrium, $\mathrm{MC}_{1}(\eta)$ and $\mathrm{MC}_{0}(\eta)$; the distribution of contracts is determined so that each firm equates the marginal cost and benefit of effort, and achieves zero profit. The figure assumes $\phi(\eta)=\eta^{1 / 3}, \alpha=\delta=3 / 4$ and $c=0.2$ 
cost of incentivizing effort is constant and equal to $1 / \alpha \delta$, so reduced-form profits 5 become

$$
\pi_{*}(\eta)=\phi(\eta)-\frac{1}{\alpha \delta} \eta-(1-\delta) V^{\varnothing}-c .
$$

The opportunity cost of taking a job acts as an endogenous fixed cost that limits entry even if the exogenous fixed costs $c$ are zero. To compute the equilibrium number of firms note that (IC) implies that the worker is indifferent between (i) working today and shirking tomorrow, and (ii) shirking today, searching for a new job tomorrow and then shirking again. Plan (i) $\operatorname{costs} \eta^{\mathrm{S}}$ in effort today, but lowers the probability of forfeiting wage $w^{\mathrm{S}}=\phi\left(\eta^{\mathrm{S}}\right)-c$ tomorrow from $1-\theta$ in plan (ii) to $(1-\alpha)(1-\theta)$ in plan (i). Indifference implies

$$
\eta^{\mathrm{S}}=\alpha \delta(1-\theta)\left(\phi\left(\eta^{\mathrm{S}}\right)-c\right) .
$$

This equation uniquely determines market tightness $\theta=(1-\alpha) n /(1-\alpha n)<1$ and thus the number of firms $n<1$. The equilibrium number of firms $n$ increases in the discount rate $\delta$, the end-of-period retention rate $\alpha$, and the wage $w^{\mathrm{S}}=\phi\left(\eta^{\mathrm{S}}\right)-c$, and decreases in the effort cost $\eta^{\mathrm{S}}$.

Symmetric matching. Suppose that $\psi^{\mathrm{Y}}(z)=z$, so that employed and unemployed workers receive job offers from the same distribution. The retention rate strictly increases from $\beta_{n}^{\mathrm{Y}}(0)=1-\theta$, the probability that an unemployed worker stays unemployed, to $\beta_{n}^{\mathrm{Y}}(1)=1$. Applying Theorem 11 the top job $\langle u(1), \eta(1)\rangle$ is identical to the unique contract under Shapiro-Stiglitz matching $\left\langle u^{\mathrm{S}}, \eta^{\mathrm{S}}\right\rangle$; effort in the bottom job is given by $\phi^{\prime}(\eta(0))=1 / \alpha \delta(1-\theta)$.

Under Symmetric matching there is no opportunity cost of taking a job. That is, the intercept of the incentive premium $u_{*}(0)$ is zero, because a worker does not forgo the opportunity to search when he takes up the hypothetical job $\langle 0,0\rangle$; this job is thus equivalent to unemployment. For the lowest firm, the marginal cost of effort is constant and equal to $1 / \alpha \delta(1-\theta)$ for all $\eta \in[0, \eta(0)]$. Thus, reduced-form profits (5) become

$$
\pi_{*}(\eta)=\phi(\eta)-\frac{1}{\alpha \delta(1-\theta)} \eta-c .
$$

Substituting in $\eta=\eta(0)$ and setting equal to zero uniquely determines market tightness $\theta$, and thus the equilibrium number of firms. As operating costs become small, $c \rightarrow 0$, the bottom job becomes very unproductive, $\eta(0) \rightarrow 0$, and there is full employment, $n \rightarrow 1$.

These two examples suggest that on-the-job search raises employment, but lowers job quality. Specifically, the top job under Symmetric matching is equivalent to the job offered by all firms under Shapiro-Stiglitz matching; all other jobs have lower retention rates, which induces lower effort, productivity and wages. Our next result establishes this tradeoff for general matching functions. For matching technologies $\psi, \tilde{\psi}$ we write equilibrium employment levels as $n, \tilde{n}$ and equilibrium job distributions as $F(u), \tilde{F}(u)$ with support $[u(0), u(1)]$ and $[\tilde{u}(0), \tilde{u}(1)]$.

Theorem 2 (Comparative statics of on-the-job search). When OJS increases, $\psi(z)<\tilde{\psi}(z)$ for all $z \in(0,1)$, then:

(a) Overall employment increases: $n<\tilde{n}$.

(b) The number of good jobs decreases: $n(1-F(u))>\tilde{n}(1-\tilde{F}(u))$ for all $u \in[u(0), u(1))$.

Proof (a) Let $n$ be equilibrium employment for matching technology $\psi$. Lemma 7 (c) in Appendix A.5 establishes that shirking incentives in the top job of a candidate equilibrium, 
$\eta(1)-\alpha \delta\left(V\left(u(1)-V^{\varnothing}\right)\right.$, strictly decrease in $\psi$, so the (IC) constraint is slack in the candidate equilibrium with $n$ jobs and matching technology $\tilde{\psi}$. This slack is removed again as firms add jobs by Lemma7 7 a).

(b) For $u \in[u(0), u(1)]$ the number of jobs above $u$ is given by $n(1-F(u))$. Rearranging, market clearing (12) yields

$$
n(1-F(u))=\frac{(1-\alpha n)\left(1-F^{\varnothing}(u)\right)+\alpha n\left(1-F^{e}(u)\right)}{1-\alpha F^{e}(u)} .
$$

As OJS increases from $\psi$ to $\tilde{\psi}$, the retention rate $F^{e}(u)$ at equilibrium job $\langle u, \eta\rangle$ remains unaffected since it is determined by the first-order condition $\phi^{\prime}(\eta)=1 / \alpha \delta F^{e}(u)$ and zero profits, independently of $\psi$ and $n$. Hence the increase in OJS strictly increases $F^{\varnothing}(u)=\psi\left(F^{e}(u)\right)$ and, by part (a), increases $n$. This decreases the RHS of equation 21]. $\|$

Theorem 2 shows that an increase in on-the-job search leads to an increase in employment, but a reduction in job quality. Intuitively, the rise in on-the-job search lowers the retention rate in any given job and raises the marginal cost of effort; thus, firms replace high-quality jobs with low-quality jobs. On the flip-side, the rise in on-the-job search reduces the opportunity cost of employment and thereby the fixed cost of offering a job; thus, more firms enter at the bottom of the market 26

This tradeoff between job quality and employment levels raises the question of whether onthe-job search increases or decreases aggregate surplus. We first argue that from the perspective of an unemployed worker the effects exactly wash out. Recall that the retention rate at the top job $\beta_{n}(1)=1$ does not depend on the matching technology $\psi$. The top equilibrium job $\langle u(1), \eta(1)\rangle$ thus coincides with the unique equilibrium contract under Shapiro-Stiglitz matching

$$
\eta(1)=\left(\phi^{\prime}\right)^{-1}(1 / \alpha \delta)=\eta^{\mathrm{S}} \quad \text { and } \quad u(1)=\phi\left(\eta^{\mathrm{S}}\right)-\eta^{\mathrm{S}}-c=u^{\mathrm{S}} .
$$

In addition, the Bellman equation for the top job (2) and the (IC) constraint for the top firm (19) uniquely pin down the value of the top job and the value of unemployment. Elementary algebra shows that27

$$
(1-\delta) V\left(u^{\mathrm{S}}\right)=\phi\left(\eta^{\mathrm{S}}\right)-\frac{\eta^{\mathrm{S}}}{\alpha}-c \quad \text { and } \quad(1-\delta) V^{\varnothing}=\phi\left(\eta^{\mathrm{S}}\right)-\frac{\eta^{\mathrm{S}}}{\alpha \delta}-c .
$$

Thus, from the perspective of either an unemployed worker or the worker in the top job, the gain from the additional low-wage jobs due to on-the-job search exactly offsets the quality-loss in the existing jobs; indeed, we show in Appendix A.4 that $V(u)$ is independent of $\psi$ for any equilibrium job $u$.

26. This increase in the number of jobs also has a knock-on effect of further lowering the quality of existing jobs. Intuitively, as unemployed workers (who are good searchers) are replaced with employed workers (who are worse searchers) at the bottom of the distribution, the retention rate of higher jobs falls, causing firms to lower their effort requirement.

27. To understand these values, suppose a job pays $\phi$ at the start of the period in exchange for work $\eta$. When the worker shirks this produces a "bad news" signal and he loses his job; such a signal also arrives with probability $1-\alpha$ when he works. To ensure that working is incentive compatible, suppose the worker must make amends and perform the work again every time a bad news signal arrives. The value of the job is then $\phi$ every period minus the cost of working, including the cost of making amends, $\eta+(1-\alpha) \eta+(1-\alpha)^{2} \eta+\ldots=\eta / \alpha$. When a worker has just lost his job, he must first make amends in period $t$ to receive his wage in period $t+1$; since he is working today for tomorrow's output, the cost of effort is $\eta / \alpha \delta$. 
Despite this invariance of equilibrium value functions to $\psi$, the equilibrium distribution of $u$ and aggregate surplus do depend on $\psi$. Specifically, a utilitarian planner evaluates on-the-job search less favourably than an unemployed worker because the latter overweights the new jobs at the lower end of the job distribution and underweights the job deterioration at the top end. More formally, when on-the-job search increases from $\psi=\psi^{\mathrm{S}}$ to $\tilde{\psi}=\psi^{\mathrm{Y}}$, we show in Appendix A.4 that aggregate surplus decreases,

$$
n^{\mathrm{S}} \int u^{\mathrm{S}}(x) d x>n^{\mathrm{Y}} \int u^{\mathrm{Y}}(x) d x .
$$

\subsection{Equilibrium for general matching technologies}

So far we have assumed that unemployed workers receive better job offers than employed workers, $\psi(z) \leq z$. This simplified our analysis because Lemma 6 allowed us to ignore the workers' participation constraint. We now relax this assumption and allow for arbitrary matching functions $\psi$. In particular, employed workers may receive better job offers than unemployed workers, $\psi(z) \geq z$, perhaps because they have superior contacts on the job market. We show that the equilibrium analysis in Section 5 extends to this case but, when (IR) binds, the equilibrium job distribution is truncated and an atom of firms offers the same entry-level job $\langle u(0), \eta(0)\rangle$. We also explicitly characterize our third example, Intern matching.

Recall that (IC) binds in equilibrium (Lemma 5). Each firm thus maximizes its reduced-form profit $\pi_{*}(\eta)=\phi(\eta)-\eta-u_{*}(\eta)-c$ subject to

$$
W(u) \geq \delta V^{\varnothing}, \text { and, if } n=1, u \geq \underline{u} .
$$

This constraint requires that the contract is more attractive than unemployment and, if $n=1$, more attractive than the lowest competing contract.

There are now two classes of candidate equilibria, depending on whether $n<1$ or $n=1$. First, consider an equilibrium with $n<1$ firms. We can rewrite (IC) as $W(u) \geq w+\delta V^{\varnothing}$ so, when (IC) binds, (IR) is equivalent to wages $w$ being non-negative. As profits $\phi(\eta)-w-c$ are zero in equilibrium, (IR) thus implies that equilibrium effort must exceed $\phi^{-1}(c)$. The firm's problem is thus equivalent to

$$
\max _{\eta} \pi_{*}(\eta) \quad \text { s.t. } \quad \eta \geq \phi^{-1}(c) .
$$

Firm $x$ 's effort is given by the first-order condition 17 or the lower bound $\phi^{-1}(c)$, whichever is greater. Utility at firm $x$ is determined by zero profits 18 . We call the job distribution defined by these necessary conditions the candidate equilibrium with $n$ firms.

Next, consider an equilibrium with $n=1$ firms and lowest utility $\underline{u}$. In equilibrium, (IR) implies that all jobs must be better than $\langle\underline{u}, \eta\rangle$, where $\eta$ is defined by zero profits $(18)$. The firm's problem is thus equivalent to

$$
\max _{\eta} \pi_{*}(\eta) \quad \text { s.t. } \quad \eta \geq \underline{\eta}
$$

Firm $x$ 's effort is by the first-order condition 177 or the lower bound $\eta$, whichever is greater. Utility at firm $x$ is determined by zero profits 18 . We call the job distribution defined by these necessary conditions the candidate equilibrium with reservation utility $\underline{u}$.

In equilibrium, the lowest utility offered $u(0)$ must coincide with $\underline{u}$; in addition, it must also exceed $-\phi^{-1}(c)$ so as to satisfy the first part of the (IR) constraint. The lowest utility $\underline{u}$ must therefore exceed $\underline{u}^{*}$, which is defined as the greater of $-\phi^{-1}(c)$ and the utility of the unrestricted solution to the first-order condition (17) and zero profits (18). For $\underline{u}=\underline{u}^{*}$, the candidate equilibrium with reservation utility $\underline{u}$ coincides with the candidate equilibrium with $n=1$ firms. As in Section 
5.1 either kind of candidate equilibrium is an equilibrium if the (IC) constraint at the top (19) binds.

When there is little on-the-job search, there is unemployment and a continuous distribution of contracts, as examined in Section 5.1. When there is more on-the-job search, there is full employment and an atom of workers at the bottom. We illustrate this finding by our third example, Intern matching, and then demonstrate it more generally.

Intern matching. Suppose that $\psi^{\mathrm{I}}(z) \equiv 1$, so that employed workers get first pick at jobs. That is, employed workers compete for the top $\alpha n$ jobs, whereas the unemployed compete for the bottom $(1-\alpha) n$ jobs. The retention rate $\beta_{n}^{\mathrm{I}}(x)=\max \{0,(x-(1-\alpha)) /(\alpha x)\}$ equals zero for $x \leq 1-\alpha$, and then increases continuously to $\beta_{n}^{\mathrm{I}}(1)=1$. In equilibrium (IR) must bind because the solution to the first-order condition (17) and zero profits 118 for jobs $x \in[0,1-\alpha]$ is $\langle u, \eta\rangle=\langle-c, 0\rangle$; this contradicts (IR) which, as argued above, implies that equilibrium wages are positive. The lowest equilibrium job, the internship, has strictly positive effort and a positive retention rate. Since some employed workers stay in the internships, unemployed workers are only ever offered internships 28

Intern matching leads to full employment, $n=1$. Otherwise, if $n<1$, the binding (IR) constraint means that unemployed workers are indifferent between accepting internships and turning them down, implying $V^{\varnothing}=0$. Any firm can thus achieve monopoly profits

$$
\pi_{*}(\eta)=\phi(\eta)-\frac{\eta}{\alpha \delta}-c
$$

which is maximized at $\eta=\eta^{\mathrm{S}}$ and is strictly positive by assumption 11; this invites entry $\triangle 29$

More generally, consider now any family of matching functions $\psi^{\lambda}(z)$ for $\lambda \in[0,1]$ such that OJS strictly increases in $\lambda$. That is, for all $z \in(0,1), \psi^{\lambda}(z)$ continuously and strictly increases in $\lambda$ with boundaries $\psi^{0}(z)=\psi^{\mathrm{S}}(z)$ and $\psi^{1}(z)=\psi^{\mathrm{I}}(z)$. To solve for equilibrium for any given $\psi^{\lambda}$, we increase shirking incentives by first raising $n$ from zero to one, and subsequently raising $\underline{u}$, until the (IC) constraint at the top 19 binds. The following result formalizes this intuition.

Theorem 3 There exists $\lambda^{*} \in(0,1)$ such that:

(a) For any $\lambda \in\left[0, \lambda^{*}\right)$ there exists a unique equilibrium. There is unemployment, $n<1$, and (IR) is slack. Equilibrium employment $n$ strictly increases in OJS $\lambda$ on $\left[0, \lambda^{*}\right)$.

(b) For $\lambda \in\left(\lambda^{*}, 1\right]$ there exists a unique equilibrium. There is full employment, $n=1$, and (IR) binds. The reservation utility $\underline{u}$ strictly increases in $\operatorname{OJS} \lambda$ on $\left(\lambda^{*}, 1\right]$.

\section{Proof See Appendix A.6 \|}

Theorem 3 identifies two cases. Case (a) assumes there is little OJS, $\lambda<\lambda^{*}$. As in Section 5.1 this allows us to ignore the (IR) constraint and there is equilibrium unemployment. Case (b) assumes there is a significant amount of OJS, $\lambda>\lambda^{*}$. As with Intern matching, the equilibrium exhibits full employment with an atom of jobs at the lowest wage. When there is unemployment

28. The internship $\langle u(0), \eta(0)\rangle$ can be characterized as follows. A worker who is unemployed at the beginning of a period always takes up an internship. As (IC) binds, shirking is optimal, yielding the worker $u(0)+\eta(0)=\phi(\eta(0))-c$ in perpetuity. Setting this equal to $(1-\delta) V^{\varnothing}$ in 23 implies $\eta(0)$ is given by $\phi(\eta(0))=\phi\left(\eta^{\mathrm{S}}\right)-\eta^{\mathrm{S}} / \alpha \delta$. Since the first-order condition 17 holds for the highest contract in the atom, a fraction $(1-\alpha) \frac{\delta \phi^{\prime}(\eta(0))}{\delta \phi^{\prime}(\eta(0))-1}$ of jobs are internships.

29. This argument implies (IC) is slack in any candidate equilibrium with $n \in(0,1]$ firms. 


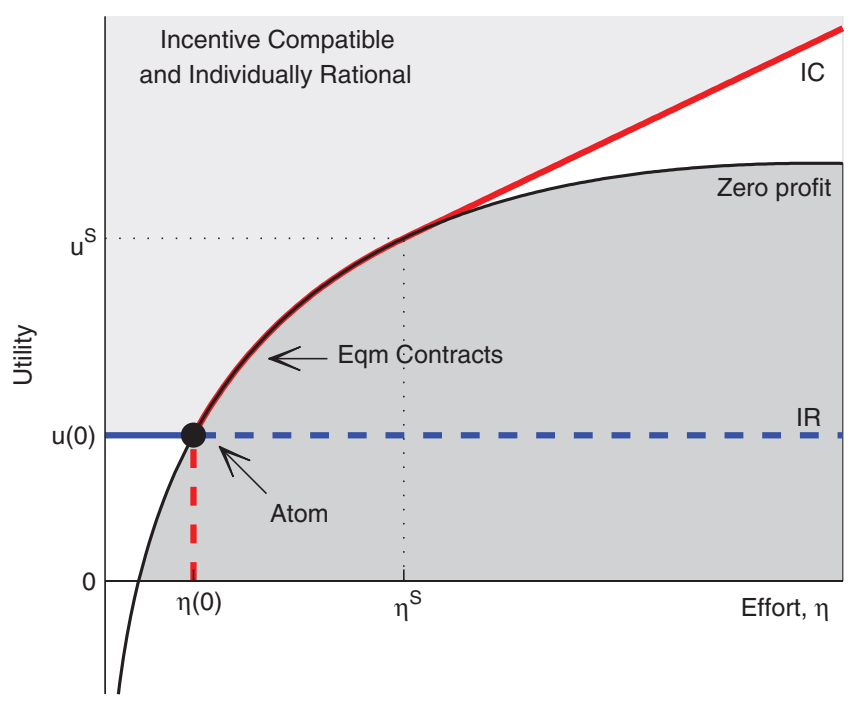

FIGURE 5

The set of optimal contracts with Intern matching

This figure shows the firm's zero profit curve, the worker's (IC) constraint, and the (IR) constraint $u \geq \underline{u}=u(0)$. Firms $x \geq \tilde{x}$ have effort satisfying the first-order condition; firms $x \leq \tilde{x}$ offer the internship. This figure assumes $\phi(\eta)=\eta^{1 / 3}$,

$$
\alpha=\delta=3 / 4, c=0.2 \text {, and Intern matching }
$$

such atoms cannot arise because a firm can profitably undercut this contract (see Figure 4); with full employment undercutting does not attract a worker (see Figure 5). In case (b), all firms offer strictly positive wages as they compete to attract workers, but the utility/surplus of these jobs may be negative. Intuitively, these firms act as gatekeepers, incentivizing their workers with the access to high-wage jobs.

One may have expected a third kind of equilibrium, with $n<1$ firms and binding (IR) constraint. Such equilibria arise only in the non-generic case, $\lambda=\lambda^{*}$. In such an equilibrium, workers are indifferent between the lowest jobs and unemployment; hence, raising $n$ increases the number of jobs in the bottom atom but does not affect $V^{\varnothing}, V(u(1))$, or the (IC) constraint at the top job 19.

\section{APPLICATIONS AND EXTENSIONS}

In this section, we explore various applications of the model, studying the broader economic implications and illustrating the model's versatility. Section 6.1 analyzes the impact of policies such as minimum wages and back-to-work schemes. Section 6.2 supposes firms differ in their underlying productivity and illustrates how on-the-job search amplifies the exogenous heterogeneity and how firms choose employment systems that complement their capabilities. We also examine how a firm's profits depend on the productivity of its competitors; this highlights how on-the-job search determines externalities between firms and yields predictions about firms' location preferences. Section 6.3 supposes workers differ in their cost of effort and shows that firms offer an overlapping range of wages for each type of worker; high-cost workers are rejected from high-wage jobs that are too demanding, and low-cost workers are rejected from low-wage jobs for being overqualified. Section 6.4 shows how to construct an equilibrium with a fixed number of firms (rather than free entry). This should be viewed as an analysis of "short-term equilibrium", or an industry with barriers to entry (e.g. taxi cabs). 

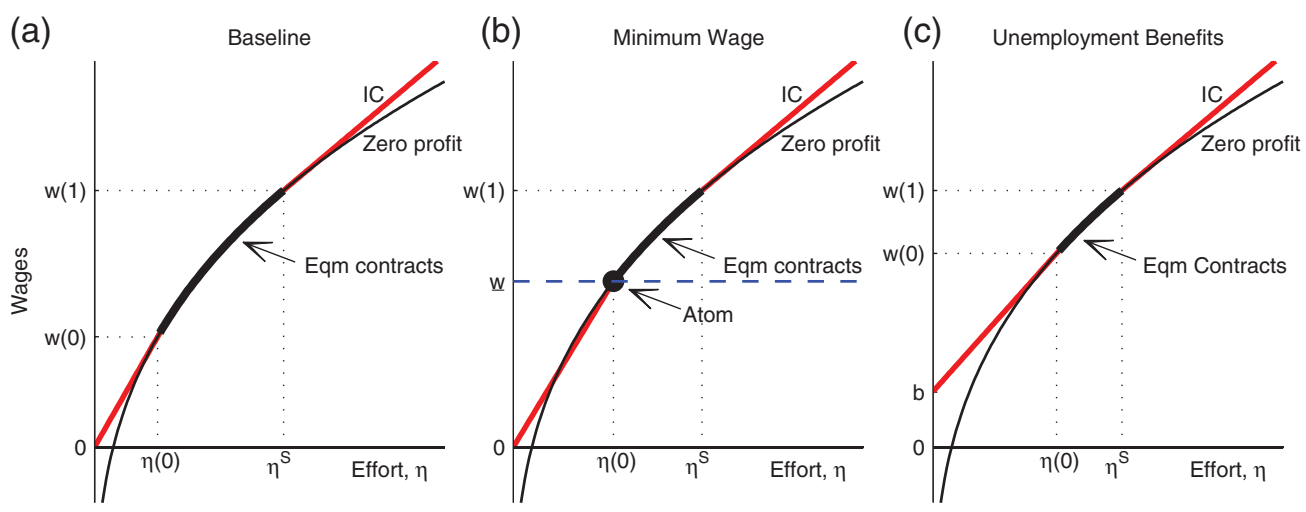

FIGURE 6

Policy experiments

Panel (a) shows the baseline equilibrium with no policy interventions. Panel (b) shows how a minimum wage eliminates some low-quality jobs, but causes others to improve in quality. Panel (c) shows how unemployment benefits eliminate low-quality jobs by raising the opportunity cost of employment. The figure assumes $\phi(\eta)=\eta^{1 / 3}, \alpha=\delta=3 / 4, c=0.2$, minimum wage $\underline{w}=0.15$, benefits $b=0.05$ and Symmetric matching

\subsection{Policy}

Applying our model to policy experiments, we find that policies that directly address the underlying moral hazard problem-e.g. by subsidizing employment or improving firms' monitoring abilities - increase surplus. In contrast, policies that try to directly help unemployed workers-e.g. unemployment benefits or back-to-work schemes-do not achieve their objective and have unintended side-effects. For specificity, we assume Symmetric matching 30

Minimum wage. In equilibrium, jobs above the minimum wage are not affected. Below the minimum wage, some firms exit while others raise their wage to the new minimum and correspondingly raise the quality of their jobs, as illustrated in Figure 6b) 31 The atom at the bottom of the job distribution is consistent with equilibrium because the minimum wage prevents the kind of undercutting illustrated in Figure 4 From the workers' perspective, the minimum wage creates winners whose wage rises, and losers whose jobs are cut. From an unemployed worker's perspective these changes exactly wash out; i.e., $V^{\varnothing}$ is independent of the minimum wage because (23) still obtains. Thus, surplus may increase: For example, if the minimum wage is set equal to the Shapiro-Stiglitz wage, then we obtain the Shapiro-Stiglitz equilibrium which has higher welfare than the Symmetric matching equilibrium by 24, 32

Unemployment benefits. For a fixed job distribution, benefits raise the value of unemployment $V^{\varnothing}$ and break the workers' incentive constraint. In equilibrium, firms at the bottom of the market exit, as illustrated in Figure 6(c). From an unemployed worker's perspective this loss of

30. We should also add the caveat that the model excludes many important features that will affect the policy analysis (e.g. risk aversion).

31. These findings are supported by empirical evidence. In Portugal, Portugal and Cardoso 2006) show that an increase in the minimum wage of teenagers led to a decline in employment and an increase in the retention rate. In the U.K., the survey of Heyes and Gray 2003) finds $60 \%$ of firms increased workers effort to offset the minimum wage, with some evidence suggesting that this increased productivity Metcalf.2008; Rizov and Croucher.2011).

32. There are other papers in which minimum wages can increase welfare. For example, Fahn 2013) considers the effect of a minimum wage in a Shapiro-Stiglitz model with imperfect monitoring. 
job prospects exactly offsets the benefits by equation (23). Thus, unemployment benefits fail to help unemployed workers and hurt workers who lose their jobs; surplus decreases even before taking into account the cost of funds for the benefits.

Back-to-work schemes. Suppose the government raises the competitiveness of unemployed workers on the labour market, maybe by helping them to apply for jobs. This decreases $\psi$. Theorem 2 a) shows this policy raises the opportunity cost of employment, reducing the number of jobs while improving the quality of the remaining jobs. Thus, preferential labour market treatment for unemployed workers increases their chances of receiving highly ranked job offers; however, ironically, it decreases their chances of receiving any job offer at all. As discussed in Section 5.2 these changes do not affect $V^{\varnothing}$ while surplus may increase.

Employment subsidies. To promote entry, the government introduces a subsidy $s$ for firms' operating costs, funded with a lump-sum tax $t=s n$. For existing jobs, entry by new firms forces existing firms to pass these subsidies on to workers for a net utility gain of $s(1-n)$. Additionally, new jobs are created at the bottom of the distribution. The analogue to 23) shows that a worker's value function increases by the same amount, even for an unemployed worker who pays the tax $t$ and only receives the subsidy once he finds a job. Since $c>0$, it is not optimal to eliminate all unemployment - if $n=1$ the lowest job has zero effort and destroys surplus.

Improved monitoring. Suppose firms' ability to detect shirking and disciplining workers improves, perhaps as a result of a change in technology, labour market deregulation or more efficient courts. In the model this reduces the period length, with corresponding reductions in the per-period interest rate $\delta$ and quit rate $\alpha$. As the benefit from shirking falls, effort increases as do wages and the number of jobs. In the limit, as shirkers can be punished instantly, equilibrium converges to first-best. This finding helps explain why productivity dispersion is higher in countries with limited contract enforcement Hsieh and Klenow, 2009; Powell, 2012).

\subsection{Heterogeneous firms}

Suppose there is mass one of firms with heterogeneous productivity $p$, governed by a continuous distribution $G$ on $[p, \bar{p}]$. The production function $\phi(\eta, p)$ is twice continuously differentiable, increasing and concave in $\eta$, and increasing in $p$. It satisfies the usual boundary conditions, $\phi(0, p)=0, \phi_{\eta}(0, p)=\infty, \lim _{\eta \rightarrow \infty} \phi(\eta, p)=0$. Importantly, productivity and output are complements, $\phi_{\eta p}(\eta, p)>0$. Finally, we impose two technical assumptions. First, we assume that the non-triviality condition (11) holds for all firms. Second, we assume that heterogeneity is moderate in that the lowest firm's first-best effort $\eta^{\mathrm{FB}}(\underline{p})$, which solves $\phi_{\eta}(\eta, \underline{p})=1$, exceeds the highest firm's Shapiro-Stiglitz effort $\eta^{\mathrm{S}}(\bar{p})$, which solves $\phi_{\eta}(\eta, \bar{p})=1 /(\alpha \delta)$. We restrict our analysis to Shapiro-Stiglitz matching, Symmetric matching, and Intern matching, and present proofs in Appendix B

As in Section 5] each firm's contract $\langle u(p), \eta(p)\rangle$ maximizes $\pi=\phi(\eta, p)-\eta-u-c$ subject to

$$
\begin{aligned}
u & \geq u_{*}(\eta) \\
W(u) & \geq \delta V^{\varnothing}, \text { and, if } p_{0}=\underline{p}, u \geq \underline{u}
\end{aligned}
$$

where $u_{*}(\eta)$ solves $\eta=\alpha \delta\left(V(u)-V^{\varnothing}\right)$ and $\underline{u}$ is the minimum of the contract distribution. As before, the (IC) constraint binds in equilibrium, so $u=u_{*}(\eta) 3$ 
The resulting reduced-form profit function, $\pi_{*}(\eta, p)=\phi(\eta, p)-\eta-u_{*}(\eta)-c$, is strictly supermodular in $(\eta, p)$, so any optimal selection $\eta(p)$ is increasing. As profits increase in $p$ there is a cutoff type $p_{0}$ such that, in equilibrium, firms $p \in\left[p_{0}, \bar{p}\right]$ enter and offer $n=1-G\left(p_{0}\right)$ jobs $\langle u(p), \eta(p)\rangle$. Equilibrium profits $\pi(p):=\pi_{*}(\eta(p), p)$ are zero for the cutoff type, $\pi\left(p_{0}\right)=0$; for all higher types profits are strictly positive and equal $\pi(p)=\int_{p_{0}}^{p} \phi_{p}(\eta(\hat{p}), \hat{p}) d \hat{p}$ by the envelope theorem.

Following Section 5.1 we first consider Shapiro-Stiglitz matching and Symmetric matching. Then the worker's (IR) constraint is slack 34 and equilibrium is characterized by three conditions:

1. Effort $\eta(p)$ at each firm $p$ is determined by the firm's first-order condition

$$
\phi_{\eta}(\eta(p), p)=\frac{1}{\alpha \delta \beta_{n}(x)}
$$

up to the number of firms, $n=1-G\left(p_{0}\right)$. In equation 26 , the rank of firm $p$ is given by $x=\left(G(p)-G\left(p_{0}\right)\right) /\left(1-G\left(p_{0}\right)\right)$.

2. Utility $u(p)=\phi(\eta(p), p)-\eta(p)-\pi(p)-c$ is determined up to $n=1-G\left(p_{0}\right)$ by the zero profit condition for the cutoff type,

$$
\pi\left(p_{0}\right)=\phi\left(\eta\left(p_{0}\right), p_{0}\right)-\eta\left(p_{0}\right)-c-u\left(p_{0}\right)=0,
$$

and by the envelope theorem for all higher types,

$$
u(p)=u\left(p_{0}\right)+\int_{p_{0}}^{p}\left(\phi_{\eta}(\eta(\hat{p}), \hat{p})-1\right) d \eta(\hat{p}) .
$$

3. The lowest firm $p_{0}$ is uniquely determined by the incentive constraint of the highest firm

$$
\eta(\bar{p})=\alpha \delta\left(V(u(\bar{p}))-V^{\varnothing}\right)
$$

Intuitively, the incentive constraint tightens as $p_{0}$ decreases and more firms enter, because these additional jobs are most valuable to unemployed workers.

In the case of Intern matching, there is full employment and the (IR) constraint binds for the lowest firm, as in Section 5.3

\section{Theorem 4 (Equilibrium characterization).}

(a) Assume Shapiro-Stiglitz or Symmetric matching. Industry equilibrium exists and is unique. There is unemployment, $p_{0}>p$. Every job $\langle u(p), \eta(p)\rangle$ is determined by the first-order condition (26) and the envelope condition (27).

(b) Assume Intern matching. Industry equilibrium exists and is unique. There is full employment, $p_{0}=p$. There exists a cutoff type $\tilde{p}$ and a contract $\langle\underline{u}, \eta\rangle$, the internship, such that low firms $p \in[\bar{p}, \tilde{p}]$ offer internships and high firms $p \in[\tilde{p}, \bar{p}]$ offer jobs $\langle u(p), \eta(p)\rangle$ that are determined by $\bar{t}$ he first-order condition (26) and the envelope condition (27). 
(a)

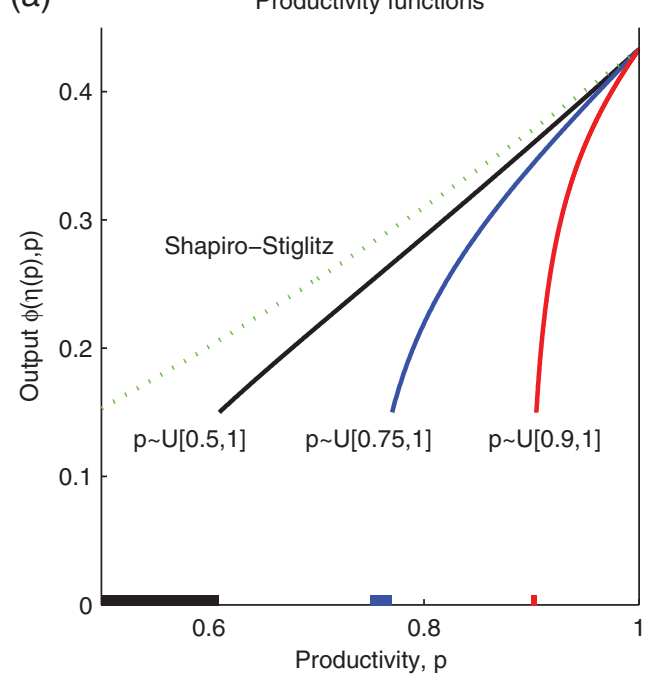

(b)

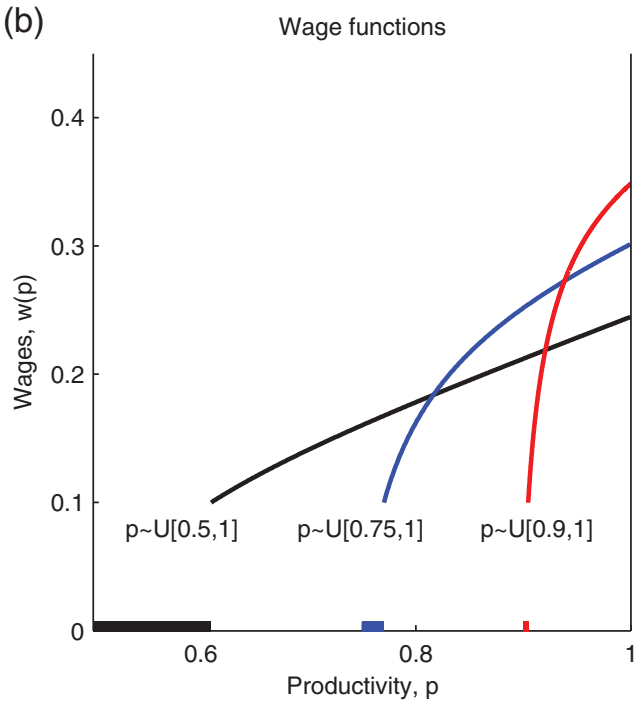

FIGURE 7

Productivity and wages with heterogeneous firms

Panel (a) shows equilibrium productivity $\phi(\eta(p), p)$ for $p \sim[0.5,1], p \sim[0.75,1], p \sim[0.9,1]$ assuming Symmetric matching, $\phi(\eta, p)=p \eta^{1 / 3}, \alpha=\delta=1 / 3$, and $c=0.1$. The lines on the $x$-axis represent firms who do not enter. The Shapiro-Stiglitz line illustrates the productivity dispersion assuming all firms have retention rate $\beta=1$. Panel (b) shows the corresponding wage functions $w(p)$

Figure 7a) shows how exogenous productivity differences are amplified by on-the-job search. In this example, with production function $\phi(\eta, p)=p \eta^{1 / 3}$, the dispersion of output is surprisingly independent of the support of the underlying productivity. Figure 7 b) also shows how exogenous and endogenous heterogeneity generate job dispersion. An increase in the lowest productivity, $p$, has two effects: First, the average wage level rises, increasing the value of unemployment and forcing any higher firm to increase wages. For this reason, the highest wage is increasing in $p$. Second, the increase in competition lowers the ordinal productivity ranking of any given firm, lowering the retention rate and reducing effort. Consequently, firm $p$ pays less when it is at the bottom of the distribution than when it is in the middle. Together, these two effects cause the wage function $w(p)$ to become steeper as $p$ rises. In the limit, as $p \rightarrow \bar{p}$, the distribution converges to that in Section 5.1 purifying the equilibrium with homogeneous firms.

We now examine how firm $p$ 's profits depend on the productivity of its competitors (see Appendix B.3 for proofs). More productive competitors command higher effort and pay higher wages, so standard intuition suggests that increased labour market competition forces firm $p$ to raise wages as well. However, labour market competition is valuable to employed workers as well as unemployed workers; its effect on firm $p$ 's incentive constraint, $\eta(p)=\alpha \delta\left(V(u(p))-V^{\varnothing}\right)$, depends on its relative effects on $V(u(p))$ and $V^{\varnothing}$.

With Shapiro-Stiglitz matching, the standard intuition is correct and firm $p$ 's profits decrease as competitors get more productive. Intuitively, an unemployed worker benefits from better job prospects as soon as he is offered one of the improved jobs, whereas firm $p$ 's employee benefits only indirectly via the continuation value after losing his current job. Therefore, an increase in competitors' productivity decreases $V(u(p))-V^{\varnothing}$, tightens the incentive constraint, and decreases firm $p$ 's profits. 
With Symmetric matching, the same argument implies that firm $p$ 's profits decrease when inferior competitors catch up. However, if productivity increases for firms above $p$, firm $p$ 's profit is not affected. By the definition of Symmetric matching, firm $p$ 's employee receives the same job offers as unemployed workers, so $V(u(p))$ and $V^{\varnothing}$ increase in lockstep as these job offers improve.

With Intern matching, the standard intuition fails and firm $p$ may benefit from more productive competitors. Specifically, when firms above $p$ get more productive, firm $p$ 's employee may receive these improved job offers immediately, whereas unemployed workers first have to work their way up the job ladder. This introduces slack into firm $p$ 's incentive constraint and profits increase. Intuitively, firm $p$ exploits its gatekeeper role to cut wages.

The qualitative effect of competitors' productivity on firm $p^{*}$ 's profit $\pi^{*}$ is summarized by the following table:

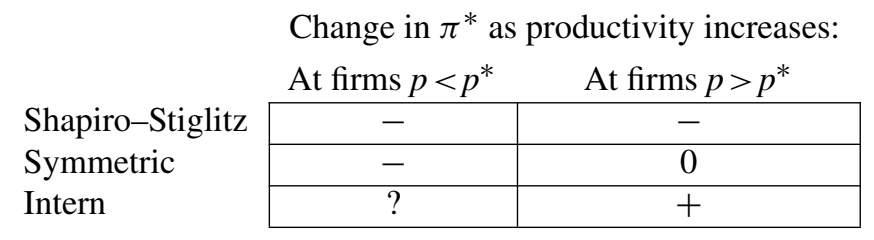

With Shapiro-Stiglitz matching and Symmetric matching, firms prefer to be in a market with unproductive competitors. Thus, an American firm may move to India to decrease turnover and attract more committed, loyal workers. In contrast, with Intern matching, firms prefer markets with productive competitors. This may lead to agglomeration, with small production studios moving to Los Angeles, obtaining a cheap workforce who are motivated by future job prospects at glitzier competitors.

\subsection{Heterogeneous workers}

We now turn to the case of heterogeneous workers. Suppose there are two publicly observed types of worker $\kappa \in\{L, H\}$, where worker $\kappa$ has cost of effort $\eta / \kappa$ and $H>L>0$. There is mass $m_{\kappa}$ of type $\kappa$, with $m_{L}+m_{H}=1$. An equilibrium is described by the number of firms $n_{\kappa}$ offering contracts to workers of type $\kappa$ and two distributions of contracts $\left\langle u_{\kappa}(x), \eta_{\kappa}(x)\right\rangle$.

Solving for equilibrium is straightforward since worker types do not interact. That is, we can characterize the equilibrium contract distribution and number of firms $n_{\kappa}$ separately for each type of worker. We assume that the matching function is such that in equilibrium we have three ranges of jobs with cutoffs $\eta_{L}(0)<\eta_{H}(0)<\eta_{L}(1)<\eta_{H}(1)$, as illustrated in Figure $8{ }^{35}$ Lowwage jobs with $\eta \in\left[\eta_{L}(0), \eta_{H}(0)\right)$ are only offered to low-type workers, even though unemployed high-type workers would willingly take them. These jobs reject high-type workers because their value of unemployment $V_{H}^{\varnothing}$ is too high, so they would shirk after accepting the job. That is, such high-type workers are "overqualified". This is consistent with Bewley's 1999, Chap. 15.2) finding that $80 \%$ of firms are unwilling to hire overqualified workers because of the belief that such workers would be unhappy and less motivated (50\%) and ultimately quit for higher paying jobs (78\%). Intermediate jobs with $\eta \in\left[\eta_{H}(0), \eta_{L}(1)\right]$ are offered to both types of workers. The marginal cost of incentivizing effort is independent of the worker's type: A high type has lower

35. The first inequality fails for Symmetric matching, where it is easy to see that $\eta_{\kappa}(0)$ does not depend on $\kappa$. Intuitively, high-type workers are willing to work in low-paying jobs as long as these jobs are not associated with an opportunity cost of forgoing search. In contrast, for Shapiro-Stiglitz matching, equilibrium jobs satisfy $\eta_{L}^{\mathrm{S}}<\eta_{H}^{\mathrm{S}}$, and hightype workers are overqualified for the equilibrium job of the low type. The overlapping contract distribution illustrated in Figure 8 arises for matching functions "between" Shapiro-Stiglitz and Symmetric matching, i.e. with $\psi(z) \in(0, z)$. 


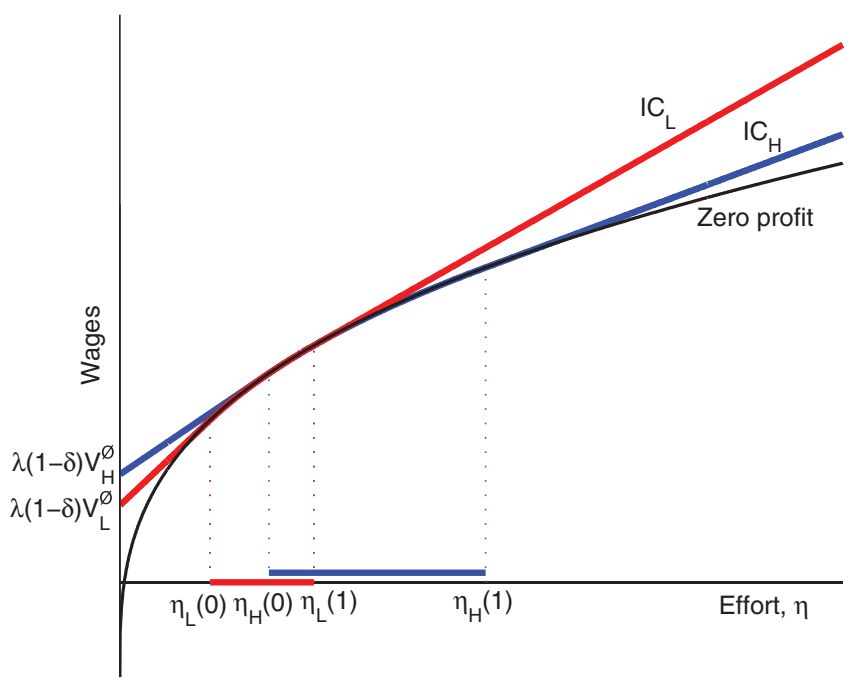

FIGURE 8

Equilibrium effort and wages with heterogeneous workers

This figure illustrates the equilibrium contracts for two types of workers. Moving along the zero profit curve, worker $\kappa$ 's (IC) constraint is satisfied with equality for $\eta \in\left[\eta_{\kappa}(0), \eta_{\kappa}(1)\right]$ and violated for other effort levels. This figure assumes $\phi(\eta)=\eta^{1 / 3}, \alpha=\delta=3 / 4, c=0.1, \kappa_{L}=0.65, \kappa_{H}=1$, and uses a matching function $\psi(z)=\max \{(z-1) / 0.6+1,0\}$

cost of effort but requires a higher incentive premium due to the lower retention rate. Finally, jobs with $\eta \in\left(\eta_{L}(1), \eta_{H}(1)\right]$ are only offered to high-type workers. These jobs reject low-type workers because their cost of effort is too high, so they would shirk after accepting the job.

\subsection{Exogenous market size}

So far we have assumed that the number of firms is determined endogenously via free entry. In this section, we perform a short-term analysis of the industry where the number of firms is fixed exogenously at $n<1$.

We first consider the case where $\psi(z) \leq z$ (e.g. Shapiro-Stiglitz, Symmetric matching). As in Section 5.1 equilibrium is uniquely determined by three conditions. The only change is that now the level of profits - rather than the number of firms - is the free parameter that adjusts to make the incentive constraint bind.

1. Effort $\eta(x)$ is uniquely determined by the firm's first-order condition:

$$
\phi^{\prime}(\eta(x))=\frac{1}{\alpha \delta \beta_{n}(x)}
$$

for all $x \in[0,1]$.

2. Utility $u(x)$ is determined up to a single parameter by the condition that all firms earn the same profits, $\pi 36$

$$
u(x)=\phi(\eta(x))-\eta(x)-\pi .
$$

36. We assume that both exit and entry are infeasible. If firms can still exit, then the profit must be non-negative; otherwise we return to the analysis of Section 5.1 
3. Profits $\pi$ are uniquely determined by the worker's incentive constraint at the top contract, $x=1$,

$$
\eta(1)=\alpha \delta\left(V(u(1))-V^{\varnothing}\right) .
$$

Intuitively, an increase in profits $\pi$ comes at the expense of workers' utility $u(1)$ and continuation value $V(u(1))$. The value of unemployment $V^{\varnothing}$ also decreases in $\pi$, but less so because unemployed workers experience the decrease in rents with a delay. Thus, $V(u(1))-$ $V^{\varnothing}$ decreases in $\pi$, and there is a unique value of $\pi$ for which the top contract's incentive constraint is met with equality.

Theorem 5 (Characterization with fixed $n$ ). Assume the number of firms $n<1$ is exogenously fixed and $\psi(z) \leq z$ for all $z$. Industry equilibrium exists and is unique. Every job $\langle u(x), \eta(x)\rangle$ is determined by the first-order condition (29), constant profits (30) and the binding (IC) constraint (31).

Proof As in Theorem 11 conditions 29-31 characterize equilibrium. To show existence and uniqueness, consider a candidate equilibrium, defined by equations 29 , and 30 , and let $I(\pi)=$ $\eta(1)-\alpha \delta\left(V(u(1))-V^{\varnothing}\right)$ be the incentive to shirk when profits are $\pi$. Equation 30 implies that an increase in $\pi$ lowers utility one-for-one, $d u(x) / d \pi=-1$. The employed worker's Bellman equation (2) implies $d V(u(x)) / d \pi$ is independent of $x$, so we have

$$
\frac{d}{d \pi}\left(V(u(x))-V^{\varnothing}\right)=-(1-\theta)+\alpha \delta(1-\theta) \frac{d}{d \pi}\left(V(u(x))-V^{\varnothing}\right)=-\frac{1-\theta}{1-\alpha \delta(1-\theta)}<0 .
$$

Hence $I(\pi)$ increases linearly; by the intermediate value theorem there exists a $\pi$ such that the incentive compatibility constraint 31 binds.

With a fixed number of firms $n<1$, the impact of the matching technologies $\psi$ on the equilibrium is particularly stark.

Theorem 6 (Comparative static of on-the-job search with fixed $n$ ). Assume $\psi(z), \tilde{\psi}(z) \leq z$. When OJS increases, $\psi(z)<\tilde{\psi}(z)$ for all $z \in(0,1)$, then:

(a) Turnover increases for all jobs: $1-\beta_{n}(x) \leq 1-\tilde{\beta}_{n}(x)$ for all $x$.

(b) Effort and surplus decrease for all jobs: $\eta(x) \geq \tilde{\eta}(x)$ and $\phi(\eta(x))-\eta(x)-c \geq \phi(\tilde{\eta}(x))-$ $\tilde{\eta}(x)-c$ for all $x$.

(c) Profits increase for all firms: $\pi \leq \tilde{\pi}$.

(d) Utilities and continuation values decrease for all employed and unemployed workers: $u(x) \geq \tilde{u}(x), V(u(x)) \geq \tilde{V}(\tilde{u}(x))$ and $V^{\varnothing} \geq \tilde{V}^{\varnothing}$.

Proof (a) This follows directly from market clearing (14).

(b) By the first-order condition (29) turnover increases the marginal cost of effort to firm $x$, so effort at firm $x$ decreases: $\eta(x) \geq \tilde{\eta}(x)$. As effort is always below its first-best level $\left(\phi^{\prime}\right)^{-1}(1)$ and surplus $\phi(\eta)-\eta-c$ is concave, a reduction in effort reduces surplus.

(c) The incentive to shirk $I$ increases in $\pi$ and decreases in $\psi$. The former follows from the proof of Theorem 5 the latter follows from the proof of Lemma7 7 ), which is stated for candidate equilibria with zero profits, but extends to candidate equilibria with any constant level of profits $\pi$. An increase in $\psi$ thus causes equilibrium profits to fall to maintain $I=0$.

(d) Parts (b) and (c) show that surplus is lower and profits are higher for all jobs, so workers' utility in firm $x$ 's job, $u(x)$, decreases for all $x$. This lowers the continuation value of employed and unemployed workers, $V(u(x)) \geq \tilde{V}(\tilde{u}(x))$, and $V^{\varnothing} \geq \tilde{V}^{\varnothing}$. 
As in Section 5.2 an increase in on-the-job search increases turnover and the marginal cost of effort, causing some firms to substitute high-quality jobs with low-quality jobs. With a fixed number of firms, this means the employment prospects of unemployed workers worsen; this introduces slack into workers' incentive constraints and allows firms to cut wages. Hence workers lose twice; first when firms substitute some stable jobs with temp jobs, and then again when all firms cut wages. Firms win because one firm's lower wage reduces the value of unemployment and exerts a positive externality on other firms, who can cut wages and increase profits accordingly. On-the-job search allows firms to reap this positive externality in equilibrium 37

When $\psi(z)>z$ for some $z$, the workers' (IR) constraint may bind, complicating the analysis. As in Section 5.3 with $n<1$ firms, (IR) is equivalent to non-negative wages. Equilibrium then consists of an atom of firms offering a zero-wage internship $\langle\underline{u}, \eta\rangle$, with higher firms offering a continuum of contracts defined by the first-order condition (29) and constant profits 30). For example, in the case of Intern matching, there is an atom of internships that pay zero wages and demand positive effort, and a continuum of firms above. Any unemployed worker must pass through an internship prior to obtaining a high-wage job; the binding (IR) constraint means that $V^{\varnothing}=0$, so the firms with internships exploit their gatekeeper role and dissipate the rents from these attractive prospects. In equilibrium, all firms make monopoly profits 25.

\section{CONCLUSION}

This article proposed a versatile framework to study relational contracts in a large anonymous labour market in which both employed and unemployed workers compete for vacancies. In equilibrium, jobs are distributed continuously, with some firms offering high-wage, high-productivity contracts whereas other, identical firms offer low-wage, low-productivity contracts. The model thus generates endogenous job ladders and explains why firms adopt different employment systems. We used the model to study the impact of changes in on-the-job search, evaluate policy proposals and examine how endogenous dispersion amplifies underlying heterogeneity.

Our insights are applicable beyond the confines of the formal model. First, one could combine firm and worker heterogeneity in a single model and study how different types of workers move between jobs of differing quality. The analysis of Sections 6.2 and 6.3 suggests that workerfirm matching is partially assortative with low-productivity firms hiring low-type workers, an intermediate range of firms hiring both types of workers, and high-productivity firms hiring hightype workers. The challenge with this extension is that firm heterogeneity implies a scarcity of high-productivity firms, so that one cannot solve the equilibria for the different worker types independently.

Second, one can use our article to model agents who work because of reciprocal preferences (e.g. Fehr and Falk, 1999), rather than because of relational incentives. Suppose an agent's effort at a firm increased in his lifetime utility over and above his utility if he were unemployed. Each firm then maximizes profits subject to a condition that is isomorphic to our (IC) constraint, yielding identical job distributions. Moving beyond our article, it would be interesting to consider alternative formulations for reciprocal preferences based on current wages or total life time utility.

Third, our analysis focused on the firm's intensive margin of motivating its single worker while deliberately ignoring the extensive margin of attracting more workers, which is central in the

37. Surprisingly, profits under Symmetric matching coincide with profits under Shapiro-Stiglitz matching if all firms could collude on contracts. To see this, note that under Symmetric matching, profits at the lowest contract do not depend on the contracts offered by other firms. Thus for firm $x=0$, the effect of reducing effort in its own contract equals the effect of reducing effort in all contracts, which is exactly the consideration of the colluding firms under Shapiro-Stiglitz matching. 
search literature (e.g. Burdett and Mortensen.1998). It would therefore be interesting to integrate the analyses and study the interaction between incentive provision and direct competition. It is also important to think about the source of workers' priorities in the labour market. In practice these depend on the accumulation of experience, the screening role of employment and the network structure of contacts.

Fourth, our framework has the potential to help analyze the competition between firms in other contracting environments such as insurance with imperfect commitment (e.g. Krueger and Uhlig. 2006) and adverse selection (e.g. Moen and Rosen, 2011). For example, in Board and Meyer-ter-Vehn 2014) we analyze insurance with imperfect commitment where agents under contract receive offers from other insurers.

\section{APPENDIX}

\section{A. HOMOGENEOUS FIRMS}

\section{A.1. Proof of stationarity, Lemma 2}

Fix an 'original' self-enforcing contract $\left\langle w_{t}, \eta_{t}\right\rangle$ with profit $\Pi_{\varnothing}$. By Lemma 1 we can assume that the job is filled with probability $p\left(W_{1}\right)=1$. We can also assume that effort never exceeds first-best, $\eta_{t} \leq \eta^{F B}:=\left(\phi^{\prime}\right)^{-1}(1)$ for all $t$; otherwise we can replace $\left\langle w_{t}, \eta_{t}\right\rangle$ with a weakly more profitable self-enforcing contract and proceed using that contract 38

We now define a stationary self-enforcing contract $\left\langle w^{*}, \eta^{*}\right\rangle$ with weakly higher profit, $\Pi_{\varnothing}^{*} \geq \Pi_{\varnothing}$. First set

$$
\eta^{*}=\sup _{t}\left\{\eta_{t}\right\}
$$

As surplus $\phi(\eta)-\eta$ is concave and $\eta^{*}$ is weakly below first-best, the stationary contract has higher surplus, $\phi\left(\eta^{*}\right)-\eta^{*} \geq$ $\phi\left(\eta_{t}\right)-\eta_{t}$ for all $t$. Next, assume that the continuation value of the original contract is maximized in some period $t^{\prime}$ and let $W^{*}=W_{t^{\prime}}$ be this maximum 39 Finally, let $w^{*}$ be the stationary wage that generates this continuation value

$$
W^{*}=w^{*}-\eta^{*}+\delta\left(\alpha V^{*}+(1-\alpha) V^{\varnothing}\right) \quad \text { where } \quad V^{*}=\int \max \left\{W, W^{*}\right\} d F^{e}(W) .
$$

We write $\Pi_{\varnothing}^{*}$ for firm profits when it has a vacancy and $\Pi^{*}$ when its position is filled. Since $\left\langle w^{*}, \eta^{*}\right\rangle$ is stationary, it satisfies (F-IC). It also satisfies (W-IC): for all $t \geq 1, \eta_{t} \leq \alpha \delta\left(V_{t+1}-V^{\varnothing}\right)$, so taking the supremum of each side implies that $\eta^{*} \leq \alpha \delta\left(V^{*}-V^{\varnothing}\right)$.

We now finish the proof by showing that

$$
\Pi_{\varnothing}^{*}=\Pi^{*} \geq \Pi_{t^{\prime}} \geq \Pi_{\varnothing} .
$$

The first equality follows because by $W^{*} \geq W_{1}$ the stationary contract fills with probability $p\left(W^{*}\right)=1$, and thus $\Pi_{\varnothing}^{*}=\Pi^{*}$. The last inequality follows from (F-IC) of the original, self-enforcing contract.

Finally, we show the middle inequality, $\Pi^{*} \geq \Pi_{t^{\prime}}$. Letting $T \geq t^{\prime}$ be the (stochastic) separation time of the original contract conditional on lasting past $t^{\prime}$, we can write profits in the original contract as a sum of flow and continuation profits

$$
\Pi_{t^{\prime}}=\mathbb{E}\left[\sum_{t=t^{\prime}}^{T-1} \delta^{t-t^{\prime}}\left(\phi\left(\eta_{t}\right)-\eta_{t}-c-u_{t}\right)+\delta^{T-t^{\prime}} \Pi_{\varnothing}\right] .
$$

In the stationary contract $\left\langle w^{*}, \eta^{*}\right\rangle$, flow profits are constant and $\Pi_{\varnothing}^{*}=\Pi^{*}$. Firm profits thus equal

$$
\Pi^{*}=\mathbb{E}\left[\sum_{t=t^{\prime}}^{T-1} \delta^{t-t^{\prime}}\left(\phi\left(\eta^{*}\right)-\eta^{*}-c-u^{*}\right)+\delta^{T-t^{\prime}} \Pi^{*}\right]
$$

for any separation time, so in particular for the separation time $T$ induced by the original contract. As $\phi\left(\eta^{*}\right)-\eta^{*} \geq \phi\left(\eta_{t}\right)-\eta_{t}$ and continuation profits in the original contract do not fall below their initial level, $\Pi_{t^{\prime}} \geq \Pi_{\varnothing}$, subtracting A.2 from

38. If $\eta_{t}>\eta^{F B}$ we set $\eta_{t}^{\prime}:=\eta^{F B}$ and $w_{t}^{\prime}=\phi\left(\eta_{t}^{\prime}\right)-\left(\phi\left(\eta_{t}\right)-w_{t}\right)$; this change does not affect profits and relaxes (W-IC) because the reduction in wages, $w_{t}-w_{t}^{\prime}=\phi\left(\eta_{t}\right)-\phi\left(\eta_{t}^{\prime}\right)$, is less than the reduction in effort costs, $\eta_{t}-\eta_{t}^{\prime}$.

39. If the supremum over $W_{t}$ is not attained, we set $W^{*}=\sup _{t}\left\{W_{t}\right\}$ and extend the proof by choosing for every $\varepsilon>0$ a period $t^{\prime}$ for which $W^{*} \leq W_{t^{\prime}}+\varepsilon$. We omit the rigorous analysis of this complication to make the substantial arguments of the proof as clear as possible. 
A.3. yields

$$
\Pi^{*}-\Pi_{t^{\prime}} \geq \mathbb{E}\left[\sum_{t=t^{\prime}}^{T-1} \delta^{t-t^{\prime}}\left(u_{t}-u^{*}\right)+\delta^{T-t^{\prime}}\left(\Pi^{*}-\Pi_{t^{\prime}}\right)\right] .
$$

To evaluate the difference in utilities, let $X_{T}$ be the worker's continuation utility when separating at time $T$; this equals $\delta V^{\varnothing}$ in the case of natural attrition, and equals the best outside offer $\hat{W}$ otherwise. Similarly, let $T^{*} \geq t^{\prime}$ be the stochastic stopping time of the new contract and let $X_{T^{*}}$ be the corresponding continuation value. Since $T$ it a sub-optimal stopping time in the stationary contract, we get

$$
\begin{aligned}
0=V_{t^{\prime}}-V^{*} & =\mathbb{E}\left[\sum_{t=t^{\prime}}^{T-1} \delta^{t-t^{\prime}} u_{t}+\delta^{T-t^{\prime}} X_{T}\right]-\mathbb{E}\left[\sum_{t=t^{\prime}}^{T^{*}-1} \delta^{t-t^{\prime}} u^{*}+\delta^{T^{*}-t^{\prime}} X_{T^{*}}\right] \\
& \leq \mathbb{E}\left[\sum_{t=t^{\prime}}^{T-1} \delta^{t-t^{\prime}} u_{t}+\delta^{T-t^{\prime}} X_{T}\right]-\mathbb{E}\left[\sum_{t=t^{\prime}}^{T-1} \delta^{t-t^{\prime}} u^{*}+\delta^{T-t^{\prime}} X_{T}\right]=\mathbb{E}\left[\sum_{t=t^{\prime}}^{T-1} \delta^{t-t^{\prime}}\left(u_{t}-u^{*}\right)\right]
\end{aligned}
$$

Inserting this back into A.4, we get $\Pi^{*}-\Pi_{t^{\prime}} \geq 0$ as required. This establishes A.1 and establishes that the stationary contract $\left\langle w^{*}, \eta^{*}\right\rangle$ is weakly more profitable than the original contract $\left\langle w_{t}, \eta_{t}\right\rangle$.

Now assume that the original contract $\left\langle w_{t}, \eta_{t}\right\rangle$ is non-stationary. To show that the stationary contract $\left\langle w^{*}, \eta^{*}\right\rangle$ is either strictly more profitable, or weakly more profitable and strictly better for the worker we consider three cases. First, if $W_{t^{\prime}}>W_{1}$ then $\left\langle w^{*}, \eta^{*}\right\rangle$ is weakly more profitable for the firm by the above argument, and strictly better for the worker because $W^{*}=W_{t^{\prime}}>W_{1}$.

Second, if $W_{1}=\max _{t}\left\{W_{t}\right\}$ and $\eta_{t}$ is non-constant, then $\left\langle w^{*}, \eta^{*}\right\rangle$ is strictly more profitable than $\left\langle w_{t}, \eta_{t}\right\rangle$ because it generates strictly more surplus but allocates the same amount to the worker. Formally, the inequality A.4 is strict and thus the middle inequality in A.1 is strict.

Third, if $W_{1}=\max _{t}\left\{W_{t}\right\}$ and $\eta_{t}$ is constant, then $W_{t}$ cannot be constant as $\left\langle w_{t}, \eta_{t}\right\rangle$ was assumed to be non-stationary; thus, $W_{t^{\prime \prime}}<W_{1}$ for some $t^{\prime \prime}>1$. Then we construct a stationary contract $\left\langle w^{\dagger}, \eta^{\dagger}\right\rangle$ by $\eta^{\dagger}=\eta_{t}$ and $w^{\dagger}$ such that $W^{\dagger}=W_{t^{\prime \prime}}$. This contract is self-enforcing because (W-IC) coincides with the (W-IC) in period $t^{\prime \prime}-1$ of the original contract. As $\left\langle w^{\dagger}, \eta^{\dagger}\right\rangle$ generates the same surplus as $\left\langle w_{t}, \eta_{t}\right\rangle$ but allocates less of it to the worker, $W^{\dagger}=W_{t^{\prime \prime}}<W_{1}$, the above argument shows that $\left\langle w^{\dagger}, \eta^{\dagger}\right\rangle$ is strictly more profitable.

\section{A.2. Irrelevance of bonus payments, Section 3.1}

Here, we consider a model extension where the firm can pay its worker a bonus after observing his effort and show that ignoring bonuses in our model is without loss of generality. Assuming the harshest possible off-path punishments, a self-enforcing contract is a sequence of wages, effort levels, and bonuses $\left\langle w_{t}, \eta_{t}, b_{t}\right\rangle$ that satisfies

$$
\begin{aligned}
& \eta_{t-1} \leq b_{t-1}+\alpha \delta\left(V_{t}-V^{\varnothing}\right), \text { and } \\
& b_{t-1} \leq \alpha \delta\left(\Pi_{t}-\Pi_{\varnothing}\right) .
\end{aligned}
$$

The worker's incentive constraint (W-IC) requires that the bonus and the continuation value of not being fired exceed the cost of effort. The firm's incentive constraint (F-IC) requires that the continuation value of keeping its worker exceeds the bonus.

For any self-enforcing contract with bonuses $\left\langle w_{t}, \eta_{t}, b_{t}\right\rangle$ we now define a weakly more profitable self-enforcing contract without bonuses $\left\langle\hat{w}_{t}, \hat{\eta}_{t}\right\rangle$. Assume without loss of generality that the original contract pays a bonus only in period $t-1$. The idea is to keep effort fixed, $\hat{\eta}_{t-1}=\eta_{t-1}$, and shift the bonus $b_{t-1}$ into next period's wage $w_{t}$ at the contract-specific discount rate. With Shapiro-Stiglitz matching this discount rate captures time discounting and the exogenous retention rate. Thus, setting $\hat{w}_{t}:=w_{t}+b_{t-1} / \alpha \delta$ we get $\hat{V}_{t}=V_{t}+b_{t-1} / \alpha \delta$ and $\hat{\Pi}_{t}=\Pi_{t}-b_{t-1} / \alpha \delta$, so that $\left\langle\hat{w}_{t}, \hat{\eta}_{t}\right\rangle$ is self-enforcing.

For general matching functions, an increase in $w_{t}$ not only shifts continuation value from the firm to the worker but also increases the retention rate. As the firm wants to keep the worker (by (F-IC)) this shift weakly increases joint surplus (and strictly so if $\Pi_{t}>\Pi_{\varnothing}$ ). Thus, it is possible to keep profits constant and (weakly) relax (W-IC) when shifting the bonus into next period's wage. Formally, we write continuation profits $\Pi_{t}$ as a function of wage $w$

$$
\Pi_{t}(w)=F^{e}\left(W_{t}(w)\right)\left(\phi\left(\eta_{t}\right)-w-b_{t}-c+\delta\left(\alpha \Pi_{t+1}+(1-\alpha) \Pi_{\varnothing}\right)+\left(1-F^{e}\left(W_{t}(w)\right)\right) \Pi_{\varnothing} .\right.
$$

where $W_{t}(w)=w-\eta_{t}+b_{t}+\delta\left(\alpha V_{t+1}+(1-\alpha) V^{\varnothing}\right)$. Inversely, we write $w_{t}(\Pi)=\sup \left\{w: \Pi_{t}(w)=\Pi\right\}$ for the wage required to achieve continuation profits $\Pi 40$ Setting $\hat{w}_{t}:=w_{t}\left(\Pi_{t}-b_{t-1} / \alpha \delta\right)$ then implies $\alpha \delta \hat{\Pi}_{t}=\alpha \delta \Pi_{t}-b_{t-1}$, so that (F-IC)

40. Taking the supremum over wages $w$ with $\Pi_{t}(w)=\Pi$ is necessary because $\Pi_{t}(w)$ need not decrease monotonically: If the retention rate $F^{e}$ has an atom at $W_{t}(w)$ and $\Pi_{t}(w)>\Pi_{\varnothing}$, then $\Pi_{t}$ jumps up at $w$. 
coincides for contracts $\left\langle\hat{w}_{t}, \hat{\eta}_{t}\right\rangle$ and $\left\langle w_{t}, \eta_{t}, b_{t}\right\rangle$. As joint surplus increases, $\hat{\Pi}_{t}+\hat{V}_{t} \geq \Pi_{t}+V_{t}$, we have $\alpha \delta \hat{V}_{t} \geq \alpha \delta V_{t}+b_{t-1}$ so that $\left\langle\hat{w}_{t}, \hat{\eta}_{t}\right\rangle$ satisfies (W-IC).

\section{A.3. Proof that (IC) binds, Lemma 5}

Assume to the contrary, that (IC) is slack in an equilibrium job $\langle u, \eta\rangle$. This job must maximize profits subject to $u$ satisfying (IR). Firm optimality implies that (IR) is tight and effort is first-best, $\phi^{\prime}(\eta)=1$. This job is the unique solution to the firm's problem, so all firms offer it. Pre-matching and post-matching values then coincide, $W(u)=V(u)$.

We now show that the binding (IR) constraint implies $V(u) \leq V^{\varnothing}$, which contradicts our original assumption that (IC) is slack. Consider separately the cases $n<1$ and $n=1$. If $n<1$ and (IR) binds, then an unemployed worker is indifferent between accepting and rejecting a job $\langle u, \eta\rangle$. Formally, $W(u)=\delta V^{\varnothing}$ and thus $V(u)=W(u) \leq V^{\varnothing}$. If $n=1$, then every unemployed worker is offered a contract with a binding (IR) constraint, so $V^{\varnothing}=W(u)$ and thus $V(u)=W(u)=V^{\varnothing}$.

\section{A.4. Proof of welfare-ranking, equation (24)}

We first show that the equilibrium value function $V(u)$ is independent of the matching technology $\psi$. By equations 22, and 23, $u(1), V(u(1))$ and $V^{\varnothing}$ are independent of $\psi$. Now fix $u<u(1)$. If $\langle u, \eta\rangle$ is an equilibrium contract, then $\eta$ is determined by the zero profit condition, independently of $\psi$. By equations 6 and 8 , the marginal value $V^{\prime}(u)$ is then also independent of $\psi$,

$$
V^{\prime}(u)=\frac{F^{e}(u)}{1-\alpha \delta F^{e}(u)}=\frac{1}{\alpha \delta\left(\phi^{\prime}(\eta)-1\right)} .
$$

Thus, $V(u)=V(u(1))-\int_{u}^{u(1)} V^{\prime}(\hat{u}) d \hat{u}$ is independent of $\psi$.

To examine surplus, it is convenient to aggregate over the exogenous number of workers, rather than over the endogenous number of firms. To do this, label workers by $y \in[0,1]$ and assume that higher labelled workers hold better jobs. After the matching phase, worker $y \in[0,1-n]$ is unemployed and worker $y \in[1-n, 1]$ occupies job $x_{y}=(y-(1-n)) / n$. Denote the post-match value of worker $y$ by

$$
W_{y}:= \begin{cases}\delta V^{\varnothing} & \text { if } y<1-n, \\ u\left(x_{y}\right)+\delta\left(\alpha V\left(u\left(x_{y}\right)\right)+(1-\alpha) V^{\varnothing}\right) & \text { if } y>1-n .\end{cases}
$$

As shown above, $W_{0}=\delta V^{\varnothing}$ and $W_{1}=V(u(1))$ are independent of the matching function $\psi$. For Shapiro-Stiglitz and Symmetric matching, the difference of the value functions then single-crosses

$$
W_{y}^{\mathrm{S}}-W_{y}^{\mathrm{Y}}= \begin{cases}\delta V^{\varnothing}-\delta V^{\varnothing}=0 & \text { if } y \in\left(0,1-n^{\mathrm{Y}}\right), \\ \delta V^{\varnothing}-W_{y}^{\mathrm{Y}}<0 & \text { if } y \in\left(1-n^{\mathrm{Y}}, 1-n^{\mathrm{S}}\right), \\ V(u(1))-W_{y}^{\mathrm{Y}}>0 & \text { if } y \in\left(1-n^{\mathrm{S}}, 1\right),\end{cases}
$$

where Theorem 2 a) tells us that $n^{S}<n^{Y}$.

As aggregate flow utility in equation 24 equals the rental value of aggregate continuation value, equation 24 is equivalent to

$$
\int W_{y}^{\mathrm{S}} d y>\int W_{y}^{\mathrm{Y}} d y
$$

To establish A.6, let $G(y):=F^{\varnothing}\left(u\left(x_{y}\right)\right)$ be the probability than an unemployed worker receives a job with utility at or below $u\left(x_{y}\right)$ in the matching process. Substituting $x_{y}$ into the definitions of Shapiro-Stigliz and Symmetric matching, we obtain

$$
G^{\mathrm{S}}(y)=\left\{\begin{array}{ll}
1-\theta^{\mathrm{S}} & \text { if } y<1-n^{\mathrm{S}} \\
1 & \text { if } y \geq 1-n^{\mathrm{S}}
\end{array} \text { and } \quad G^{\mathrm{Y}}(y)= \begin{cases}1-\theta^{\mathrm{Y}} & \text { if } y<1-n^{\mathrm{Y}} \\
\frac{y}{1-\alpha(1-y)} & \text { if } y \geq 1-n^{\mathrm{Y}}\end{cases}\right.
$$

Observe that $G^{\mathrm{Y}}\left(1-n^{\mathrm{S}}\right)=\frac{1-n^{\mathrm{S}}}{1-\alpha n^{\mathrm{S}}}=1-\theta^{\mathrm{S}}$. Using this fact, we claim that

$$
\int W_{y}^{\mathrm{S}} d G^{\mathrm{S}}(y)=\left(1-\theta^{\mathrm{S}}\right) \delta V^{\varnothing}+\theta^{\mathrm{S}} V(u(1))=G^{\mathrm{Y}}\left(1-n^{\mathrm{S}}\right) \delta V^{\varnothing}+\left(1-G^{\mathrm{Y}}\left(1-n^{\mathrm{S}}\right)\right) V(u(1))=\int W_{y}^{\mathrm{S}} d G^{\mathrm{Y}}(y)
$$

where the last equality uses the fact that $W_{y}^{\mathrm{S}}$ is a step function, equal to $\delta V^{\varnothing}$ below $1-n^{\mathrm{S}}$ and equal to $V(u(1))$ above. We next claim that:

$$
0=\int W_{y}^{\mathrm{S}} d G^{\mathrm{S}}(y)-\int W_{y}^{\mathrm{Y}} d G^{\mathrm{Y}}(y)=\int\left(W_{y}^{\mathrm{S}}-W_{y}^{\mathrm{Y}}\right) d G^{\mathrm{Y}}(y)=\int_{1-n^{\mathrm{Y}}}^{1}\left(W_{y}^{\mathrm{S}}-W_{y}^{\mathrm{Y}}\right) d G^{\mathrm{Y}}(y)<\int_{1-n^{\mathrm{Y}}}^{1}\left(W_{y}^{\mathrm{S}}-W_{y}^{\mathrm{Y}}\right) d y
$$

The first equality follows because $V^{\varnothing}=\int W_{y} d G(y)$ is independent of the matching process, as shown above. The second applies A.7. The third equality follows since $W_{y}^{\mathrm{S}}-W_{y}^{\mathrm{Y}}$ is zero on $\left(0,1-n^{Y}\right)$. The inequality then uses the fact that the 
density $d G^{\mathrm{Y}}(y) / d y$ strictly decreases on $\left(1-n^{\mathrm{Y}}, 1\right)$ and is thus strictly MLRP-dominated by the uniform distribution, and then applies Karlin and Rubin 1956, Lemma 1) 4 Using $W_{y}^{\mathrm{S}}-W_{y}^{\mathrm{Y}}=0$ for $y \in\left(0,1-n^{Y}\right)$, we have A.6, as required.

\section{A.5. Comparative statics of candidate equilibria}

Recall the definition of a candidate equilibrium (with either $n$ firms, or reservation utility $\underline{u}$ ) from Sections 5.1 and 5.3 The defining feature of a candidate equilibrium is that if (IC) is tight/slack/violated in one of its contracts, it is tight/slack/violated in all of its contracts. Thus, a candidate equilibrium is an equilibrium if shirking incentives at the top are zero:

$$
I:=\eta(1)-\alpha \delta\left(V(u(1))-V^{\varnothing}\right)=0
$$

In this appendix, we study how $I$ depends on the parameters of the candidate equilibrium: $n, \underline{u}$, and $\psi$. It is convenient to parametrize $\psi=\psi^{\lambda}$ by a one-dimensional parameter $\lambda \in[0,1]$ capturing the degree of OJS such that $\psi^{\lambda}(z)$ strictly and continuously increases in $\lambda$ for all $z \in(0,1)$. Let $I^{\lambda}(n)$ and $I_{\lambda}(\underline{u})$ be the shirking incentives in our two classes of candidate equilibria, with $n$ firms or with reservation utility $\underline{u}$.

Recall from Section 5.1 that $n^{*}$ is the smallest number of firms $n$ such that the zero-wage constraint binds at the bottom job of a candidate equilibrium with $n$ firms; if the constraint binds for no $n$, we set $n^{*}=1$. Also recall that if wages are zero in the bottom job then $\eta(0)=-u(0)=\phi^{-1}(c)$.

It is convenient to restrict the domain for the reservation utility $\underline{u}$. When defining these candidate equilibria, we bounded this domain below by $\underline{u}^{*}$ to ensure that the lower bound is attained by the lowest candidate equilibrium contract. We now additionally bound $\underline{u}$ above by the Shapiro-Stiglitz equilibrium utility $u^{\mathrm{S}}$; by equation [22], $u^{\mathrm{S}}$ is the solution to the first-order condition 17 and the zero profit condition 18 for $x=1$ and any $\psi$. In a candidate equilibrium with reservation utility $\underline{u}>u^{\mathrm{S}}$ all firms would offer the same contract, determined by $u=\underline{u}$ and the zero profit condition 18 ; thus, (IC) is obviously violated.

When comparing two candidate equilibria we write firm $x$ 's contract as $\langle u(x), \eta(x)\rangle$, and $\langle\tilde{u}(x), \tilde{\eta}(x)\rangle$; we extend this notation to other variables, say, $\tilde{I}$ for shirking incentives in the latter candidate equilibrium. Also, we write differences of shirking incentives as $\Delta I=\tilde{I}-I$, and similarly for other variables.

\section{Lemma 7 (Comparative static of candidate equilibria). Fix a matching technology $\psi^{\lambda}$.}

(a) $I^{\lambda}(n)$ is continuous in $n$ and strictly single-crossing on $\left(0, n^{*}\right]$; additionally, if $I^{\lambda}(n)=0$ for some $n \in\left[n^{*}, 1\right]$, then $I^{\lambda}(n)=0$ for all $n \in\left[n^{*}, 1\right]$.

(b) $I_{\lambda}(\underline{u})$ is continuous and strictly increasing on $\left[\underline{u}^{*}, u^{S}\right]$.

Next fix any $n \in(0,1]$ and any $\underline{u} \in\left[\underline{u}^{*}, u^{S}\right)$.

(c) $I^{\lambda}(n)$ and $I_{\lambda}(\underline{u})$ are continuous and strictly decreasing in $\lambda$.

Proof We first establish some useful facts about candidate equilibria. The support of a candidate equilibrium is convex and equals $[u(0), u(1)]$. This follows because $\beta_{n}(x)$ increases continuously in $x$ by Lemma $4 \mathrm{a}$ ), so the solution $u(x)$ to the first-order condition 17 and zero profits 18 increases continuously in $x$ with range $[u(0), u(1)]$. For the top job, effort and utility are given by 22, $\langle u(1), \eta(1)\rangle=\left\langle u^{\mathrm{S}}, \eta^{\mathrm{S}}\right\rangle$, for all candidate equilibria. In addition, fixing a zero profit job $\langle u, \eta\rangle$ in the support of some candidate equilibrium, the retention rate $F^{e}(u)$ and marginal value of utility $V^{\prime}(u)$ are independent of the parameters $n, \underline{u}$, and $\psi$. This is because the first-order condition 8 determines the retention rate

$$
F^{e}(u)=\frac{1}{\alpha \delta \phi^{\prime}(\eta)},
$$

which in turn determines the marginal value of utility via equation 6 ,

$$
V^{\prime}(u)=\frac{F^{e}(u)}{1-\alpha \delta F^{e}(u)} .
$$

Next, we establish that value functions and shirking incentives in a candidate equilibrium are fully determined by the value of unemployment. First, consider the value of the top job $V(u(1))$, which is characterized by the Bellman equation 2. Taking differences between two candidate equilibria, we get

$$
\Delta V(u(1))=\delta\left(\alpha \Delta V(u(1))+(1-\alpha) \Delta V^{\varnothing}\right)=\frac{\delta(1-\alpha)}{1-\alpha \delta} \Delta V^{\varnothing}
$$

41. The two distributions do not integrate to the same mass on $\left(1-n^{\mathrm{A}}, 1\right)$, but this is not needed; one can always rescale one of the distributions without affecting the sign. 
Next, for all $u$ in the joint support of the candidate equilibria, the derivative of the value function is given by A.10 for either candidate equilibrium, so that $\Delta V(u)=\Delta V(u(1))$. That is,

$$
\Delta V(u)=\frac{\delta(1-\alpha)}{1-\alpha \delta} \Delta V^{\varnothing}
$$

Finally, by the definition of shirking incentives A.8

$$
\Delta I=\alpha \delta \frac{1-\delta}{1-\alpha \delta} \Delta V^{\varnothing}
$$

Intuitively, the worker in the top job cares about changes in the candidate equilibrium only via the contingency of future unemployment; so, by discounting, whenever $V^{\varnothing}$ increases $I$ increases as well.

We now claim that

$$
\Delta I \propto \Delta V^{\varnothing} \propto \int \tilde{W}(u)\left(d \tilde{F}^{\varnothing}-d F^{\varnothing}\right)(u) .
$$

The first proportionality follows from A.12. To prove the second, we decompose $\Delta V^{\varnothing}$ into differences of the distribution $F^{\varnothing}$ and differences of the continuation values,

$$
\Delta V^{\varnothing}=\int \tilde{W}(u) d \tilde{F}^{\varnothing}(u)-\int W(u) d F^{\varnothing}(u)=\underbrace{\int \tilde{W}(u)\left(d \tilde{F}^{\varnothing}-d F^{\varnothing}\right)(u)}_{\text {change in job offers }}+\underbrace{\int \Delta W(u) d F^{\varnothing}(u)}_{\text {change in cont. value }}
$$

Using the definition of the post-match value function 3 and equation A.11, we obtain

$$
\Delta W(u)=\delta\left(\alpha \Delta V(u)+(1-\alpha) \Delta V^{\varnothing}\right)=\delta\left(\alpha \frac{\delta(1-\alpha)}{1-\alpha \delta}+(1-\alpha)\right) \Delta V^{\varnothing}=\frac{\delta(1-\alpha)}{1-\alpha \delta} \Delta V^{\varnothing}
$$

for the employed and $\Delta W(\varnothing)=\delta \Delta V^{\varnothing}$ for the unemployed. Thus, the continuation value from equation A.14 equals

$$
\int \Delta W(u) d F^{\varnothing}(u)=(1-\theta) \delta \Delta V^{\varnothing}+\theta \delta \frac{1-\alpha}{1-\alpha \delta} \Delta V^{\varnothing}=\gamma \Delta V^{\varnothing}
$$

where $\gamma:=\delta\left(1-\theta \frac{\alpha(1-\delta)}{1-\alpha \delta}\right)<1$. Substituting back into A.14, we get

$$
\Delta V^{\varnothing}=\int \tilde{W}(u)\left(d \tilde{F}^{\varnothing}-d F^{\varnothing}\right)(u)+\gamma \Delta V^{\varnothing}=\frac{1}{1-\gamma} \int \tilde{W}(u)\left(d \tilde{F}^{\varnothing}-d F^{\varnothing}\right)(u),
$$

establishing A.13.

To analyze the RHS of A.13, recall that the distribution of job offers to unemployed workers is given by

$$
F^{\varnothing}(u)=\left\{\begin{array}{cc}
1-\theta & \text { for } u<u(0) \\
\psi\left(F^{e}(u)\right) & \text { for } u \geq u(0)
\end{array}\right.
$$

where the retention rate $F^{e}(u)$ is given by A.9, independently of $n, u$ and $\psi$.

We now prove part (c). Equation A.15 implies that the job distribution $F^{\varnothing}$ strictly decreases in $\lambda$ (in the usual stochastic order), as illustrated in Figure A1 b). Since $W(u)$ strictly increases, the value of unemployment $V^{\varnothing}$ strictly decreases. Equation A.13 then implies that the incentive to shirk, $I^{\lambda}(n)$ and $I_{\lambda}(\underline{u})$, strictly decrease in $\lambda$. It is apparent that this dependence is also continuous.

For part (b), suppose $n=1$. An increase in $\underline{u}$ leads to a one-to-one increase in $u(0)$. This leads to a strict increase in $F^{\varnothing}$ (in the usual stochastic order), as illustrated in Figure A1 b). Since $W(u)$ strictly increases, the value of unemployment $V^{\varnothing}$ rises, along with the incentive to $\operatorname{shirk} I^{\lambda}(\underline{u})$ via A.13. It is apparent that this dependence is also continuous.

For part (a), consider $1 \geq \tilde{n}>n$. As shown in Figure $\mathrm{A} 1$ a), the two distributions of job offers $\tilde{F}^{\varnothing}$ and $F^{\varnothing}$ coincide on $[u(0), u(1)]$. Below $u(0), \tilde{F}^{\varnothing}$ offers a positive mass of jobs with utility $u \in[\tilde{u}(0), u(0)]$ while the corresponding worker under $F^{\varnothing}$ is unemployed, $u=\varnothing$. Hence the value of the change in job offers equals

$$
\int \tilde{W}(u)\left(d \tilde{F}^{\varnothing}-d F^{\varnothing}\right)(u)=\int_{\tilde{u}(0)}^{u(0)}\left(\tilde{W}(u)-\delta \tilde{V}^{\varnothing}\right) d \tilde{F}^{\varnothing}(u) .
$$

Clearly, this term is of order $\tilde{n}-n$, and so $I^{\lambda}(n)$ is continuous.

First, we show that $I^{\lambda}(n)$ single-crosses on $[0,1]$. Suppose $I(\tilde{n})=0$, so the candidate equilibrium with $\tilde{n}$ firms is an equilibrium. Since equilibrium jobs satisfy (IR), $\tilde{W}(u) \geq \delta \tilde{V}^{\varnothing}, \mathrm{A.16}$ is positive, as required.

Second, we show that $I^{\lambda}(n)$ strictly single-crosses on $\left(0, n^{*}\right]$. If $n<n^{*}$, then by definition of $n^{*}$ the equilibrium job $\langle\tilde{u}(x), \tilde{\eta}(x)\rangle$ with $\tilde{u}(x)=u(0)$ and $\tilde{\eta}(x)=\eta(0)$ has a strictly positive wage; since (IC) binds the (IR) constraint is slack, $\tilde{W}(u(0))>\delta \tilde{V}^{\varnothing}$, so $\mathrm{A} .16$ is strictly positive.

Third, if $I(n)=0$ for some $n \in\left[n^{*}, 1\right]$ then $I(n)=0$ for all $n \in\left[n^{*}, 1\right]$. If $\tilde{n}, n \geq n^{*}$ then the lower bound $\tilde{u}(0)=u(0)=$ $\underline{u}=-\phi^{-1}(c)$ binds in both candidate equilibria. The additional job offers in distribution $\tilde{F}^{\varnothing}$ are all identical to the bottom job $\langle\tilde{u}(0), \tilde{\eta}(0)\rangle$. By construction, this job pays zero wage and the tight (IC) constraint implies that (IR) is tight as well; i.e. $\tilde{W}(u)=\delta \tilde{V}^{\varnothing}$. Thus, A.16 is zero and $\Delta I=0$. $\|$ 

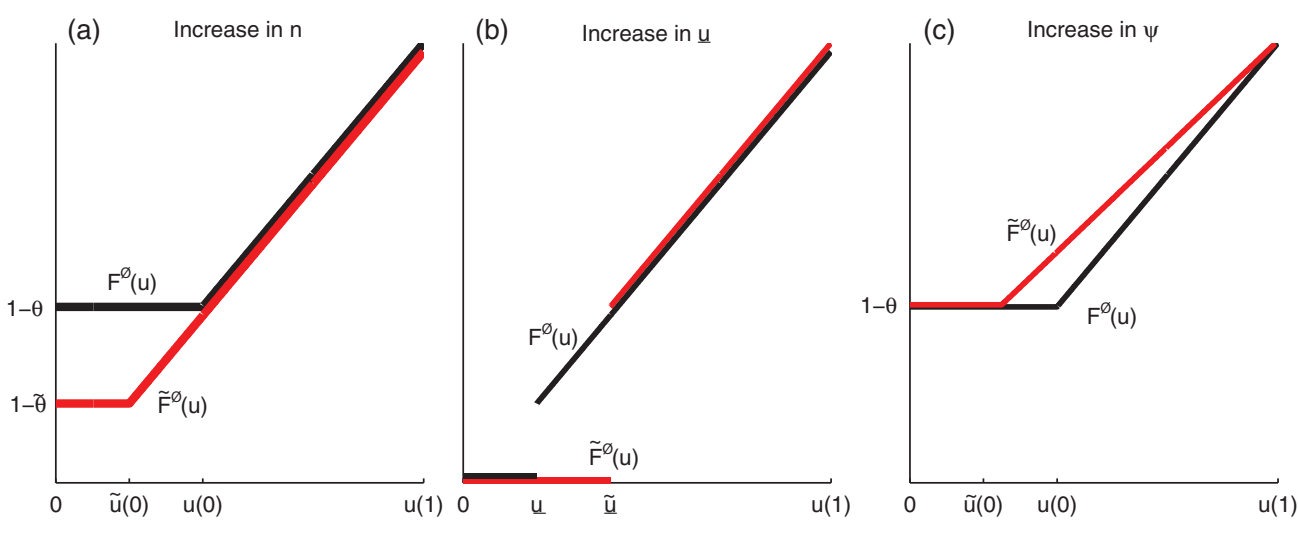

FIGURE A1

Comparative statics for $F^{\varnothing}$ in $n, \underline{u}$ and $\psi$.

This figure illustrates that an increase in $n$ adds job offers at the bottom of $F^{\varnothing}$, an increase in $\underline{u}$ increases $F^{\varnothing}$ (in the usual stochastic order) and an increase in $\psi$ decreases $F^{\varnothing}$

\section{A.6. Proof of Theorem 3}

This proof uses notation and concepts introduced in Appendix A.5

Recall that a candidate equilibrium is an equilibrium if and only if shirking incentives $I^{\lambda}(n)$, or $I_{\lambda}(\underline{u})$, are zero. Recall also that the candidate equilibrium with $n=1$ firms coincides with the candidate equilibrium with reservation utility $\underline{u}^{*}$. The proof relies critically on the shirking incentives in this candidate equilibrium $I^{\lambda}(1)=I_{\lambda}\left(\underline{u}^{*}\right)$, which we will now analyze.

Lemma $7 \mathrm{c}$ ) shows that $I^{\lambda}(1)$ strictly and continuously decreases in $\lambda$. For Shapiro-Stiglitz matching, $\lambda=0$, full employment violates (IC), $I^{\lambda}(1)>0$ (see Section 5.1. Conversely, for Intern matching, $\lambda=1$, (IC) is slack, $I^{\lambda}(1)<0$ by note 29 Then the intermediate value theorem implies there exists $\lambda^{*}$ such that $I^{\lambda}(1)$ is strictly positive on $\left[0, \lambda^{*}\right)$, strictly negative on $\left(\lambda^{*}, 1\right]$, and $I^{\lambda^{*}}(1)=0$.

Now, consider first $\lambda \in\left[0, \lambda^{*}\right)$, so that $I^{\lambda}(1)>0$. The proof of Theorem 1 showed that $I^{\lambda}(n)$ is negative as $n \rightarrow 0$; thus Lemma 7 a) implies that there exists a unique $n \in(0,1)$ such that $I^{\lambda}(n)=0$. This is the unique equilibrium because Lemma $7 \mathrm{~b}$ ) implies $I^{\lambda}(\underline{u})>0$ for any candidate equilibrium with reservation utility $\underline{u} \geq \underline{u}^{*}$. Our assumption that $I^{\lambda}(1)>0$ implies $n<n^{*}$; otherwise Lemma 7 a) implies that $I^{\lambda}(n)=0$ for all $n \in\left[n^{*}, 1\right]$, yielding a contradiction. By the definition of $n^{*},(\mathrm{IR})$ is thus slack. Finally, Lemma7 7 a),(c) imply that $n$ strictly increases in $\lambda$.

Next, consider $\lambda \in\left(\lambda^{*}, 1\right]$, so that $I_{\lambda}\left(\underline{u}^{*}\right)<0$. Lemma 7 a) implies $I^{\lambda}(n)<0$ for all candidate equilibria with $n<1$ firms. Thus, equilibrium must have full employment, $n=1$. To see that there is a unique equilibrium, we again apply the intermediate value theorem. At the bottom, $I^{\lambda}\left(\underline{u}^{*}\right)<0$. At the top, $I^{\lambda}\left(u^{\mathrm{S}}\right)>0$; otherwise if $n=1$ and all firms offer the same contract with effort $\eta^{\mathrm{S}}$, then there is no cost to shirking and (IC) is violated. By Lemma 7 b) there exists a unique value of $\underline{u} \in\left(\underline{u}^{*}, u^{\mathrm{S}}\right)$ such that $I_{\lambda}(\underline{u})=0$, and this $\underline{u}$ characterizes the unique equilibrium. Finally, Lemma $\left.7 \mathrm{~b}\right),(\mathrm{c})$ imply that $\underline{u}$ strictly increases in $\lambda$.

\section{B. HETEROGENEOUS FIRMS}

\section{B.1. Proof of Theorem 4}

Lemma 8 In equilibrium (IC) binds, $u=u_{*}(\eta)$.

Proof The proof strategy is the same as in Lemma 5 Assume counterfactually that (IC) is slack in firm $p$ 's equilibrium contract $\langle u(p), \eta(p)\rangle$. Then (IR) binds and $\eta(p)$ solves $\phi_{\eta}(\eta(p), p)=1$. Assumption $\eta^{\mathrm{FB}}(p) \geq \eta^{\mathrm{S}}(\bar{p})$ implies that (IR) binds in all equilibrium contracts 42 Thus, all equilibrium contracts offer the same utility, $u=u(p)$, and pre- and post-matching values coincide, $V(u)=W(u)$. This leads to the same contradiction as in Lemma 5

42. Assume counterfactually that (IR) is slack, and (IC) is tight, in firm $\hat{p}$ 's equilibrium contract $\langle u(\hat{p}), \eta(\hat{p})\rangle$. Then $\eta(\hat{p})$ is characterized by the firm's first-order condition $\phi_{\eta}(\eta(\hat{p}), \hat{p})=1 / \alpha \delta \beta_{n}(x)$; assumption $\eta^{\mathrm{FB}}(\underline{p}) \geq \eta^{\mathrm{S}}(\bar{p})$ then implies 
Lemma 9 (a)Assume Shapiro-Stiglitz or Symmetric matching. In equilibrium there is unemployment, $p_{0}>\underline{p}$, and (IR) is slack for all firms.

(b)Assume Intern matching. In equilibrium, there is full employment, $p_{0}=\underline{p}$, and (IR) is tight for firm $\underline{p}$.

Proof Part (a) is the same as the proof of Lemma 6 Part (b) is the same as the discussion of Intern matching with homogeneous firms in Section 5.3 \|

We now perform a change of variables and define the corresponding candidate equilibria. In Section 5 we indexed the $n$ homogeneous firms that entered the market by their quantiles in the contract distribution $x \in[0,1]$. With heterogeneous firms, it is convenient to work instead with firm $p$ 's quantile in the productivity distribution, $y=G(p)$, rather than its rank among entrants $x=\left(G(p)-G\left(p_{0}\right)\right) /\left(1-G\left(p_{0}\right)\right) 43$ For Shapiro-Stiglitz matching, Symmetric matching, and Intern matching with $n=1$ the retention rate as a function of $y$ is given by

$$
\gamma^{\mathrm{S}}(y)=1, \quad \gamma^{\mathrm{Y}}(y)=\frac{y}{1-\alpha(1-y)}, \quad \gamma^{\mathrm{I}}(y)=\max \left\{\frac{y-(1-\alpha)}{\alpha y}, 0\right\} .
$$

Under Shapiro-Stiglitz and Symmetric matching, Lemma 9a) implies that there is unemployment in equilibrium, $p_{0}>p$. Lemma 8 then implies that equilibrium is determined by the first-order condition 26, the envelope condition on utilities 27] and the binding (IC) constraint 28]. Correspondingly, we define a candidate equilibrium with marginal firm $p_{0},\left\{u(p), \eta(p), p_{0}\right\}$, as the contract distribution where firms $p \in\left[p_{0}, \bar{p}\right]$ enter and their jobs $\langle u(p), \eta(p)\rangle$ satisfy

$$
\begin{aligned}
\phi_{\eta}(\eta(p), p) & =\frac{1}{\alpha \delta \gamma(G(p))}, \\
u\left(p_{0}\right) & =\phi\left(\eta\left(p_{0}\right), p_{0}\right)-\eta\left(p_{0}\right)-c, \\
u(p) & \left.=u\left(p_{0}\right)+\int_{p_{0}}^{p} \phi_{\eta}(\eta(\hat{p}), \hat{p})-1\right) d \eta(\hat{p}) .
\end{aligned}
$$

As with homogeneous firms, we can interpret B.2 and B.4 as a marginal incentive constraint. Thus, given marginal firm $p_{0}$, we can define shirking incentives for the highest contract,

$$
I=\eta(\bar{p})-\alpha \delta\left(V\left(u(\bar{p})-V^{\varnothing}\right),\right.
$$

and a candidate equilibrium is an equilibrium if and only if $I=0$.

Under Intern matching, Lemma $9 \mathrm{~b}$ ) establishes that all firms enter, $p_{0}=p$, and the (IR) constraint, $u \geq \underline{u}$, binds for firm $p$. Given $\underline{u}$, define the internship, $\langle\underline{u}, \eta\rangle$, by the lowest firm's zero profit condition, $\phi(\eta, p)-\eta-\underline{u}-c=0$. With heterogeneous firms we find it convenient to fix $\underline{\eta}$ rather than $\underline{u}$; correspondingly, we define a candidate equilibrium with minimal effort $\eta,\{u(p), \eta(p), \eta\}$, as the contract distribution where firm $p$ 's effort $\eta(p)$ solves the first-order condition B.2 subject to $\eta(p) \geq \eta$, and utility $u(p)$ is determined by zero profits B.3 and the envelope condition B.4; if $\eta(p) \geq \underline{\eta}$ binds, this means that firm $p$ offers the internship $\langle\underline{u}, \underline{\eta}\rangle$.

As with homogeneous firms, we must limit the range of $\underline{\eta}$. At the bottom, define $\underline{\eta}^{*}$ by zero profits and zero wages for firm $\underline{p}$, i.e. $\phi\left(\underline{\eta}^{*}, \underline{p}\right)=c$. At the top end, we can restrict attention to $\underline{\eta} \leq \eta^{\dagger}$, where $\overline{\phi_{\eta}}\left(\eta^{\dagger}, \bar{p}\right)=1 / \alpha \delta$; if $\underline{\eta} \geq \eta^{\dagger}$, then all firms offer the internship, violating (IC).

Theorem 4 is a corollary to the following comparative static result, which we prove in the next subsection.

Lemma 10 (a) Assume Shapiro-Stiglitz or Symmetric matching. Shirking incentives I( $\left.p_{0}\right)$ continuously and strictly single-cross from above in $p_{0}$.

(b) Assume Intern matching. Shirking incentives $I(\underline{\eta})$ continuously and strictly increase in $\underline{\eta}$ on $\left[\eta^{*}, \eta^{\dagger}\right]$.

Proof of Theorem 4 Part (a). Lemma9a) implies that $I(p)>0$, whereas the proof of Theorem 1 implies that $I(\bar{p})<0$. Lemma 10 a) and the intermediate value theorem implies there is a unique $p_{0}$ where $I\left(p_{0}\right)=0$.

Part (b). Lemma 9 b) implies $I\left(\eta^{*}\right)<0$, whereas the definition of $\eta^{\dagger}$ implies $I\left(\eta^{\dagger}\right)>0$. Lemma 10 b) and the intermediate value theorem implies there is a unique $\underline{\eta}$ where $I(\underline{\eta})=0 . \quad \|$

$\eta(\hat{p}) \leq \eta(p)$. Since (IR) is assumed to be slack for $\hat{p}$, we have $u(\hat{p})>u(p)$. As $p$ 's contract $\langle u(p), \eta(p)\rangle$ has higher effort and lower utility than $\hat{p}$ 's contract $\langle u(\hat{p}), \eta(\hat{p})\rangle$, it violates (IC), contradicting the original assumption that (IC) is slack.

43. Specifically, this ensures that retention rates $\gamma(y)$ in B.1] do not depend on the marginal firm $p_{0}$. 


\section{B.2. Proof of Lemma 10}

For the proof of Lemma 10 it is convenient to define the candidate equilibria with marginal firm $p_{0}$ and top utility $\bar{u}$ as the contract distribution for firms $p \in\left[p_{0}, \bar{p}\right]$ where $\langle u(p), \eta(p)\rangle$ is defined by B.2. B.4, and

$$
u(\bar{p})=\bar{u} .
$$

Condition B.5 fixes utility $\bar{u}$ in firm $\bar{p}$ 's job, and replaces the zero profit condition B.3 at the lowest firm $p_{0}$. Similarly, define the candidate equilibria with minimal effort $\underline{\eta}$ and top utility $\bar{u}$ : Firm $p$ 's effort $\eta(p)$ solves B.2 subject to $\eta(p) \geq \underline{\eta}$, and utility $u(p)$ is determined by B.4 and B.5.

These definitions are justified by the following two properties:

(P1) Firm $p$ 's contract in the candidate equilibria with marginal firm $p_{0}$ and top utility $\bar{u}$ does not depend on $p_{0} \leq p$; similarly, firm $p$ 's contract in the candidate equilibria with minimal effort $\underline{\eta}$ and top utility $\bar{u}$ does not depend on the level of $\eta<\eta(p)$.

(P2) Shirking incentives $I$ in the candidate equilibrium with marginal firm $p_{0}>p$ and top utility $\bar{u}$ strictly decrease in $\bar{u}$; shirking incentives $I$ in the candidate equilibrium with minimal effort $\eta$ and top utility $\bar{u}$ do not depend on $\bar{u}$.

To show (P1) observe that $\gamma(p)$ does not depend on $p_{0}$ by B.1; then, $\bar{\eta}(p)$ does not depend on $p_{0}$ by B.2]; finally, $\left.u(p)=u(\bar{p})-\int_{p}^{\bar{p}} \phi_{\eta}(\eta(\hat{p}), \hat{p})-1\right) d \eta(\hat{p})$ does not depend on $p_{0}$ by B.4 and B.5. To show (P2) observe that utility $u(p)$ increases one-for-one in $\bar{u}$ at all firms $p$ by the envelope condition B.4; if there is unemployment, $p_{0}>p$, this increases continuation values of jobs $V(u(p))$ more than the value of unemployment $V^{\varnothing}$ and relaxes (IC); if there is full employment, $V(u(p))$ and $V^{\varnothing}$ increase in lockstep and shirking incentives are constant.

Proof of Lemma 10 a). Define three candidate equilibria with contracts $\langle u(p), \eta(p)\rangle,\langle\check{u}(p), \check{\eta}(p)\rangle,\langle\tilde{u}(p), \tilde{\eta}(p)\rangle$, illustrated in Figure B1 a). We will show that $\tilde{I}<\check{I}<I=0$. First, let $\langle u(p), \eta(p)\rangle$ be firm $p$ 's contract in the candidate equilibrium with marginal firm $p_{0}$. To show that $I$ single-crosses from above in $p_{0}$ we assume that (IC) is tight, $I=0$.

Second, let $\langle\breve{u}(p), \check{\eta}(p)\rangle$ be firm $p$ 's contract in the candidate equilibrium with marginal firm $\tilde{p}_{0} \geq p_{0}$ and top utility $\bar{u}=u(\bar{p})$ as in the top job of the original candidate equilibrium. Property (P1) implies $u(p)=\breve{u}(p)$ for all $p \geq \tilde{p}_{0}$. The jobs lost by firms $p \in\left[p_{0}, \tilde{p}_{0}\right]$ were more valuable to unemployed workers than to firm $\bar{p}$ 's employee, relaxing (IC), $\check{I}<I=0$. Moreover, the lowest job $\left\langle\check{u}\left(\tilde{p}_{0}\right), \check{\eta}\left(\tilde{p}_{0}\right)\right\rangle$ is strictly profitable, $\check{\pi}\left(\tilde{p}_{0}\right)>0$, because it coincides with the inframarginal job $\left\langle u\left(\tilde{p}_{0}\right), \eta\left(\tilde{p}_{0}\right)\right\rangle$ of the original candidate equilibrium.

Third, let $\langle\tilde{u}(p), \tilde{\eta}(p)\rangle$ be firm $p$ 's contract in the candidate equilibrium with marginal firm $\tilde{p}_{0}$. By definition, profits of the marginal firm fall to zero, $\tilde{\pi}\left(\tilde{p}_{0}\right)=0<\check{\pi}\left(\tilde{p}_{0}\right)$, and so the utility of its job increases, $\tilde{u}\left(\tilde{p}_{0}\right)>\breve{u}\left(\tilde{p}_{0}\right)$. By the envelope condition B.4 utility increases for all jobs and also at the top, $\tilde{u}(\bar{p})>\breve{u}(\bar{p})=\bar{u}$. By property (P2) this transfer of utility to workers further relaxes (IC), so that $\tilde{I}<\check{I}<I=0$.

Finally, as in the proof of Lemma $7 \mathrm{a}$ ), $|\tilde{I}-I|$ is of order $\tilde{p}_{0}-p_{0}$, so $I$ is continuous in $p_{0}$.
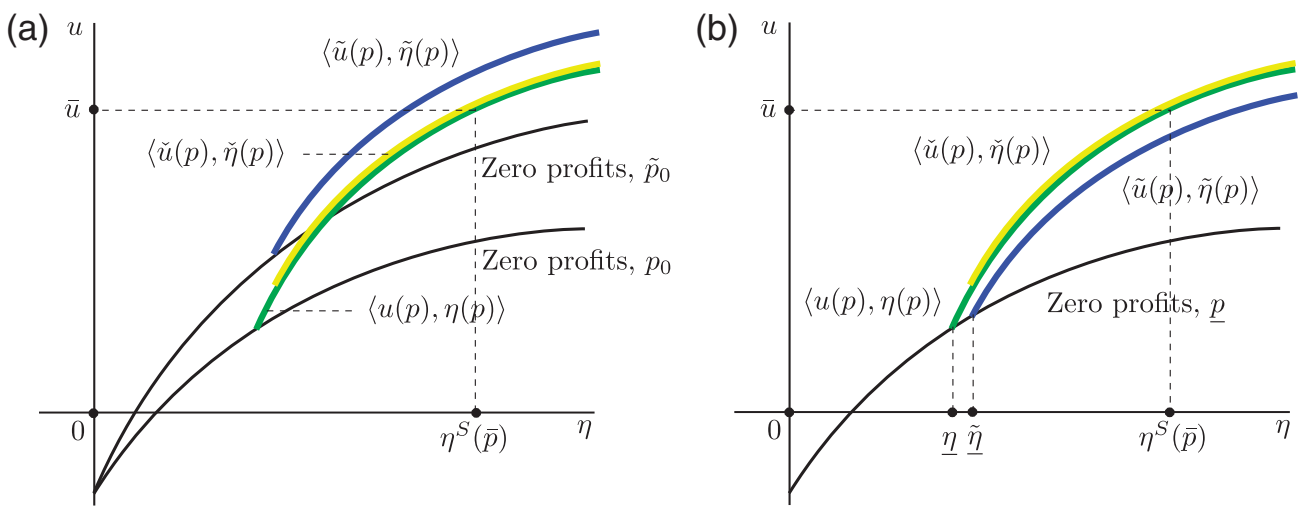

FIGURE B1

Three candidate equilibria

Panel (a) illustrates candidate equilibrium contracts as we first raise $p_{0}$ to $\tilde{p}_{0}$ in the candidate equilibrium with top utility $\bar{u}$, and then increase the top utility $\bar{u}$. Panel (b) illustrates candidate equilibrium contracts as we first raise $\underline{\eta}$ to $\underline{\tilde{\eta}}$ in the candidate equilibrium with top utility $\bar{u}$, and then decrease the top utility $\bar{u}$ 
Proof of Lemma10 b). Again, we define three candidate equilibria with contracts $\langle u(p), \eta(p)\rangle,\langle\breve{u}(p), \check{\eta}(p)\rangle,\langle\tilde{u}(p), \tilde{\eta}(p)\rangle$, illustrated in Figure B1 b), and show that $\tilde{I}=\check{I}>I=0$. First, let $\langle u(p), \eta(p)\rangle$ be firm $p$ 's contract in the candidate equilibrium with minimal effort $\underline{\eta}$ (and internship $\langle\underline{u}, \underline{\eta}\rangle$ ).

Second, let $\langle\breve{u}(\bar{p}), \check{\eta}(p)\rangle$ be firm $p$ 's contract in the candidate equilibrium with minimal effort $\underline{\tilde{\eta}}>\underline{\eta}$ and top utility $\bar{u}=u(\bar{p})$ as in the top job of the original candidate equilibrium. The locus of candidate equilibrium contracts in $\eta, u$ space, illustrated in Figure B1 b), increases at a rate greater than firm $p$ 's iso-profit curve, $u^{\prime}(\eta)=\phi_{\eta}(\eta, p)-1>\phi_{\eta}(\eta, p)-1>0$. Thus, the lowest job in this candidate equilibrium, $\langle\underline{\tilde{u}}, \tilde{\eta}\rangle$, is more attractive to workers, $\underline{\tilde{u}} \geq \underline{u}$, but unprofitable for the lowest firm, $\check{\pi}(p)<0$. Property (P1) implies $u(p)=\breve{u}(p)$ for all $p$ with $\eta(p) \geq \underline{\eta}+\varepsilon$. The improvement of the internships is strictly more valuable to unemployed workers than to firm $\bar{p}$ 's employee, tightening (IC), $\check{I}>I$.

Third, let $\langle\tilde{u}(p), \tilde{\eta}(p)\rangle$ be firm $p$ 's contract in the candidate equilibrium with minimal effort $\tilde{\eta}$. By property (P2), shirking incentives in a candidate equilibrium with minimal effort $\tilde{\eta}$ do not depend on the top utility $\bar{u}$, so that $\tilde{I}=\breve{I}>I$.

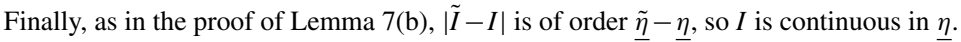

\section{B.3. Equilibrium profits/ derivation of table in section 6.2}

Fix a firm $p^{*}$. By the envelope theorem and the zero profit condition for the marginal firm $p_{0}$ its equilibrium profits equal

$$
\pi\left(p^{*}\right)=\int_{p_{0}}^{p^{*}} \phi_{p}(\eta(p), p) d p .
$$

They thus decrease in $p_{0}$ and increase in $\eta(p)$ for all $p \in\left[p_{0}, p^{*}\right]$. Now consider a productivity increase

$$
\tilde{G}(p) \leq G(p)
$$

for all $p \in[\underline{p}, \bar{p}]$.

Shapiro-Stiglitz Matching: Let $\left\{u(p), \eta(p), p_{0}\right\},\left\{\check{u}(p), \check{\eta}(p), p_{0}\right\},\left\{\tilde{u}(p), \tilde{\eta}(p), \tilde{p}_{0}\right\}$ be the equilibrium with productivity $G$, the candidate equilibrium with marginal firm $p_{0}$ and productivity $\tilde{G}$, and the equilibrium with productivity $\tilde{G}$. We extend this notation to other variables, say, $\check{I}$ for shirking incentives for the candidate equilibrium $\left\{\breve{u}(p), \breve{\eta}(p), p_{0}\right\}$.

We now show that $\check{I} \geq 0$. As $\gamma^{\mathrm{S}} \equiv 1$, equations B.2-B.4 are independent of the productivity distribution, and so $\langle u(p), \eta(p)\rangle=\langle\breve{u}(p), \breve{\eta}(p)\rangle$ for all $p \geq p_{0}$. Thus, for every level $u$ the probability of receiving a job above $u$ increases. Formally, the market clearing condition 12 with $F^{e}(u)=1$ implie 44

$$
1-\breve{F}^{\varnothing}(u)=\frac{(1-\alpha)(1-\tilde{G}(p(u))}{1-\alpha\left(1-\tilde{G}\left(p_{0}\right)\right)} \geq \frac{(1-\alpha)(1-G(p(u))}{1-\alpha\left(1-G\left(p_{0}\right)\right)}=1-F^{\varnothing}(u)
$$

To understand this equation, note that (1) the number of jobs above $u$ increases, $1-\tilde{G}(p(u)) \geq 1-G(p(u))$; (2) the number of unemployed workers competing for these jobs decreases, $1-\alpha\left(1-\tilde{G}\left(p_{0}\right)\right) \leq 1-\alpha\left(1-G\left(p_{0}\right)\right)$. Thus, unemployed workers benefit from the productivity increase. Employed workers experience this improvement only with a delay, so (IC) tightens, implying $\breve{I} \geq 0$.

By Lemma 10 a), marginal firms have to exit to decrease shirking incentives, so the marginal firm in equilibrium with productivity $\tilde{G}$ must satisfy $\tilde{p}_{0} \geq p_{0}$. Moreover, effort at firm $p \geq \tilde{p}_{0}$ is determined by the first-order condition B.2 and so $\tilde{\eta}(p)=\check{\eta}(p)=\eta(p)$. Thus, firm $p^{*}$ 's profits B.6 decrease, $\tilde{\pi}\left(p^{*}\right) \leq \pi\left(p^{*}\right)$.

If the productivity increase B.7 is strict for some $p \in\left[p_{0}, \bar{p}\right]$, then job offers to unemployed workers strictly increase, the marginal firm strictly increases, and firm $p$ 's profits strictly decrease.

Symmetric Matching: First, we claim that in a candidate equilibrium with marginal firm $p_{0}$, (IC) is equivalent to

$$
\phi\left(\eta\left(p_{0}\right), p_{0}\right)-\eta\left(p_{0}\right) \phi_{\eta}\left(\eta\left(p_{0}\right), p_{0}\right) \geq c .
$$

This is because with Symmetric matching, the job $\langle u, \eta\rangle=\langle 0,0\rangle$ is identical to unemployment and hence (IC) holds with equality; the marginal cost of effort to the firm below $\left\langle u\left(p_{0}\right), \eta\left(p_{0}\right)\right\rangle$ equals $\phi_{\eta}\left(\eta\left(p_{0}\right), p_{0}\right)$, so (IC) in job $\left\langle u\left(p_{0}\right), \eta\left(p_{0}\right)\right\rangle$ is equivalent to $w\left(p_{0}\right)=u\left(p_{0}\right)+\eta\left(p_{0}\right) \geq \phi_{\eta}\left(\eta\left(p_{0}\right), p_{0}\right) \eta\left(p_{0}\right)$; as $\pi\left(p_{0}\right)=0$, this is equivalent to B.8.

As above, consider the three contract distributions $\left\{u(p), \eta(p), p_{0}\right\},\left\{\breve{u}(p), \check{\eta}(p), p_{0}\right\},\left\{\tilde{u}(p), \tilde{\eta}(p), \tilde{p}_{0}\right\}$. We now show $\check{I} \geq 0$. As productivity increases, the rank of firm $p$ decreases, $\tilde{G}(p) \leq G(p)$; as $\phi_{\eta \eta}<0$, firm $p$ 's effort, determined by the first-order condition B.2, decreases as well, $\check{\eta}(p) \leq \eta(p)$. Finally, the LHS of B.8 increases in $\eta\left(p_{0}\right)$ because $\phi_{\eta \eta}<0$, so (IC) tightens and $\breve{I} \geq 0$. 
By Lemma 10 a), marginal firms have to exit to restore equilibrium, so $\tilde{p}_{0} \geq p_{0}$. Moreover effort at firm $p \geq \tilde{p}_{0}$, as determined by the first-order condition B.2, depends on rank $G(p)$ but not on $p_{0}$ and so $\tilde{\eta}(p)=\check{\eta}(p) \leq \eta(p)$. Thus, firm $p^{*}$ 's profits B.6 decrease, $\tilde{\pi}\left(p^{*}\right) \leq \pi\left(p^{*}\right)$.

If the productivity increase B.7] is strict for some $p \in\left[p_{0}, p^{*}\right]$, then effort at this firm strictly decreases, and firm $p^{*}$ 's profits strictly decrease. However, if productivity increases only for firms that do not enter anyway, $p<p_{0}$, and for stronger competitors, $p>p^{*}$, then firm $p^{*}$ 's profits are unchanged.

Intern Matching: Let $\{u(p), \eta(p), \eta\},\{\breve{u}(p), \check{\eta}(p), \eta\},\{\tilde{u}(p), \tilde{\eta}(p), \tilde{\eta}\}$ be the equilibrium with productivity $G$, the candidate equilibrium with minimal effort $\eta$ and productivity $\tilde{G}$, and the equilibrium with productivity $\tilde{G}$. We will abuse notation by writing $\eta(y)$ and $u(y)$ for the effort and utility at a firm of rank $y=G(p)$ in a (candidate) equilibrium. Similarly, we will write $u(\eta)$ and $p(\eta)$ for the utility and productivity of a job with effort $\eta$ To show $\breve{I} \leq 0$ we establish a few facts.

Fact 1: Effort decreases for a fixed productivity $p, \breve{\eta}(p) \leq \eta(p)$. Proof: As other firms' productivity rises, firm $p$ 's retention rate falls, $\gamma^{\mathrm{I}}(\tilde{G}(p)) \leq \gamma^{\mathrm{I}}(G(p))$ and its effort declines via the first-order condition B.2 using $\phi_{\eta \eta}<046$

Fact 2: Effort increases for a fixed rank $y, \check{\eta}(y) \geq \eta(y)$. Proof: As the firms' productivity rises, the productivity of rank $y$ also increases, $\breve{p}(y) \geq p(y)$. Since the retention rate is constant, the effort rises via the first-order condition, $\phi_{\eta}(\eta(y), p(y))=1 /\left(\alpha \delta \gamma^{\mathrm{I}}(y)\right)$ using $\phi_{\eta \eta}<0$ and $\phi_{\eta p}>0$.

Fact 3: Utility increases for a fixed effort level, $u(\eta) \leq \breve{u}(\eta)$. Proof: As firms' productivity rises, Fact 1 implies that productivity for a fixed effort level rises, $\breve{p}(\eta) \geq p(\eta)$. A change in variables in B.4 yields $u(\eta)=\underline{u}+\int_{\underline{\eta}}^{\eta}\left(\phi_{\eta}(\hat{\eta}, p(\hat{\eta}))-1\right) d \hat{\eta}$. Since $\phi_{\eta p}>0$, utility increases.

Jointly, Facts 2 and 3 imply that the job distribution increases, $\breve{u}(y)=\breve{u}(\breve{\eta}(y)) \geq u(\eta(y))=u(y)$. Interns directly benefit from these improved job prospects, whereas unemployed workers first need to take up the internship, $\langle\underline{u}, \underline{\eta}\rangle \underline{47}$ and thus experience the benefit with a delay. Thus, $V(\underline{u})$ increases more than $V^{\varnothing}$, so (IC) relaxes and $\check{I} \leq I=0$.

Turning to the new equilibrium $\{\tilde{u}(p), \tilde{\eta}(p), \underline{\eta}\}$, Lemma 10 b) implies that the minimal effort has to rise to restore equilibrium, so the internship $\langle\underline{\tilde{u}}, \tilde{\tilde{\eta}}\rangle$ in the equilibrium with productivity $\tilde{G}$ satisfies $\underline{\tilde{u}} \geq \underline{u}$ and $\underline{\tilde{\eta}} \geq \underline{\eta}$. Equilibrium effort under productivity $\tilde{G}$ is given by $\overline{\tilde{\eta}}(p)=\max \{\check{\eta}(p), \tilde{\eta}\} \geq \check{\eta}(p)$.

We now compare effort levels $\eta(p), \tilde{\eta}(p)$ of the two equilibria. Fact 1 establishes $\eta(p) \geq \check{\eta}(p)$, so the equilibrium effect of the productivity increase is generally ambiguous: At low firms, for which $\eta(p) \leq \underline{\tilde{\eta}}$, effort increases,

$$
\eta(p) \leq \max \{\check{\eta}(p), \underline{\tilde{\eta}}\}=\tilde{\eta}(p) ;
$$

at high firms, for which $\eta(p) \geq \tilde{\eta}$, effort decreases,

$$
\eta(p) \geq \max \{\check{\eta}(p), \underline{\tilde{\eta}}\}=\tilde{\eta}(p) .
$$

Now, suppose productivity strictly increases only for firms above $p^{*}$. For $p \leq p^{*}$, we have $G(p)=\tilde{G}(p)$ and $\eta(p)=\check{\eta}(p)$, so effort increases $\breve{\eta}(p) \leq \max \{\check{\eta}(p), \tilde{\eta}\}=\tilde{\eta}(p)$, with strict inequality if $p$ offers the internship. As a result, firm $p^{*}$ 's profits B.6 increase, $\tilde{\pi}\left(p^{*}\right)>\pi\left(p^{*}\right)$.

Acknowledgments. We would like to thank the editor Marco Ottaviani and four anonymous referees for invaluable advice that significantly improved the article. We have also benefited from conversations with Andy Atkeson, Paco Buera, Ettore Damiano, Jeff Ely, Andres Erosa, Li Hao, Christian Hellwig, Hugo Hopenhayn, Philipp Kircher, Pete Klenow, Jon Levin, David Miller, Shouyong Shi, Rob Shimer, Ron Siegel, Balazs Szentes, Jon Vogel, Till von Wachter, Joel Watson, Pierre-Olivier Weill, and Mark Wright. We also thank seminar audiences at Berkeley, Caltech, Chicago, Edinburgh, Minnesota, Northwestern, NYU, Princeton, Rice, Toronto, UCLA, UCSD, UCL, UCR, USC, UT-Austin, Warwick, Washington, CETC (Vancouver), Games World Congress (Evanston), NAWM (New Orleans), SED (Boston and Ghent), SWET (Santa Barbara), Wisconsin, and Zurich. YangBo Song, Kyle Woodward, and Simpson Zhang provided excellent research assistance. This paper supersedes the single-authored paper by Simon Board entitled "Relational Contracts and On-the-Job Search".

\section{REFERENCES}

ABOWD, J. M. and KRAMARZ, F. (2005), "Human Capital and Worker Productivity: Direct Evidence from Linked Employer-Employee Data”, Annales d'Economie et de Statistique, 79, 323-338.

ABOWD, J. M.,Kramarz, F. and Roux, S. (2006), "Wages, Mobility and Firm Performance: Advantages and Insights from Using Matched Worker-Firm Data*”, Economic Journal, 116, F245-F285.

45. If there is an atom at $\eta$ then define $p(\eta)=p$.

46. If the minimum effort $\bar{\eta}$ binds then this does not affect the direction of the inequality.

47. This assumes that the lowest firm $p$ is the same for $G$ and $\tilde{G}$, which is the relevant case for our result. 
ACEMOGLU, D. (2001). "Good Jobs Versus Bad Jobs”, Journal of Labor Economics, 19, 1-21.

AKERLOF, G. A., ROSE, A. K. and Yellen, J. L. (1988), "Job Switching and Job Satisfaction in the US Labor Market," Brookings Papers on Economic Activity, 2, 495-594.

ALBRECHT, J. W. and VROMAN, S. B. (1992), "Non-Existence of Single-Wage Equilibria in Search Models with Adverse Selection", Review of Economic Studies, 59, 617-624.

BEWLEY, T. F. (1999), Why Wages Don't Fall During a Recession (Cambridge: Harvard University Press).

BOARD, S. and MEYER-TER-VEHN, M. (2014), "Competitive Insurance Markets with Limited Commitment", (Working paper, UCLA).

BUCHINSKY, M., FOUGERE, D., KRAMARZ, F. and TCHERNIS, R. (2010), "Interfirm Mobility, Wages and the Returns to Seniority and Experience in the United States", Review of Economic Studies, 77, 972-1001.

BUHAI, I. S., PORTELA, M. A., TEULINGS, C. N. and VAN VUUREN, A. (2014), "Returns to Tenure or Seniority?", Econometrica, 82, 705-730.

BULOW, J. I. and SUMMERS, L. H. (1986), “A Theory of Dual Labor Markets with Application to Industrial Policy, Discrimination, and Keynesian Unemployment”, Journal of Labor Economics, 4, 376-414.

BURDETT, K. and MORTENSEN, D. T. (1998), "Wage Differentials, Employer Size, and Unemployment", International Economic Review, 39, 257-273.

CAPPELLI, P. and CHAUVIN, K. (1991), “An Interplant Test of the Efficiency Wage Hypothesis”, Quarterly Journal of Economics, 106, 769-787.

CARD, D., HEINING, J. and KLINE, P. (2013), "Workplace Heterogeneity and the Rise of West German Wage Inequality*", Quarterly Journal of Economics, 128, 967-1015.

CARMICHAEL, H. L. (1990), "Efficiency Wage Models of Unemployment - One View”, Economic Inquiry, 28, $269-295$.

DAVIS, S. J. and VON WACHTER, T. (2011), "Recessions and the Costs of Job Loss", Brookings Papers on Economic Activity, 43, 1-72.

DELACROIX, A. and SHI, S. (2006), "Directed Search On the Job and the Wage Ladder", International Economic Review, 47, 651-699.

FAHN, M. (2013), "Minimum Wages and Relational Contract", Unpublished paper, Universität Würzburg.

FEHR, E. and FALK, A. (1999), "Wage Rigidity in a Competitive Incomplete Contract Market", Journal of Political Economy, 107, 106-134.

FOSTER, L., HALTIWANGER, J. and SYVERSON, C. (2008), "Reallocation, Firm Turnover, and Efficiency: Selection on Productivity or Profitability?", American Economic Review, 98, 394-425.

GALENIANOS, M. and KIRCHER, P. (2009), "Directed Search with Multiple Job Applications", Journal of Economic Theory, 114, 445-471.

GHOSH, P. and RAY, D. (1996), "Cooperation in Community Interaction Without Information Flows", Review of Economic Studies, 63, 491-519.

HEYES, J. and GRAY, A. (2003), "The Implications of the National Minimum Wage for Training in Small Firms", Human Resource Management Journal, 13, 76-86.

HORNSTEIN, A., KRUSELL, P. and VIOLANTE, G. L. (2011), "Frictional Wage Dispersion in Search Models: A Quantitative Assessment", American Economic Review, 101, 2873-2898.

HSIEH, C.-T. and KLENOW, P. (2009), "Misallocation and Manufacturing TFP in China and India", Quarterly Journal of Economics, 124, 1403-1448.

KARLIN, S. and RUBIN, H. (1956), "The Theory of Decision Procedures for Distributions with Monotone Likelihood Ratio", Annals of Mathematical Statistics, 27, 272-299.

KRUEGER, A. B. and SUMMERS, L. H. (1988), "Efficiency Wages and the Inter-Industry Wage Structure", Econometrica, 56, 259-293.

KRUEGER, D. and UHLIG H. (2006), "Competitive Risk Sharing Contracts with One-sided Commitment", Journal of Monetary Economics, 53, 1661-1691.

LANG, K. and KAHN, S. (1990), "Efficiency Wage Models of Unemployment: A Second View”, Economic Inquiry, 28, 296-306.

LEVIN, J. (2002), "Multilateral Contracting and the Employment Relationship", Quarterly Journal of Economics, 117, $1075-1103$.

LEVIN, J. (2003), "Relational Incentive Contracts", American Economic Review, 93, 835-857.

LEVINE, D. I. (1993), "What Do Wages Buy?”, Administrative Science Quarterly, 38, 462-483.

MACLEOD, W. B. and MALCOMSON, J. M. (1998), "Motivation and Markets", American Economic Review, 88, 388-411.

MCAFEE, R. P. and SCHWARTZ, M. (1994), “Opportunism in Multilateral Vertical Contracting: Nondiscrimination, Exclusivity, and Uniformity”, American Economic Review, 94, 210-230.

MENZIO, G. and SHI, S. (2011), "Effcient Search on the Job and the Business Cycle", Journal of Political Economy, 119, 468-510.

METCALF, D. (2008), "Why Has the British National Minimum Wage Had Little or no Impact on Employment?", Journal of Industrial Relations, 50, 489-512.

MOEN, E. and ROSÉN, A. (2006), "Equilibrium Incentive Contracts and Efficiency Wages", Journal of the European Economic Association, 4, 1165-1192.

MOEN, E. and ROSEN, A. (2011), "Incentives in Competitive Search Equilibrium", Review of Economic Studies, 78, 733-761. 
MONTGOMERY, J. D. (1991), "Equilibrium Wage Dispersion and Interindustry Wage Differentials", Quarterly Journal of Economics, 106, 163-179.

MOSCARINI, G. (2005), "Job Matching and the Wage Distribution”, Econometrica, 73, 481-516.

NAGYPAL, E. (2008), "Worker Reallocation over the Business Cycle: The Importance of Job-to-Job Transitions", (Working paper, Northwestern University).

OSTERMAN, P. (1994), "How Common is Workplace Transformation and Who Adopts It?", Industrial and Labor Relations Review, 2, 173-188.

PETERS, M. (2010), "Noncontractible Hetergeneity in Directed Search" (Working paper, UBC).

PISSARIDES, C. A. (2000), Equilibrium Unemployment Theory (Cambridge: MIT Press).

PORTUGAL, P. and CARDOSO, A. R. (2006), "Disentangling the Minimum Wage Puzzle: An Analysis of Worker Accessions and Separations", Journal of the European Economic Association, 4, 988-1013.

POSTEL-VINAY, F. and ROBIN, J.-M. (2002a), "The Distribution of Earnings in an Equilibrium Search Model with State-Dependent Offers and Counter-Offers", International Economic Review, 43, 989-1016.

POSTEL-VINAY, F. and ROBIN, J.-M. (2002b), "Equilibrium Wage Dispersion with Worker and Employer Heterogeneity", Econometrica, 70, 2295-2350.

POWELL, M. (2012), "Productivity and Credibility in Industry Equilibrium" (Working paper, Northwestern).

RAFF, D. M. G. and SUMMERS, L. H. (1987), "Did Henry Ford Pay Efficiency Wages?", Journal of Labor Economics, 5, S57-S86.

RIZOV, M. and CROUCHER R. (2011), “The Impact of the UK National Minimum Wage on Productivity by Low-Paying Sectors and Firm-Size Groups" (Working paper, Report prepared for the Low Pay Commission).

ROCHETEAU, G. (2001), "Equilibrium Unemployment and Wage Formation with Matching Frictions and Worker Moral Hazard", Labour Economics, 8, 75-102.

RUDANKO, L. (2009), "Labor Market Dynamics Under Long-Term Wage Contracting”, Journal of Monetary Economics, 56, 170-183.

SHAPIRO, C., and STIGLITZ, J. E. (1984), "Equilibrium Unemployment as a Worker Discipline Device", American Economic Review, 74, 433-444.

SHI, S. (2009), "Directed Search for Equilibrium Wage-Tenure Contracts”, Econometrica, 77, 561-584.

WALSH, F. (1999), “A Multisector Model of Efficiency Wages”, Journal of Labor Economics, 17, 351-376. 